
SWPS 2018-23 (November)

How Deep Is Incumbency? Introducing a 'Configuring Fields' Approach to the Distribution and Orientation of Power in Socio-Material Change

\author{
Andy Stirling
}

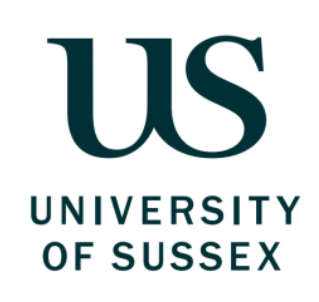




\section{SPRU Working Paper Series (ISSN 2057-6668)}

The SPRU Working Paper Series aims to accelerate the public availability of the research undertaken by SPRU-associated people, and other research that is of considerable interest within SPRU, providing access to early copies of SPRU research.

\section{Editors}

Tommaso Ciarli

Daniele Rotolo

Associate Editors
Karoline Rogge
Paul Nightingale,
Ben Martin, \&
Ohid Yaqub
Tommaso Ciarli
Joe Tidd \&
Carlos Sato
Maria Savona
Andrew Stirling
Caitriona McLeish
Editorial Assistance
Martha Bloom

\section{Contact}

T.Ciarli@sussex.ac.uk

D.Rotolo@sussex.ac.uk

\author{
Area \\ Energy \\ Science, \& Technology Policy \\ Development \\ Technology Innovation Management \\ Economics of Technological Change \\ Transitions \\ Civil Military Interface \\ K.Rogge@sussex.ac.uk \\ P.Nightingale@sussex.ac.uk \\ B.Martin@sussex.ac.uk \\ O.Yaqub@sussex.ac.uk \\ T.Ciarli@sussex.ac.uk \\ J.Tidd@sussex.ac.uk \\ C.E.Y.Sato@sussex.ac.uk \\ M.Savona@sussex.ac.uk \\ A.C.Stirling@sussex.ac.uk \\ C.A.McLeish@sussex.ac.uk
}

\section{Guidelines for authors}

Papers should be submitted to swps@sussex.ac.uk as a PDF or Word file. The first page should include: title, abstract, keywords, and authors' names and affiliations. The paper will be considered for publication by an Associate Editor, who may ask two referees to provide a light review. We aim to send referee reports within three weeks from submission. Authors may be requested to submit a revised version of the paper with a reply to the referees' comments to swps@sussex.ac.uk. The Editors make the final decision on the inclusion of the paper in the series. When submitting, the authors should indicate if the paper has already undergone peer-review (in other series, journals, or books), in which case the Editors may decide to skip the review process. Once the paper is included in the SWPS, the authors maintain the copyright.

\section{Websites}

UoS: www.sussex.ac.uk/spru/research/swps

SSRN: http://www.ssrn.com/link/SPRU-RES.html

IDEAS: ideas.repec.org/s/sru/ssewps.html

Research Gate: www.researchgate.net/journal/2057-6668_SPRU_Working_Paper_Series 


\title{
HOW DEEP IS INCUMBENCY? Introducing a 'configuring fields' approach to the distribution and orientation of power in socio-material change
}

\author{
Andy Stirling, SPRU and STEPS Centre, University of Sussex
}

September 2018

\begin{abstract}
$\underline{\text { Abstract }}$
This paper examines a variety of theories bearing on 'socio-material incumbency' and explores methodological implications. The aim is to develop a systematic general approach, which builds on strengths and mitigates weaknesses in prevailing analytical frameworks. Defining power as 'asymmetrically structuring agency', incumbency is visible in a diversity of power gradients constituted by multiple economic, political and social processes. But existing representations of these incumbency-reinforcing dynamics often neglect their own exposures to effects of incumbency. The result can be a self-acknowledged tendency to "reify" focal categories and assumptions. Under an ostensibly detached 'eagle-eye view' (as if from a lofty governance 'cock-pit'), 'fallacies of misplaced concreteness' emphasise unduly simplified notions like 'the regime'. These can serve to exaggerate the confined, congruent, discrete and singular properties of incumbency in any setting. This picture may in turn overstate the tractability of incumbency to conventional policy instruments. Resulting actions that aim to challenge incumbency, but neglect its wider and deeper forms, may inadvertently help reinforce it.
\end{abstract}

An alternative is argued to lie in addressing incumbency as a 'multiplexity' of overlapping 'configuring fields'. Pervading an entire 'milieu' of imaginably viable socio-material configurations, these gradients in structuring agency display both 'scalar intensity' (in concentrating power) and 'vector intensity' (in orienting particular associated pathways for change). For purposes of interrogating empirical evidence, this allows a heuristic distinction between different 'topologies of incumbency'. With a conventional 'eagle-eye view' of a 'closed topology' forming one ideal-type, the paper systematically contrasts an alternative 'worm-eye view' of an 'open topology' of incumbency. This recognises that patterns in configuring fields that constitute incumbency are often more pervasive, polycongruent, entangled and plural (so less tractable) than envisaged in an 'eagleeye' view. This more nuanced, less instrumentalised, picture suggests other kinds of methodological responses in which some potentially empirically testable questions are explored. Possible practical implications extend beyond narrow policy interventions, to embrace broader and deeper kinds of political collective action, culture change and democratic struggle. The findings will be tested in a second empirical paper in this two-part series.

Keywords: socio-material incumbency; power; political transformations; sustainability transitions; multi-level perspective; deep transitions; socio-technical systems; sociotechnical imaginaries; systems of innovation; regime theory; social field theory; structuration; material agency; social practices; configuring fields;

Acknowledgements: [1]

\section{Contents}

1: Introduction: the Political Importance of Socio-Material Incumbency

2: Complexity and Power in Understandings of Socio-Material Incumbency

2.1: The Ontological Scope of Incumbency

2.2: Challenges in Interrogating Incumbency

3: A 'Configuring Fields' Approach to Socio-Material Incumbency

3.1: Ideal-Typical 'Eagle-Eye' and 'Worm-Eye' Views

3.2: Contrasting the 'Eagle-Eye' and 'Worm-Eye' Views of Incumbency

4: Challenging Socio-Material Incumbency: from Method to Action

4.1: Summary and Lessons for Methodology

4.2: Conclusions and Wider Political Implications 


\section{1: Introduction: the Political Importance of Socio-Material Incumbency}

Long used to refer to the occupation of a position of authority ${ }^{12}$, the term 'incumbency' increasingly also applies to more general concentrations of influence, privilege and power 345678910 . With many traditionally sanguine voices in global science ${ }^{11} 12$ and governance ${ }^{13} 1415$ expressing growing concerns about a series of serious and intractable worldwide 'grand challenges' 1617 , the salience of incumbency is coming further to the fore. It is increasingly recognised that the depths and extents of particular kinds of incumbency often form a reason why so many grave worldwide problems remain so persistently unresolved - including inequality 1920 ${ }^{21}$, oppression ${ }^{22} 23$, climate disruption ${ }^{24} 25$, ecological destruction 2627 , toxic pollution 2829 and nuclear risks 3031 as well as the age-old obscenity and waste of war ${ }^{32}{ }^{33}$. Finding ways to balance the effects of incumbent interests on such issues present some of the most pressing political priorities in the contemporary world ${ }^{34}$.

Despite their many benefits 3536 , science and technology are not immune to their own dynamics of incumbency ${ }^{38}$. Those 'socio-technical trajectories' 39404142 that are most readily realised in research and innovation are usually conditioned not only by declared aims (like mitigating the above global challenges), but also by more private and proximate forces and interests [2]. As a result, a variety of possible responses may be available to address these global challenges that are more favourable than status quo directions for change ${ }^{43}$, but which may remain unduly under-supported. This can be so in sectors as diverse as food 44454647 , water 48 4950 , health 10351 , energy 5253545556957 , security 585960 , mobility ${ }^{61} 62$, resources 636465 , computing ${ }^{66} 67$ and industrial production ${ }^{689} 70$. Of course, there remain many complications, uncertainties and ambiguities ${ }^{71}$. And the issues are more encompassing than just the 'socio-technical' domain of human society and technology. With 'natural' materialities also playing crucial roles both as drivers and as implications, the scope extends to wider and deeper 'socio-material' dynamics 7273747576 . But for all the resulting complexity and diversity a central common issue is, that there typically exists in any setting, a number of alternative 'sociomaterial pathways' for change that are clearly more generally desirable than the established 'innovation trajectories' that dominate both prevailing infrastructures and imaginations of viable futures 77787980 .

The simple point is, then, that even where these neglected alternative pathways are scientifically realistic, technically practicable, economically feasible and socially viable, dynamics of incumbency can prevent them becoming historically realisable ${ }^{81}$. With high and rising stakes for global social justice and ecological integrity ${ }^{82}$ 83848586 , there could hardly be a more pressing object of attention in academic study or policy making on research and innovation, than dilemmas around what is often called 'socio-technical incumbency' 878889909192 ${ }^{93}$. With scrutiny extending from society, through technology to the encompassing material phenomena of the world, it is this wider challenge of 'socio-material incumbency' that will form the primary focus of this paper.

However described, these longstanding imperatives are well recognised by much research into patterns of being and change in a range of variously-characterised interacting social, technical and material phenomena. Especially prominent in current understandings in this area are: 'techno-economic paradigms' 9495 , 'technoeconomic networks' 9697 98, 'large technical systems' 99100101102 103, 'socio-technical systems' 104105106107108 and (more recently) 'sociotechnical imaginaries' 78109110 111, 'socio-technical regimes' 112113114115116117 and 'deep transitions' ${ }^{118}{ }^{119}$. Work in related areas has for many decades been giving growing attention to processes and relations implicated in the 'destabilising' 120121122 123, 'discontinuing' 124 125, 'disrupting' 126127 (and countervailing 'maintaining' ${ }^{128}$ ) of entrenched directions for change in research and innovation. There are many contrasting emphases. But for present purposes, these literatures inform a general definition for the central concept of 'socio-material incumbency', as: a 'multiplexity' 129130 of dynamics through which a particular pathway in interacting social, economic, cultural, political, discursive, cognitive, technical and wider material phenomena, is reproduced by - and reinforcing of-associated power gradients.

Of course (as always), this definition begs many questions. The breadth of scope, in what might be counted as a 'power gradient', will be discussed in detail below. Specific reasons for use of the technical terms 'sociomaterial' 131132133 and 'multiplexity' 134135 will also be discussed later. What is most useful to establish at this initial stage in the discussion, though, is that the starting point from which incumbency is interrogated should be as broad-based and unbiased as possible with respect to specific perspectives or instances. So, however associated processes are viewed and in whatever contexts, this understanding of 'socio-material incumbency' 
is sufficiently general as to give confidence at minimising undue emphasise or exclusion. For, despite often dramatic historical turbulence, socio-material incumbencies abound in various senses relating to this understanding. Fossil fuels ${ }^{136}$, military practices ${ }^{137}$, private automobiles ${ }^{138}$, high-input agriculture ${ }^{139} 140$, the tobacco industry ${ }^{141}$, organised-criminal narcotics ${ }^{142} 143$, pharmaceutical based healthcare ${ }^{144}{ }^{145}$, nuclear power ${ }^{146}$ and nuclear weapons ${ }^{81}$ are all, for instance, proving similarly durable and exercising comparably serious and far-reaching effects. Indeed, it is in helping to ameliorate these adverse impacts, that the approaches to the study of research and innovation from which this definition is drawn (and with which it chimes), can offer their most important contributions. And this is the main aim, towards which this present analysis will try to contribute.

To this end, this first in a series of two companion papers will explore key theoretical and political issues in play around these themes, and set out some methodological and wider practical policy implications. With this paper being conceptual, the next paper will be empirical. As an alternative (not necessarily a substitute) for conventional approaches to socio-material incumbency (like 'innovation systems' ${ }^{147}$, 'sustainability transitions' 148; 'transition management' 149 150, 'deep transitions' ${ }^{118}$ or the 'multi-level perspective' ${ }^{151}$ ), the present conceptual analysis goes back to various traditions in the study of structuration, sociality and power in order to propose what is called a 'configuring fields approach'. Drawing on many key strands in preceding social theory, it will be argued that prevailing understandings in policy making and wider politics can do a better job of avoiding expedient simplifications of the kind that can themselves favour incumbency. Greater account can thereby be taken of important ways in which forces of incumbency (as objects of scrutiny) can condition modes of understanding (in subjects of scrutiny - like academic analysis or policy appraisal). Recognising this can help avoid overly circumscribed and 'reified' frameworks for understanding incumbency, and so mitigate dangers that actions undertaken on this basis can fail to address the deeper and wider aspects.

The next section (2.1) explores issues of complexity and power in socio-material incumbency. Distinctions are drawn between aspects of incumbency alternatively seen to highlight deliberate agency or emergent structure. Likewise, incumbency in general is distinguished from other aspects of socio-material 'persistence', that can be held to arise even where there operate no power-driven dynamics of incumbency at all. If the diversity of social and material positive feedback phenomena relevant to incumbency is to be duly appreciated and addressed, it is argued that the resulting canvas must be broad in its ontological scope. This helps not only to reduce idiosyncrasies in associated circumscribed engagements with power, but also to avert the many ways in which power dynamics can serve to attenuate and restrict social understandings of incumbency itself.

Some of the consequences are explored in the following section (2.2), which builds on prior social theory around processes of structuration to introduce a distinctive field-like understanding of the social and material power dynamics associated with incumbency. Because this analysis focuses on the general relational processes through which socio-material phenomena are configured, it is called a 'configuring fields approach'. Crucially (and unlike many other social field theories), this avoids simply assuming into being any particular notionally discrete categories of object - like specific kinds or modalities of 'field'. Instead, the approach applies the field concept in a straightforward way as a general heuristic, applying in principle equally to all aspects both of social and material dynamics. Across all contexts, the most significantly operational feature of these fields are their asymmetries with respect to the relevant processes of structuration at any given focus, that serve to make some outcomes more likely and others less. As such, these structuration fields display properties both of 'scalar' intensity (in the power with which they variously pressure different kinds for change), as well as of 'vector' directionality (with respect to associated effects on the orientation of this change).

On this relational-processual basis, the section that follows (3.1) develops a systematic contrast between a conventional (quite simple categorical) 'eagle-eye' view of incumbency and a novel alternative (more complex relational) 'worm-eye' view. Characterising the different incumbency-sustaining dynamics as 'configuring fields' in a socio-material 'milieu', it is shown how mainstream notions like 'the regime' can represent incumbency to be significantly more confined and discrete than may often actually be the case. This is referred to as an 'eagle-eye view', since the constituting dynamics thereby highlighted appear to be monocongruent and singular - as if viewed from a lofty perspective that foreshortens appreciation of greater complexity, depth or scope. Since these kinds of reduction tend to favour incumbent interests, the point is made that it is 
perhaps not surprising that such simplifications are so prominent in academic and policy understandings of incumbency and associated possibilities for intervention.

Accordingly, section 3.2 discusses practical implications for political action that follow the distinction between these two ideal-typical views. It is argued that a 'worm-eye view' offers to extend scope for understanding incumbency in many important ways - in particular highlighting necessities for counter-incumbency actions to take forms that cannot be achieved mainly by performance of vertical policy interventions choreographed from a notional governance 'cock-pit'. What may often be required as well, in order to address the full depth and extent of incumbency, are more unruly, horizontal and mutualistic forms of political action. It is these kinds of engagements that can be restricted in notionally reformist efforts that over-rely on conventionally reified expert models, formal procedures and policy mixes. So, 'creative destruction' of incumbency is often better enabled not so much by specific policies - or even 'policy mixes 152153154155 - as by more diverse general and deeply political processes of grassroots mobilisation, collective action, cultural expression and democratic struggle. The analogy here is not with the circumscribed technical orders, understood as ordered hierarchies of categorical objects. Instead, what come to the fore are the more open-ended organic and mutualistic dynamics observable in nature as 'murmurations'. Here politics and encompassing cultures can be understood in more process-relational ways, with patterns of change sometimes appearing like exquisitelychoreographed flocking behaviours of many animals. Here, when the time is right, radical change can emerge rather easily.

The final section (4) then explores concrete methodological implications. It outlines ways to engage and interrogate socio-material incumbency, that are less restricted by prevailing circumscribed academic and policy understandings, related to the approaches with which this discussion began. This sets the stage for the design of onward research of kinds that may help inform more effective political challenges to incumbency. In particular, the follow-on paper in this present pair of articles, will offer a companion empirical study of the particular circumstances of incumbency around UK civil nuclear power. Although individual case studies can be viewed as a precarious basis for wider generalisation, they can nonetheless serve as a reliable - and potentially important - guide to necessary expansions of theoretical frames ${ }^{156}$. Just as the term 'murmurations' signifies mutually-coordinated movement, so it also refers to processes of criticism and resistance. Especially when envisaging transformative change, it is thus at least equally pragmatic for research into incumbency to be oriented towards these more 'unruly' politics, as towards the orderly incumbent structures of 'evidence-based' policy making. It will be on this basis the present theoretical analysis can be tested and substantiated - with the possibility of illuminating potentially significant (but hitherto neglected) practical findings.

\section{2: Complexity and Power in Understandings of Socio-Material Incumbency}

\section{1: The Ontological Scope of Socio-Material Incumbency}

Some processes and relations that are widely seen to help constitute socio-material incumbency are at least partly intentional in deliberate human terms. Examples might include aspects of interlinked and mutually reinforcing feedback phenomena ${ }^{157}$ variously referred to with specialist words like 'entrapment' ${ }^{158}$, 'coercion' 159 , 'dominant prototyping' ${ }^{160}$, 'path creation' ${ }^{161}$, 'alignment' 162, 'social shaping' 41 , 'momentum' ${ }^{100}$, 'routines'

163, 'regime resistance' ${ }^{164}$, 'status quo bias' ${ }^{165}$, 'stabilization' 108 166, 'instrumentalisation' ' 167, 'autonomy' 107 and 'imaginaries' ${ }^{168}$ - as well as in processes around the forming of 'paradigms' ${ }^{169}$, 'expectations' ${ }^{170}$ and many other kinds of 'learning' $171{ }^{172}$. Of course, the active intentionalities in these dynamics are not always explicitly conscious on the part of individual people or specific social actors. Indeed, the formative condition broadly referred to as 'agency' may also unfold in under-appreciated ways, around various more heterogeneous kinds of networks, collective groups or distributed interests - and in contingently emergent societal (or even more diffuse) senses ${ }^{173} 174$.

Referring simply to the "capacity for action" ${ }^{175}$, the venerable idea of 'agency' can become very complex and slippery ${ }^{176}$. Definable in many ways and always at least partly conditional on a subjective perspective and focus of interest, associated issues remain central (at least by implication) to many contemporary social 
challenges. Major queries arise around what might constitute 'capacity' for action; the roles of intentionality; the degree of human specificity; the implications of materiality; and the underlying meanings of 'action'. Accordingly, direct discussions of perennial concerns around 'agency' - for instance through the lens of structuration theory - have (rather oddly), somewhat fallen out of fashion in current social theory ${ }^{177}$. Yet for anyone with interest in the practical politics of real-world struggles to balance incumbent power and enable emancipations of various kinds, some general heuristic idea akin to agency must unavoidably remain central.

In seeking to reconcile these dilemmas, then, a move is necessary that remains practically operational, but which helps avoid some of the pitfalls of overly presumptuous or simplistic notions of agency. Here the work of the philosopher Whitehead arguably becomes especially interesting ${ }^{178}$, in reflecting hard about what it means to 'grasp' - or 'prehend' - anything (including 'agency') [3]. A useful distinction thereby emerges between relatively self-contained, categorical procedures of cognitive 'apprehension' and encompassing (perhaps less visible) processes of 'prehension' that are more materially distributed and relationally ecological in nature. It is in these general terms that agency in many forms becomes characterisable as creative processes (of multiple kinds) for "orienting among many prehensible pathways for change" ${ }^{179}$. This general formulation may apply irrespective of specific conundrums concerning 'capacity' or 'intentionality' for agency, the exclusivity of the 'human' focus; or what it is exactly, that is thought of as 'action'. And reference to 'prehension' acknowledges that what might 'potentially' be 'possible' in the orienting of action is not a separable 'objective' matter. It is intrinsic to the dilemma that agency itself is at the interface of objectivity and subjectivity. Accordingly, what is needed for the generatively 'change-orienting' aspects of incumbency to be recognisable as 'agency', is that they must not only in some way be prehending in agential ways, but also likewise be prehended as such ${ }^{180}$.

Whatever the details, however, it is in these general terms that other constituting dynamics of incumbency often tend to be prehended instead to be more about 'structure'. Whilst always implicating some forms of agency, these aspects can (in some languages) be referred to as relatively "deterministic" in nature ${ }^{181}$. Either way (as endlessly pored over in theoretical literatures), recognition of possibly-salient distinctions between structure and agency should not be assumed to assert a universalising dichotomy 182183184185 , nor an ostensibly essential dualism ${ }^{186} 187$, still less a mutually-constituting duality ${ }^{188}{ }^{189}$. To make a distinction in one axis for differentiation of itself says nothing of possible distinctions under other axes. Instances will always present complex constellations on multidimensional scales imposed by subjective perspectives ${ }^{190}$. So relations between subjectively-distinguished aspects of structure and agency may thus rather be seen as a more contingent dialectic ${ }^{191}$ - prehensible only with respect to enacted strategies on the part equally of subjects and objects ${ }^{192}{ }^{193}$. Recursively co-constituted with and by 'agency', then, the 'structural' aspects of incumbency also become implicated in the same broad relational understanding of agentive orientation of change discussed above. In these terms, 'structure' (in whatever view) refers to 'the conditions constituting potentialities across contrasting prehensible orientings of change' [4].

Placing more of an emphasis on this aspect of 'structure', then, a range of additional processes also come to the fore in studies bearing on socio-material incumbency. These go by a plethora of further technical names like 'entrenchment' ${ }^{194}$, technological drift 107, 'channelling' 195 196, 'canalization' 197198 , 'chreodization' 199, 'inertia' 200 201, 'obduracy' 202, 'inflexibility' 203, 'longevity' 204 205, 'economies of scale' 206, 'lock-in' 138, 'lock-outs' 207 , 'crowding out' 208209 , 'increasing returns to adoption' 210211 , 'network effects' 212 213, ' path-dependency' 214 , 'emerging irreversibilities' 215 . 'homeostasis' 198, 'embedding' 216217 , 'endogenous renewal' 218 , 'technique' 219 , 'cosmopolitanisation' 220221 , 'technicity' 222 and 'sociodicy' ${ }^{223}$. Each of these ideas highlights further aspects of the contexts in which incumbencies can be reproduced. Again, all are deeply entangled with the more overtly intentional dynamics listed above. Each is related; all lie on scales defined by others; several are similar; some are variously nested or overlapping; but none are identical ${ }^{224}$. Widely-used terms are also employed in contrasting (sometimes inconsistent) ways ${ }^{224}$ and many additional and combined concepts are also recognised 225226227228229230 .

In the face of the many resulting ambiguities, a schematic picture of one impression of some key attributes of these diverse positive feedback dynamics is shown in Figure 1. This brings to the fore, three dimensions of differentiation. First (on the left hand side), is the epistemic lens through which these aspects of incumbency are viewed, ranging from interpretive and constructivist through more qualitative and positive to quantitative 
aggregative perspectives. Second (on the vertical axis), there is the relative emphasis that is placed on distinctions between the variously-prehended 'structural' or 'agential' aspects of incumbency discussed above. Third, there cuts across both these dimensions (on the horizontal axis), a distinction between relatively mechanistic causes or more emergent influence. Despite the evident diversity in these human and material incumbency-constituting processes, however, what all share in common is that they present distinct aspects of the ubiquitous set of social phenomena known straightforwardly as 'power'. In other words, what Figure 1 shows, are the many ways in which power reinforces particular directions for change and suppresses others.

Despite the 'ontological scope' 231 of this picture of socio-material incumbency, then, it is significant that a crucial common feature, is the relevance of various contexts, kinds and degrees of 'power gradient' 232233. Here, there are many resonances with diverse wider literatures in social and political science, cultural studies and institutional theory 234235164 . Among these structuration theories of various kinds represent an especially strongly acknowledged, widely generalized and deeply-developed body of ideas 186175236237 . Whilst many other theoretical frameworks are available in social science, few (as discussed above) offer such a specific focus on the circumstances of agency. So few are as directly relevant as a practical heuristic, for enquiries focusing on dynamics of progressive political change of the kinds entailed in concerns over incumbency. By unfolding specifically from thinking about dilemmas of agency, then, structuration theories remain (for all their abstraction) usefully focused on practical challenges of political action. And it is in the broadly-applicable process-relational terms of structuration theory, that the multiplicities of power asymmetries which constitute gradients of incumbency can be formulated into a quite easily-expressed and readily-operational heuristic definition for 'power': as different forms and conditions of 'asymmetrically structuring agency' 81238 [3].

To scholarship concerned always to differentiate and nuance, it can be problematic to refer to something as important and undoubtedly complex as 'power', in such ostensibly simple terms as this single colloquial word. Sometimes this aversion merely reflects the identity politics of disciplinary dogmas, institutional conceits or pressures to solicit or assert academic patronage. But where imperatives to attend to contextual detail are more substantive, they still in no way require refusal to recognise generalities. Why should a phenomenon as readily identified in all its multiple forms in any everyday conversation as 'power', find no correspondingly encompassing term in technical vocabularies? Although relatively straightforward in expression, then, it is arguable that a concise general characterisation of power as 'asymmetrically structuring agency' can workably apply in principle to a first order, across virtually all aspects, dimensions and contexts of power.

Articulating all broadly prehensible forms, contexts and mixes for action on structure or structuring of agency, this characterisation can include in a relatively balanced way, many otherwise canonically-distinguished notions of power. It applies serviceably, for instance, across jealously-guarded distinctions between: "power over" 239; "power with" 240; "power through" 241; "power to" 242; "power to do things" 243; "power to make change" 244; "power to rule" 245; "power to manage" 246; "power to create" 247; "power within" 248; "power from within" 249; "power between" 250251 ; "power as energy" 252; "power under" 253; "power to negate" 254 and "power to undo" 255 . Each involves at least some subset of aspects relating to structuring agency that is asymmetric with respect to the orienting of some onward course of events rather than others. The necessity in any given situation always to be more precise about the particular aspects and dimensions of power that come to the fore, is not necessarily obstructed by a general heuristic framework like this. Indeed, such nuance can actually be assisted by a framework for comparison that is explicit and accountable across divergent views.

Either way, the first order characterisation here, of power of all kinds as 'asymmetrically structuring agency', begs many specific questions in different contexts. But this simple general understanding does at least crucially address the manifest fact that - whatever form is taken by specific modalities or circumstances for structuring of agency or acting on structure - it is a familiar characteristic of what is known in everyday life as 'power', that all these processes and relations are in some way asymmetrically formative as between different outcomes. So, it is arguably the single most generalised feature of power, that (subject of course to multiple forms of contingent turbulence), its diversely-manifested gradients in any given setting, tend to drive onward dynamics more in some kinds of directions, than in others. 
Figure 1: a schematic view of one impression of key attributes in socio-material positive-feedback dynamics (key sources for each dynamic provided in main text)

\section{A Constellation of Incumbency Reinforcing Dynamics}

As defined in references cited in main text (albeit contrasting by context), each dynamic reinforces scalar and vector aspects of 'configuring fields' in power gradients driving specific features of a socio-material pathway

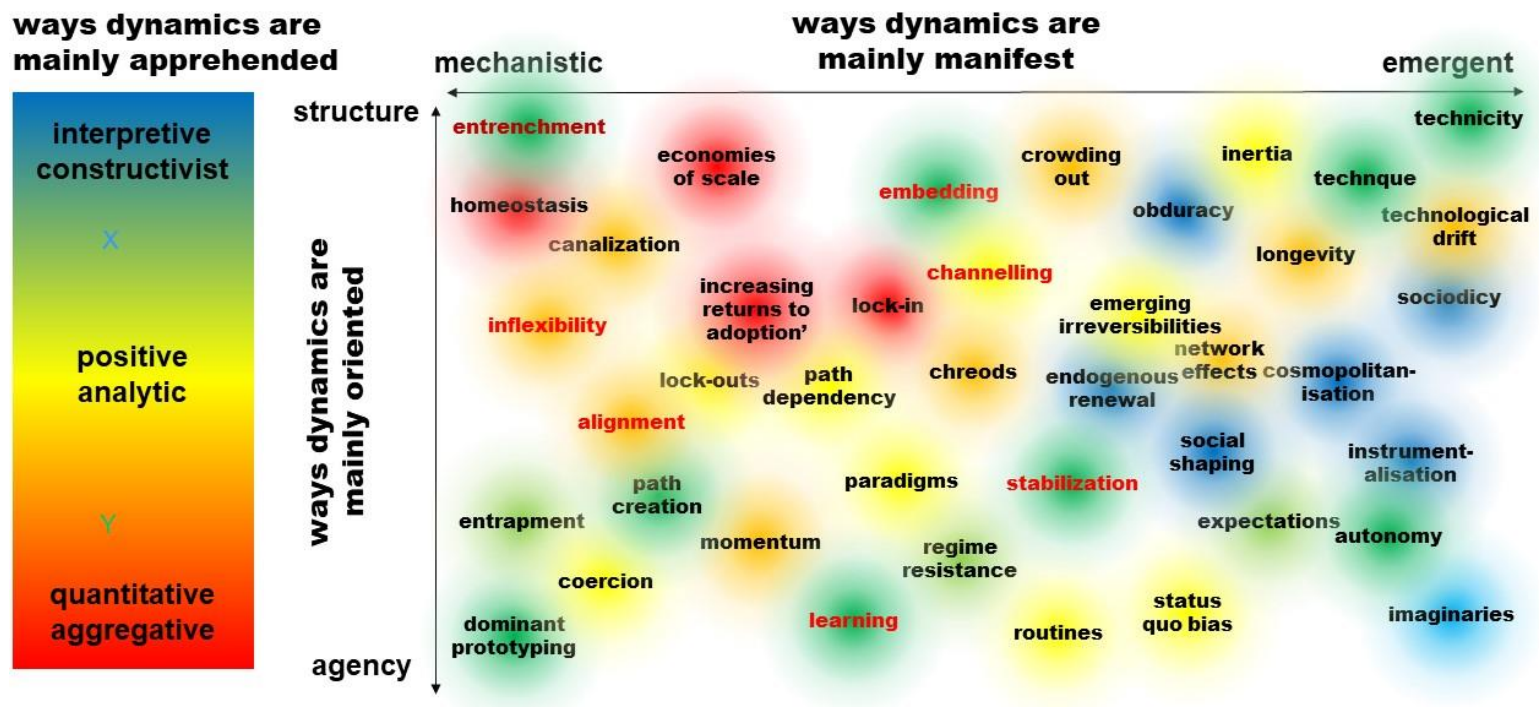

So, what most shapes and steers the 'ecological' relations among these diverse processes of socio-material change 257258259 . Beyond each individual dynamic, what patterns are evident in their collective 'epi-dynamics' over time [5]? In seeking to answer this, a significant indication again arises in the importance of the processes of prehension that (sometimes tacitly) interlink both subjects and objects of attention. This is, that the degree to which resulting patterns might be seen to be about 'power' (and thence possibly 'incumbency') on the one hand; or simply to emergent change on the other; typically remains (at least to a degree) a matter of perspective. As we have seen, intentionalities of many incommensurable kinds are deeply entangled with multiple ostensibly inanimate material phenomena. But there will be circumstances of prehension in which entire generative chains of events might alternatively be thought to be effectively contingent in relation to any meaningful notion of social purpose [6].

Depending on how they are manifest ${ }^{260}$, then, aspects of these more circumstantial prehensions of change might be found, for instance, in some of more apparently 'deterministic' forms of path-dependency (like those argued to play large roles in the canonical case of the QWERTY keyboard 214261262263 ). In settings where there are judged to be no specific relevant intense or enduring gradients of power primarily responsible for particular structurings of agency or actions on structure 264265266 , then, the processes in question are arguably not best viewed as 'incumbency' at all: but as a more contingent phenomenon that might be called 'sociomaterial persistence' ${ }^{267}$. In the end, the emphasis placed on the ostensible contingency of persistence, or on kinds or degrees of structuring agency seen behind incumbency, will be a function of more general political subjectivities concerning power. By using a relational notion of prehension, as discussed earlier, the present framework encompasses the range of this spectrum, whilst retaining a clear practical focus around agency.

Even when construed as broadly as this, however, the dynamics included in the present notion of incumbency should not be assumed to be the only reasons why history unfolds as it does. Yet, this being said, it must also equally be acknowledged that nearly all the major inflections and permutations of contexts, dimensions and modalities of power recognised to operate in society at large, are variously understood to be implicated (in some way, at least in principle) in (re)production of socio-material incumbency 81268269270 . In this way, general understandings of socio-material incumbency might variously be expected to emphasise aspects of power across the full range of manifestations recognised in a vast array of contrasting approaches to different modes 
and contexts of power in political inquiry 271272273251274275276277278279280281282283284285286287288 . As with the academically-differntiated modalities of power identified above, then, gradients and flows in 'asymmetrically structuring agency' may variously be prehended in contexts and dimensions of: agency ${ }^{289}$; organisations ${ }^{290}$; networks ${ }^{291}$; relations ${ }^{292}$; structures ${ }^{293}$; structuration ${ }^{175}$; institutions ${ }^{294}$; fields ${ }^{295}$; practices ${ }^{296}$; cultures $^{297}$; discourses ${ }^{298}$; knowledges ${ }^{299}$; infrastructures ${ }^{300}$; and imaginations ${ }^{238}$. So: incumbency is evidently not only societally, but also analytically, highly diverse and pervasive. It is a crucial distinctive feature of the present approach, that it also seeks to accommodate this contextual diversity of prehensions of power in a balanced way.

Whatever circumstances or forms of power might be of greatest interest, however, and whichever styles of prehension are most favoured, it will be a characteristic shared in common that key aspects of incumbency can in any view and context be characterised in terms of various kinds relational processes summarised among the many dynamics shown in Figure 1 (eg: 'lock-in', 'obduracy', 'entrenchment', 'entrapment' etc). Left to is own devices and all else being equal, then, any given instance incumbency will (subject to other instances and contingent turbulence) in these terms tend to reinforce itself. But, it is the fact that constituting phenomena are as wide and as disparate as this, that also means that notions of 'incumbency' are not easily addressed under any single generalised analytical framework. Nor are the implications simple. Yet there do emerge even in a general analysis like this, some quite straightforward insights, of potentially significant practical relevance. In particular, the twin components in this conceptualisation of power (as relational 'asymmetries' in processes of 'structuring agency' $81{ }^{238}$ ) highlight two specific main aspects of interest: asymmetry and directionality.

First, with regard to the asymmetries referred to in this formulation (of 'asymmetrically structuring agency'), there are issues around the intensities of the power gradients themselves. This concerns the repercussions for society and wider environments, of the particular degrees and modalities of asymmetric relations in structuring agency concentrated around any given instance of socio-material incumbency. And here it is important to note, that for this aspect of power to be of concern, need not imply a generally 'critical' position. All that is assumed, is that - as arguably the single most important social fact ${ }^{301} 302-$ power in these very broad senses is at least an issue worthy of attention. After all, it is not necessary to see any given concentration of power as automatically being a problem in its own right, in order to realise that it is most likely to become so, if it is left invisible, uninterrogated or unaccountable ${ }^{303}$. In this straightforward 'scalar' aspect of power, then, key issues concern the forms and magnitudes of authority and privilege in which a given incumbency is constituted 304284280305 .

Second, with regard to processes of 'structuring agency' themselves (like those summarised in Figure 1), there are questions over 'directionality' - the particular directions of change which these magnitudes of intensities orient ${ }^{306} 307$. What specific kinds of socio- material pathways are favoured (among other possible orientations for change) by the working of any given instance of incumbency ${ }^{308}$ ? What other possible forms of wider interlinked social and material change (socio-material pathway) might be suppressed by these patterns ${ }^{77}$ ? These questions can be quite independent of general issues around power distributions per se. This is because normative judgements over pros and cons of any given power concentration will depend on alignments of interest in subjects and objects. Even a self-styled emancipatory view of incumbency (for instance) might often welcome some specific re-concentration of power, if this favours an alternative pathway that happens to be preferred by the 'critical' interest in question ${ }^{309}$.

So, this second aspect of interest concerns not just the 'scalar intensity' of incumbency around a given sociomaterial configuration - the simple quantitative magnitude of the associated power concentrations. It also concerns their 'vector intensity' ${ }^{310}$ [7] - the propensity of incumbent power in this instance to reinforce the orientation of a specific social and political direction for change. Although neglected in much policy-related discussion of innovation and transition ${ }^{218}$, this issue of directionality is - at least in political terms - arguably the most important single aspect ${ }^{43}$. With 'technological cultures' 311312 , 'tastes' ${ }^{313}$, aesthetics ${ }^{314}$ and 'genres' 315 being matters of wider normativity ${ }^{316}$ - and so politics ${ }^{317} 318$ - around particular socio-material orientations as compared with others, it is clear that evaluative questions over incumbency are rarely simple or selfevident. The questions raised are typically intrinsically and unavoidably subjective, with no necessary single 'right' answers even in specific settings ${ }^{71}$. In other words, whatever forms they take (and no matter what 
academic etiquettes of scholarly distance or policy neutrality might be performed 319320321322323 ), both sociomaterial incumbency and any analysis thereof, are necessarily irreducibly political 32415732534 .

To summarise, by addressing each of these two aspects of asymmetry and directionality in a balanced way, conceiving of power in terms of the simply-stated relational verb ${ }^{326} 327$ of 'structuring agency' arguably applies in principle serviceably across a wide diversity of approaches. It does this for purposes of generalisation, without unduly reducing the important disparities and context-specificities that remain salient in particular settings. As such, this approach is an aid to heuristic reasoning 328329330 , that allows a number of crucial features to come to the fore, that are relevant across all contexts but may otherwise sometimes be neglected.

Despite the intimately-inseparable co-implication of structure and agency, then, the effects exercised by these dual properties of incumbency ('scalar asymmetry' and 'vector directionality') may in this way (despite their own linkages), often reasonably be seen (both analytically and normatively) as quite independent of each other. For instance, in the face of various contingent kinds of 'forcing' pressures ${ }^{331}$ or 'focusing events' ${ }^{332}$, even the strongest asymmetries in power concentrations may find themselves unable to forestall the tidal momentum of unfolding circumstances in particular directions. This is the declared predicament, for instance, with many of the global challenges with which this paper began. No matter how compelling and consensual the evident solutions, persistent problems like poverty, environmental destruction and war can nonetheless appear, quite simply, to defy even the most powerful forms of human agency 333334335336337 . In these respects, scalar concentrations of power ares manifest largely without the aspired forms of vector orientation. This is a large part of why it is so important to engage with the phenomenon of incumbency in the first place.

Likewise, there arises here a kind of 'paradox of embedded agency' ${ }^{338}$. For it is equally true in a countervailing sense, that even a relatively weak gradient of 'structuring agency' operating at a particular 'critical juncture' 339 may exert a disproportionate influence on the direction of onward developments ${ }^{340}$. And here again, it is not difficult to think of instances. The history of technology - like history more generally [8] - abounds with dynamics in which relatively modest actions undertaken in particular 'windows of opportunity' 341342 , can in retrospect be seen to exercise disproportionately formative effects on the onward direction of events. Current large-scale wind turbine designs arguably offer one example, which might never have grown even to become a feasible possibility (let alone their current highly commercially competitive status in worldwide electricity supply markets ${ }^{343}$ ), had it not been for crucial exercise of marginalised agency acting at 'salient moments' 344 in very particular settings 'below the radar' of powerful global energy incumbencies ${ }^{345}$ [9]. Contemporary commercial wind power is thus an instance of a manifestly generally viable socio-material configuration, that could easily have been rendered by global patterns of incumbency to be historically effectively unrealisable. Strong effects prevailed in the orienting of wider change, without intense concentrations of power. Again, the value becomes clear, of distinguishing 'scalar asymmetry' and 'vector directionality' in incumbency.

It is therefore the case that much more may be radically possible in socio-material change, than meets the incumbent eye - or the self-aligning views of its clients (or the thereby-skewed prehensions of wider affected society). And the greatest constraint on the progressive interests that are so often marginalised by incumbency, may often lie in the restrictions on subaltern imaginations and ambitions concerning the scope of what is seen to be achievable ${ }^{346}$. So it is in this sense, that the title of this paper applies: addressing both the dimensions and the magnitudes constituting the 'depth' of socio-material incumbency in the social discourses, cultures, institutions and infrastructures that bear on any given pathway. Characterised in ways that will be elaborated in the following discussion, then, it is these magnitudes of intensity and dimensions for orientation in 'asymmetrically structuring agency', distributed across the totality of socio-material configurations, that can be envisioned as 'configuring fields'. It is the associated processes and relations like those described in Figure 1 above (eg: 'lock-in', 'obduracy', 'entrenchment', 'entrapment' etc), that configure the particular directions for socio-material change that actually unfold in any given setting - and which suppress so many others. 


\section{2: Challenges in Interrogating Socio-Material Incumbency}

Alongside the issues discussed above, the fact that socio-material incumbency is fundamentally about power also raises a deeper consideration. This further issue follows from the discussion above, of the importance of how agency is 'prehended' (ie: the ways in which how it looks and weighs and feels), depends on circumstances both of subjective perspective and object context. The need to consider this, arises in the perennial predicament recognised in Giddens' 'double hermeneutic' ${ }^{175}$. This acknowledges that it is only in social science and humanities (rather than, say, in natural science), that that both subject and object are comprised equally of human social processes and relations ${ }^{347}$. Other disciplines involve such social processes prehending non-social processes. Physical, chemical or biological objects, after all, are not themselves constituted by social phenomena. So it is uniquely in understandings of social dynamics (like incumbency) that the subjects of understanding are constituted in broadly similar terms to the objects.

In short, it is only in social science and the humanities that society prehends itself. With natural science itself being a social activity ${ }^{348}$, but not its objects, it is arguably this 'ontological distance' that renders its categories and processes so apparently enviably clear - and its predictive capabilities sometimes so exquisitely precise. The greater ontological distance between object and subject, permits bolder forms of reduction, generalisation and manipulation ${ }^{349}$. There are temptations for social enquiry to imitate this ${ }^{350}$. And this can lead to the ignoring of the double hermeneutic - and a corresponding pretence that social knowledge production is not a social activity. Such denials of the formative effects of society on the substance of resulting knowledges are highly problematic anywhere in natural science. But it is especially pernicious in social science. Here, no matter how inconvenient to aspirationally 'objective' accounts, the ontological proximity of social subjects and social objects is an unavoidable fact of life - with a propensity to bite back hard. Aspirations to emulate the positive idiom of higher status disciplines, can lead to serious forms of denial and self-deception. Expediently for incumbency, the effect is to obscure some of the most important ways in which power works in the world ${ }^{350}$.

So, the conjunction of the viewing with what is viewed is often ignored, but its effects cannot be escaped. And this is especially so, in the case of incumbency. If only emergently, dynamics of incumbency can often extend from being separate objects of prehension, to entangle strongly with subjective conditions of prehension: the processes of incumbency-related research themselves. It is in this way, for instance, that incumbent pressures can condition 'strategies of obduracy' ${ }^{351}$ - gravitating a shaping effect on the forms taken by knowledges about itself. When (as is so often the case in study of socio-technical systems ${ }^{352}$ ), notionally independent academic research is subject to explicit pressures (and self-conscious aims) to 'influence decision making' and be seen to have 'policy impact' 353354355120 , then the effects of these 'gravitational' forces exercised by incumbency can be seriously reinforced. In short, it might reasonably be expected that the constituting dynamics of incumbency will include tendencies to condition knowledges about incumbency, in ways that make the principal constituting phenomena of incumbency more difficult to erode - or even prehend.

If this seems an unduly pessimistic 'critical' take on the circumstances of academic research in this field, it may be worth considering the same issue from another angle. If (as is routinely the case 3616835635778 ) 'discourse', 'knowledge' and 'imaginations' are recognised to count among the constitutive dynamics of incumbency, then would it not be irrational simply to assume that academic and policy analyses of incumbency (as sociallyembedded subjects) will somehow be immune to the very processes on which they focus? And would not this social congruence of subject and object mean there can be few other areas than study of incumbency, where the 'double hermeneutic' discussed above is more salient - and where knowledge is more likely to bear the imprints of power ${ }^{128}$ ? At least in the absence of conclusive evidence otherwise, it seems a more reasonable default to assume that research on incumbency might - rather than will not - bear the imprints of its object.

Also relevant here, is that it is a repeated finding in science and technology studies ${ }^{358}{ }^{359}$ as well as in work on regulation and governance more widely 360361362363364 , that efforts at ostensibly independent technology assessment or regulatory appraisal that are intended (and claimed) to inform future socio-material commitments, are typically at least as much influenced by prevailing patterns of incumbency, as they are shaping of them ${ }^{365}{ }^{366}$. Likewise many kinds of framework for studying processes of 'socio-technical transition' are (with important exceptions) frequently criticised for undue neglect for the importance of various kinds of 
power 36736836937037137237334374375 . This kind of denial or side-lining of politics in any given arena, is wellunderstood to favour whatever happen to be prevailing vested interests ${ }^{168}$. There seems little reason to hold the study of research and innovation to somehow be immune. As a result, it would again be prudent not to rule out that how socio-material incumbency is thought about, can be a major means by which it is asserted.

Once these possibilities are acknowledged, there lurk (amid the complexities), many further important, intractable - but very practical - unresolved questions ${ }^{157} 372$. This is how at least some of the implications may extend beyond the reach of prevailing academic understandings. What exactly is socio-material incumbency in any given setting? What kinds and circumstances of incumbency might most usefully be distinguished? Under which conditions and perspectives may specific forms of incumbency be judged positive or negative? How can incumbency be developed, supported, harnessed, countered or reoriented in order to address wider social goals? How is incumbency most effectively understood and interrogated to these ends? In particular: how best to advance interests (like sustainability, peace or social justice) that are undermined by many prevailing forms of socio-material incumbency 227376 ? How may such efforts be obstructed, by ways in which understandings of incumbency can bear the imprints of the very power dynamics and relations that they seek to scrutinise? How might such regressively conservative effects on knowledge itself, best be countered? These questions are crucial to resolving the pressing global challenges with which this paper began.

And it is these particular questions that this paper will seek to help address. In so doing, there arise a number of specific concerns about the adequacy or completeness of many accounts of incumbency offered in currently dominant frameworks for the study of socio-technical systems. How reasonable is it, for example, to seek to confine or partition incumbency according to a scheme of ostensibly separable or strictly-nested entities? Such neatly-ordered structures are ubiquitous in existing study of socio-material incumbency, implicating notional 'middle range' 377378 social categories such as 'levels', 'niches', 'regimes', 'landscapes', 'networks', 'functions', 'industries', 'systems', 'regions' or 'sectors' 379380381 ? Such heuristics can offer many insights ${ }^{322}$. But they may also raise questions and require some rather strong assumptions, of kinds that may be problematic, but which can be under-scrutinised in the enthusiasm of adherents for "necessary simplification" ${ }^{373}$. With the defining and bounding of such categories being especially vulnerable to the gravitational effects of incumbency (as discussed above) acting on subjective conditions of knowledge production, resulting framings (despite their professed academic independence) may not be entirely innocent in relation to the dynamics they seek to interrogate. It is here that the present approach may hold profound practical implications for policy.

For instance, many current ways of envisioning sociotechnical incumbency perform a notional posture described by Gyawali as an 'eagle-eye view' ${ }^{382}$. This is consistent with high profile contemporary accounts of governance, envisioning that policy analysis should aim at informing - even 'designing' 383 - a notional overarching 'cockpit' ${ }^{384}$. Like the broader phenomenon of "seeing like a state" famously observed in relation to other aspects of power ${ }^{385}$, the frameworks resulting from this kind of 'cockpit-ism' ${ }^{386}$ present themselves as if 'looking down' on society [10]. In this way, there unfolds a dynamic under which efforts to gain the attention of power, find themselves pressurised by expediency to pre-adopt an idiom of 'seeing like power' 238. The kinds of problems that can arise from unfettered forms of this dynamic are well known and widely agreed across political divides. They are well documented, for example, in histories of high-rise housing ${ }^{387}$, modernistic urban design ${ }^{388}$, forced agrarian collectivisation ${ }^{389}$, the re-engineering of river systems ${ }^{390}$ and large hydro-electric schemes ${ }^{391}$ - as well the many repeatedly oddly-unanticipated disastrous outcomes of war 392393394395396397398 . Despite the wealth of evidence and experience qualifying romanticised aspirations to control ${ }^{399}$, the inconvenient fact that 'there is no cockpit' in global governance, remains effectively ignored ${ }^{400}$.

Yet, although they are so effectively wrong, representations of society as if from an epistemic standpoint so elevated as to transcend the phenomena under scrutiny, serves potentially highly instrumental alignments of interests. Resulting storylines emphasise 'control', in the sense that feasible interventions are held not only to correspond with intended ends, but to map so closely with these that other collateral kinds of outcome may effectively be ignored 401402403 . Such representations are expedient equally to academic disciplines striving to assert status and individuals seeking to acquire policy 'impact stories' ${ }^{404}$, as well as to incumbent interests seeking to sponsor research that reinforces justification for its own prior commitments 405406407408 . The feedbacks between the two further intensify the instrumental dynamics. So acute can this regress become, 
that resulting intensely romanticised ideas of elite agency can foster potentially seriously misleading 'illusions of control' ${ }^{409}$. In the 'real worlds' of governance and politics - especially the long run dynamics of technology such idealised forms of control simply do not exist [11]. But the belief that they do, can help sustain prevailing patterns of privilege. So, it is in this fashion that - even where the aim is to challenge incumbency - the implicit reproduction of such 'fallacies of control' 41041181 can (even if only in analysis) have the effect of supporting it.

In such ways, some existing research on socio-technical change may be at risk (if only inadvertently and tacitly) of some rather eccentric assumptions concerning the simplicity and tractability of relevant patterns of sociomaterial incumbency and associated possibilities for any kind of 'complete' 'independent' analysis of these. This can be so, even if research is aware of the diversity of dimensions, processes and relations mentioned above. Despite acknowledged complexities, the multiplicities of patterns in incumbency-sustaining dynamics may be characterised as more confined and monocongruent than might actually be the case. This can be seen, for instance, with many kinds of 'middle range' social categories referred to above ${ }^{412}$. In varying degrees, concepts like 'levels', 'niches', 'regimes', 'landscapes', 'networks', 'functions', 'industries', 'systems', 'regions' and 'sectors' 379380381 may each be treated as more discrete, robust and self-evident in their instantiations (and so apparently tractable to policy), than justified by the underlying phenomena ${ }^{413}$. Indeed, the same can be true of different kinds of notionally discrete categories and instances of dispositional 414415416 , social ${ }^{417}$, socio-technical ${ }^{418}$, organizational 112419420421 , institutional ${ }^{422} 423$, strategic action ${ }^{424} 295$ and policy ${ }^{425}$ fields [12]. It is a distinguishing feature of this configuring fields approach, that - whilst many indicative examples are summarised above (eg: Figure 1) - the approach does not rest on partitionings of assertedly separable kinds.

But this kind of deconstruction is not enough on its own. The gravity of the issues around incumbency with which this paper began, also requires a sense of responsibility towards the finding of better practical responses. The main value of criticism - especially in this present unusually expansive form - is to prompt positive alternatives. So, it is in order to enable more direct interrogation of the concerns raised here and to identify less problematic possibilities, that a 'configuring fields' approach will be elaborated in the next section. And it is on this basis, that attention will turn to the development of a systematic complement and possible substitute for this prevalent 'eagle-eye' view of incumbency. To see the value of this, is not to assume automatically that the above analysis is correct, or that the 'eagle-eye' view described here is necessarily problematic. It is simply rational not to neglect possible alternatives.

\section{3: A 'Configuring Fields' Approach to Socio-Material Incumbency}

\section{1: Ideal-Typical 'Eagle-Eye' and 'Worm-Eye' Views}

Discussion in the last section was based on seminal findings in the analysis of 'structuration', which themselves relate to foundational insights across a large sweep of historical and contemporary social theory 186175236237. Acting in particular concrete settings, but extending across a multiplicity of dimensions in social and technological phenomena, a large array of more-or-less human-intentional or material-emergent positive feedback phenomena were identified as helping to shape directions for socio-material change (cf: Fig. 1) . Among these, it was argued that the diverse power dynamics that constitute socio-material incumbency can be envisaged as multiple topologies in 'asymmetrically structuring agency'. In ways that will be returned to in discussing methodology later, the notion of topologies is useful because it offers a way to help bridge the chasm between quantitative and qualitative phenomena - and calculative and interpretive perspectives ${ }^{426}$.

To have such a broad and balanced way of thinking about power and incumbency is helpful because it must, as has been argued, address asymmetries associated with incumbency that have properties not only of scalar intensity, as concentrations of power, conceivable in a broadly quantitative idiom. Also crucial, it has been shown, are questions over the vector directionality of incumbency, in terms of variously-characterisable - and thus more interpretive - normative orientations in the social and material effects of these power dynamics. Put in one sentence, then, a pragmatic way to approach what is envisaged, might be in general terms of 'configuring fields' - as 'patterns of propensity with respect to a particular focal socio-material pathway, across the totality of all imaginably possible socio-material configurations, that serve to foster this specific orientation 
for change more than others' [12]. A schematic illustration of mutually-defining relations between the key concepts that this entails are shown in Figure 2 below.

Figure 2: schematic picture of mutually-defining relations between key concepts in this analysis (formative sources for each concept are variously discussed in the main text)

\section{SOCIO-MATERIAL MILIEU}

manifold of all prehensible interacting social, economic, cultural, political, discursive, cognitive, technological,

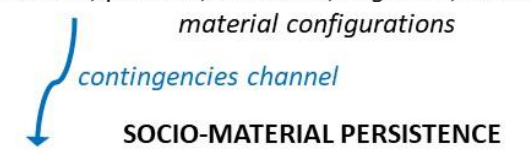

no prehended gradients of power orienting change

STRUCTURE

conditions constituting potentialities across contrasting prehensible orientations for change

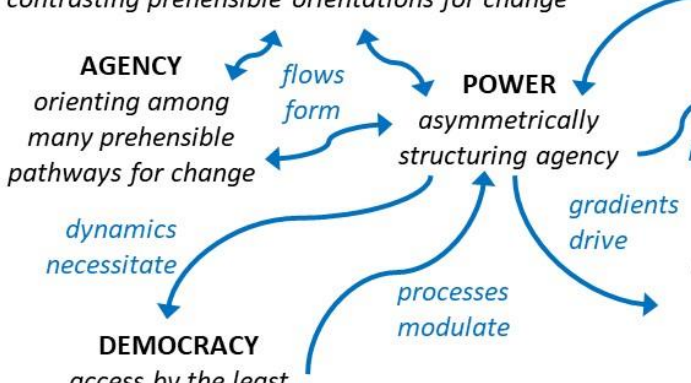

access by the least

powerful to capacities for challenging power
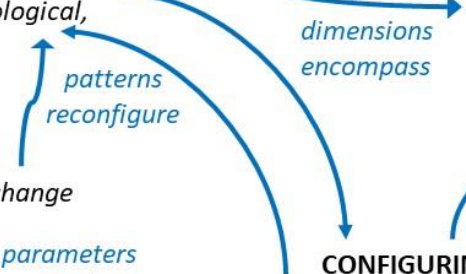

parameters mediate
FOCAL SOCIO-MATERIAL PATHWAY a particular pathway of change in the socio-material milieu (selected as focus for prehension)

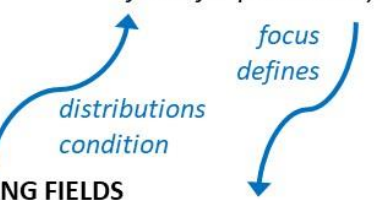
milieu, that serve with respect to a particular focal socio-material pathway, to foster this specific orientation for change more than others patterns constitute

\section{SOCIO-MATERIAL INCUMBENCY}

a 'multiplexity' of dynamics through which a particular socio-material pathway is reproduced by - and reinforcing of associated power gradients

Any merit in such theoretical abstractions must rest strongly on the utility of the insights they help generate and their practical implications for action. So, the potential value of this 'configuring fields' approach, might be examined first in its possible application to systematically defining meaningful alternatives to the conventional 'eagle-eye' view of socio-material incumbency characterised in the discussion so far. And a first step towards this, lies in clearly characterising the salient attributes of this orthodoxy itself. To this end, then Figure 3 (below) provides a schematic illustration of some key features of the 'eagle-eye' view. The white ellipse in the diagram can be thought of as a two-dimensional projection of a multidimensional manifold of all possible socio-material "configurations that work" 162 [13]. This total 'milieu' for socio-material change does not represent any kind of literal ('territorial' ${ }^{427}$ ) space, but uses extension and positioning in the plane of the page as an analogy for radically high-dimensional relations of proximity, dependency and association in the constituting of different prehensible socio-material configurations ${ }^{428}$. So it is the generally possible topologies that matter in the milieu projected in Figure 3, more than the detailed geometries of particular forms [14].

Unlike other spatial metaphors applied in this kind of analysis [15], the compound term 'timespace' 429430 is used here to refer to the white elliptical representation of the milieu in Figure 3. This addresses an essential issue in socio-material incumbency that might otherwise be neglected, concerning the vector (as well as the scalar) properties of associated configuring fields. This engages with questions over the particular directions in which incumbency might be driving socio-material change and with what degree of reversibility ${ }^{96}$. The 'space' side of this metaphor captures aspects of the dynamics that might be regarded as reversible. But the 'time' analogy evokes better the irreversible path-dependencies that often characterise the directionalities of change. This was arguably a crucial issue, for instance, in the earlier example of wind turbines. If all else remains equal, reinforcing the 'vector intensity' of incumbency around any one pathway might be expected to make such reinforcement more likely for adjacent (necessary, associated or dependent) pathways 96431432433 . It is in this sense, that incumbency can be thought of as 'contagious' in socio-material timespace. 
Figure 3: an 'eagle-eye' view of 'closed topology' in 'shallow incumbency':

confined, monocongruent, discrete and singular

(sources for concepts ordered here are given in the main text)

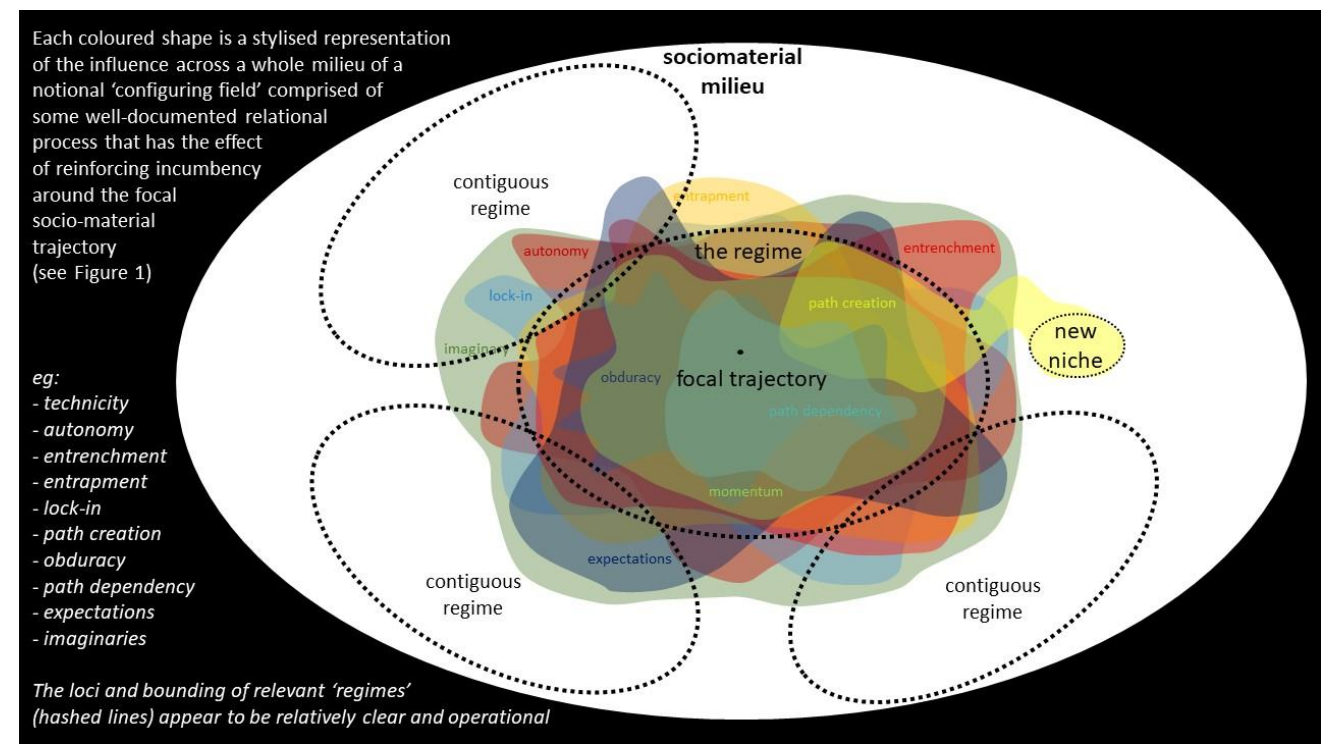

It is not necessary however, fully to fathom all such technical details - still less to concur with them - in order to appreciate what is summarised in Figure 3. In showing the total context of all possible loci and extents of incumbency, this schematic diagram illuminates an encompassing 'milieu' for the social and material dynamics of power as they relate to interlinked social and material change ${ }^{434} 435$. Nor is this a particularly novel notion. Indeed, one version of this general idea that is especially widely known in mainstream studies of research and innovation, is "the socio-technical landscape" ${ }^{162}$. In these terms, the socio-material milieu in Figure 3 can also be thought of as an "external environment" constituting the "deep structural trends" 436 [16] that shape social and technological change over time. The reasons for turning back to an older vocabulary will become evident below. However it is interpreted or referred to, though, the elliptical white area of Figure 3 can usefully be thought of as the 'stage' on which to explore different kinds of performances by the power dynamics that constitute socio-material incumbency. It is by this means, that crucial differences might be distinguished.

Despite contrasting emphases ${ }^{437}$, the particular picture of these power dynamics referred to in Figure 3 as an 'eagle-eye view' are shared in common across a variety of otherwise differing kinds of socio-technical 'regime theory' 438439440 (as well as the many other approaches mentioned above [17]). Key features are well expressed in a multiplicity of diagrams developed in various literatures on socio-technical change 151441149116 ${ }^{121}$ (one of which is reproduced in Figure 4 below). Across many forms, however, what all such representations tend to hold in common, is the following characteristics.

First, these 'eagle eye' pictures generally represent each incumbency-constituting dynamic in any given setting as being relatively confined, rather than extending across the entire milieu. This is shown by the restricted extent of each coloured field in the total milieu of Figure 3.

Second, the different incumbency-constituting dynamics are seen to be 'monocongruent' with one another. This term refers to the tendency of the distributions of the fields strongly to overlap with each other in just one particular area of the wider milieu.

This in turn means, as a third characteristic, that the resulting picture of incumbency - for instance of 'the regime' - is quite discrete and singular in each case (Figure 3). In other words, the palimpsest of all coloured fields taken together, is quite readily representable as a single coherent combined nexus.

As mentioned above, it is not the main purpose here comprehensively to critique the often-useful frameworks for understanding socio-material incumbency that take this kind of 'eagle-eye' form. The aim is instead, simply 
to substantiate the principal shared distinguishing features of this eagle-eye view, so that a clear practical alternative can be formulated for equal consideration. What will be focused on for purposes of illustration to this end, then, is the currently most well-established way to view socio-material incumbency: as 'the sociotechnical regime'. Associated notions are arguably paradigmatic in this field ${ }^{442}$. So if this criticism is sustainable even in this best-elaborated case, then it might be held to apply even more strongly to less-established but epistemically similar 'middle range' frameworks. The particularity of this illustrative criticism with respect specifically to 'socio-technical regimes' should therefore not detract from the essential point, that the same basic issues arise with respect to all the frameworks mentioned above - including terminologies (for instance) of 'systems', 'industries' or 'sectors' as well as 'regimes' 379380381.

To start then with one especially widely adopted formulation, 'the socio-technical regime' as shown in Figure 4 below (after Geels ${ }^{443}{ }^{436}$ ), is defined as "the rule-set or grammar embedded in a complex of engineering practices, production process technologies, product characteristics, skills and procedures, ways of handling relevant artefacts and persons, ways of defining problems; all of them embedded in institutions and infrastructures" 162444445 . This "semi-coherent set of rules" 151 represents "the dominant way that a societal function is fulfilled" 446. Often repeated 151443445116447448121321 449, the term 'semi-coherence' evidently refers not so much to the monocongruence of any given regime (as described above) as to "...the possibility of tensions between rules from different sub-regimes" 436 [18]. Crucial to the constituting of each given regime in these terms, are processes of "alignment" 162436116 , in which "regulations, infrastructure, user practices, maintenance networks are aligned to the existing technology" ${ }^{151}$.

Figure 4: presumptively confined, "semi-coherent" dynamics yield an ostensibly discrete, singular 'regime' (after Geels, 2004; 2011)

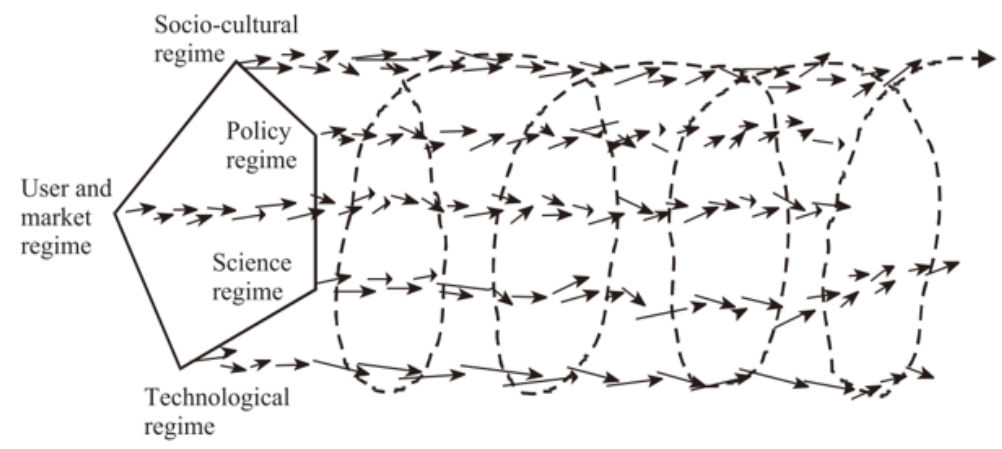

Alignment of ongoing processes in a socio-technical regime.

This property of alignment shown in Figure 4 is reflected in the congruence of the configuring fields shown in Figure 3. In accord with established conventions in this field, the hashed lines in Figure 3 delineate an envisaged overlap in the distributions of the coloured fields, such as to suggest that a given focal 'regime' displays relatively clear boundaries that partition it within a "patchwork" ${ }^{151}$ of notionally discretely contiguous regimes 450437436 and from associated phenomena like 'challenger' 295 'niches' 451 162. What this stylised picture brings out as a notable general feature of conventional approaches, then, is the relatively discrete and singular manner in which 'the regime' is commonly held to relate to the wider milieu, and to other social categories ${ }^{372}$. The resulting 'closed topology' portrayed in Figure 3, is why leading figures in this field can (with respect to particular activities), routinely refer to (for instance) 'the energy regime' 45240453 , 'the electricity regime' 454452 454455 , 'the fossil fuel regime' 456 , 'the coal regime' ${ }^{164}$, 'the oil regime' 457, 'the gas regime' 458431459 , and 'the solar regime' ${ }^{457}$. The point for the present argument, of course, is that the apparent clarity and assertive singularity of the definite article in each case, may contrast with the latent ambiguities in the overlapping pluralities and nestings of the specific sectoral references.

Of course, much analysis in this genre acknowledges that 'the regime' is just a "heuristic" construct ${ }^{151}$ and "an interpretive analytical concept" ${ }^{436}$. So it is clear to practitioners of regime-based understandings, that real- 
world instances and their connections will be more complicated. Beyond issues of regime boundaries 218460 ${ }^{461}$, there is often sophisticated discussion of these ambiguities in this literature concerning nuanced details relating to regime structure ${ }^{462}$, culture ${ }^{463}$, power ${ }^{464}{ }^{268}$, discourse ${ }^{465}$, agency ${ }^{448}$, relations between regimes 466450 and nestings of regimes and 'sub-regimes' ${ }^{443}$. To also be fair to the present critique, however, such complexities are already acknowledged in the overlaps and fine-grain structures shown in the characterisation of the 'closed topology' in multiple configuring fields in Figure 3. Despite such details, the crucial point is, that what nonetheless typically prevails in much current academic understanding in this field, remains a relatively simplistic and challengeable assumption concerning the degree to which the constituting dynamics of any given 'regime' can safely be assumed to be relatively confined and congruent with respect to the regime itself.

A good illustration of this assumption - and of the associated vision of 'alignment' - is provided by a further detail in Figure 4. It is notable in this illustration from a key text by a leading protagonist, that the term 'regime' refers to some strongly contrasting things: first, to a specific focal 'socio-technical regime' (in the diagram label); and, second, to general patterns in entire milieu-spanning societal phenomena (eg: 'policy', 'science', 'technology', 'markets', 'culture' - on the left hand side). Which of these two, is 'the regime' that this is supposed to illustrate? This results in a range of serious - and rather surprising - ambiguities at the core of this framework [19]. But for present purposes, this is not the main difficulty in the performed clarity and completeness of this notion of 'the regime' ${ }^{443}$. More striking in this regard, are the simplistic and challengeable assumptions underlying the picture of 'alignment' in Figure 4. In short, Geels' canonical diagram also displays a conflation between the orientation of a particular 'incumbent trajectory', with the dimensionalities of the general dynamics that foster this.

To see this, it is worth asking what is meant to be illustrated by the little near-horizontal arrows in the middle of the picture in Figure 4? Most obviously, these represent an aligning effect on the trajectory of the specific focal socio-technical 'regime' (in the sense used in the diagram label). But what these little arrows also suggest is a much more general alignment between the milieu-spanning 'regimes' (in the different sense indicated on the left-hand side of the diagram). In other words, the phenomenon of alignment in any particular instance, is taken here to imply a high degree of congruence in the wider general processes and relations that are responsible for this. It is the resulting impression of clarity that arises from this conflation, that makes it possible to assert in the face of much wider potential multiplicity, such an ostensibly simple and singular term as 'the regime'. And it is this picture of assumed congruence, that is reflected in the presumptively high degree of overlap in the configuring fields of the 'eagle-eye' view shown in Figure 3.

The problem with this implication is that just because certain social and material processes and relations have the effect of sustaining a specific socio-material pathway, does not necessarily mean that each of these constituting dynamics are themselves enacted in dimensions that are congruent with - or confined within - all the others that also constitute the associated incumbency. That the general milieu-spanning phenomena help constitute the particular socio-material configurations associated with this pathway does not necessarily mean that they all also (separately and in all other ways) neatly align with each other, in a fashion shown by the monocongruent overlaps in Figure 3. The possibility also seems worth including in such a supposedly general framework, that a given socio-material pathway might be sustained by dynamics that are themselves in (perhaps many) other respects not aligned with one another [20]?

Seen in this light, then, it seems highly questionable simply to assume that the processes and relations that constitute incumbency in any given locus, will also be so congruent with one another as to effectively be confined to the identity of a discrete and singular 'regime'. Holding potentially massive practical implications for the interrogation of incumbency - and for practical efforts to modulate it - it is this highly questionable feature of currently widespread regime theory that is inadvertently highlighted in Figure 4 - and represented by the schematic overlaps in Figure 3.

What is at issue here, however, extends far beyond the details of particular diagrams. And it is not a matter for parochial academic wrangles. Indeed, what is at issue is a flaw in prevailing understandings that Geels himself incidentally regrets as "a tendency to reify" notions of 'the socio-technical regime' 436372 . In short, both Figure 4 (and its translation in Figure 3) convey a lofty sense of 'looking down' on a set of monocongruent dynamics, effectively coterminous with the regime that they notionally constitute, which therefore appears to be discrete 
and unitary. However applicable it might be thought to be in any given setting, this picture at least prompts a possible alternative view. This contrasting approach might embody an immersive sense of 'looking around' at a partially-obscured encompassing milieu, rather than 'looking down' on a notionally clearly-surveillable 'landscape'. Although the dynamics in focus are still sufficiently 'coherent' (in Geels' terms) to help constitute a focal pathway (and thus not entirely incongruent with one another), they nonetheless display so many separate loci of overlaps, that they must be recognised as 'polycongruent' rather than monocongruent [21].

Given the diversity of incumbency-reinforcing dynamics referred to in Figure 1 (eg: 'lock-in', 'obduracy', 'entrenchment', 'entrapment', etc), this alternative ideal-typical possibility might readily be seen to be at least equally plausible, to what even key authors of regime theory acknowledge to be problematically-reified current default understandings. Here, the manifest disparities between many well-recognised contrasting reinforcing dynamics like those summarised in Figure 1, are acknowledged to admit far more multifarious topologies across contrasting settings, than are admitted in conventional regime theory. In this wider view it emerges as quite eccentric simply to assume such simplistically congruent patterns of reinforcement as shown in the 'eagle-eye' view of Figure 3. At minimum, the possibility is opened up for acknowledging that a least some of these incumbency-constituting processes around a particular pathway, may be radically mismatched with each other in respect of their implications for other socio-material configurations. In this sense, the idea of a singular proximate 'regime' defined by a notionally coherently-aligned set of 'rules' can be seriously misleading in its wider policy implications. If a deeper, more distributed, complex and plural idea of incumbency is appropriate, then the associated political challenges are far less tractable.

Figure 5: a 'worm-eye' view of 'open topology' in 'deep incumbency': pervasive, polycongruent, entangled and plural (sources for concepts are given in the main text)

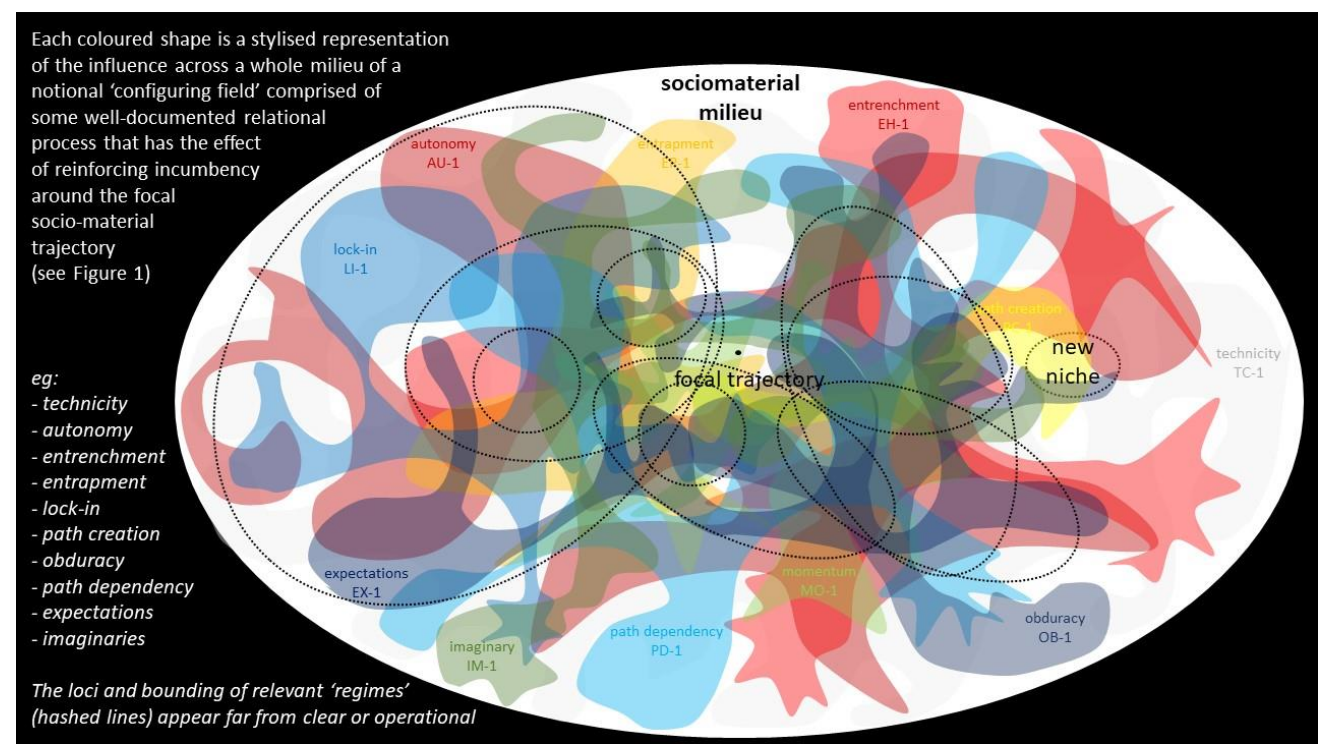

Figure 5 (above), then, illustrates just such an alternative view of socio-material incumbency. It provides a clearly contrasting ideal-typical representation to what Geels laments as the 'reified' conventional views of 'the regime' envisaged in Figure $3^{436}{ }^{372}$. And it is on this basis that the particular ways in which Figures 3 and 5 differ may offer fruitful axes for heuristic comparison, also holding practical implications for political action. Perhaps the most crucial contrast involves the divergent complexity (and thus tractability) of the two views of socio-material incumbency. In Figure 5, diverse incumbency-sustaining dynamics are viewed as if ('horizontally') from within the same milieu, rather than ('vertically') assuming congruence and detachment. This refers back to the earlier discussion of the double hermeneutic, to acknowledge that subjective efforts at understanding power-laden social processes around incumbency are deeply embedded in the notionally 
'objective' phenomena they seek to understand. Far from the hubristic 'cockpit-ism' of presumptively 'seeing like an eagle', then, Figure 5 reflects the greater epistemic humility of 'seeing like a worm'.

\section{2: Contrasting the Eagle- and Worm-Eye Views of Incumbency}

For purposes of research design, these contrasts might usefully be interrogated more forensically. A first practical consequence of contrasting the 'eagle-eye' view in Figure 3, with the 'worm-eye' view of incumbency in Figure 5, is that the latter is explicitly immersive. Rather than being foreshortened by performative distance into a roughly singular constellation, diverse incumbency-sustaining dynamics are much more clearly divergent in Figure 5, in their social and technological provenance and implications. Represented by strikingly different complementary and overlapping - 'configuring fields' within the milieu, each dynamic (like 'lock-in', 'obduracy', 'entrenchment', 'entrapment' and so on) is seen as reinforcing disparate subsets of relevant sociomaterial configurations. Indeed, each field is itself shown as comprised of interlinked multiple separate parts, because the orthogonal dimensions in which these parts are linked are recognised to be invisible under any particular low-dimensional projection (like Figure 5) of the milieu as a whole.

This raises again a point made in defining incumbency at the beginning of this discussion - as being constituted by a 'multiplexity' of dynamics. Referring in colloquial terms to the quality of "[h]aving many aspects, elements, characteristics, parts, or (esp. interrelated) features" 2 , technical usage of this word in network analysis ${ }^{129130}$ further underscores the strikingly different distributions of configuring fields in the worm-eye view in Figure 5, as compared with the closed topology assumed in the eagle-eye view shown in Figure 3. And focusing on these dynamics as fields in the milieu of socio-material timespace (the white ellipse in Figures 3 and 5) also recalls another point made earlier. Incumbency was characterised in the last section as being (re)produced by 'vector intensities' in power distributions - intensities not just in the scalar values of concentrations of 'asymmetrically structuring agency', but also in their relations with contrasting possible orientations for change. It is in these terms, that the contrasting incumbency-sustaining dynamics in Figure 5, might be thought of as a multiplexity 129130 in the 'configuring fields' defined above, whose overlapping distributions collectively foster or suppress different possible pathways in socio-material configurations [22].

A second related feature of this multiplexity-acknowledging worm-eye view of incumbency, is that it is clear that many of the phenomena under scrutiny cannot reasonably be limited to any particular confined 'region' of the socio-material milieu - of a kind associated with 'the regime'. In other words, it is difficult to justify seeing incumbency of any particular kind, as being so distinctively coterminous with anything as ostensibly discrete and singular as conventional ideas of 'the regime' (or 'the system', 'the industry', 'the sector'). The point here is not that different patterns of intensity in the sustaining of incumbency are entirely incongruent with one other. With many overlaps, they are actually mutually reinforcing in a multiplicity of different ways and settings. But rather than there being a single notionally instrumentally-tractable site of overlap in 'the regime', these overlaps can be seen instead as more intractably polycongruent across an entire political milieu. Such additional epistemic and operational humility offers a crucial consistency with the general importance of the double hermeneutic in social science, which is arguably neglected in conventional eagle-eye views. What the more immersive worm-eye view underscores, is that what counts as 'the regime' in any given context is a function not only of the supposedly objective phenomena being prehended, but also of the more overtly subjective conditions of prehension themselves.

It is in these terms, that ostensibly neatly-partitioned ideas of 'level' and 'scale' in conventional theories of socio-material change are - like notions of 'the regime' - apparently straightforward in exposition, but in practice open to radical ambiguities and confusions [23]. Despite the performed simplicity so expedient to discipline-building pedagogy, then, these framings can obscure many crucial real-world complexities. For instance, there may exist 'fractal' orders in configuring fields, whose self-similarity at every scale would undermine the asserted distinctions between 'levels' 467468181 that are so essential (for instance) to the ' $m u l t i-$ level perspective' 15144149116121 . Likewise, 'rhizomic' patterns and flows also subvert rigid differentiations between both hierarchical scales and horizontal categories within these 469312 . In this light, simply to assume universal neatly-nested category structures with self-evident boundaries (like 'the regime'), is to commit an 
error diagnosed by the philosopher Whitehead as 'the fallacy of misplaced concreteness' 470372 . As with control fallacies discussed earlier (to which they are related in their presumed tractability), such fictions might be expedient in 'the real world' of policy making (as conditioned as this is by incumbency). But they can be deeply misleading (and so impractical) in 'the real real world' of sociotechnical phenomena themselves ${ }^{471}$.

A third important point that arises in comparing Figures 1 and 3 is the possibility envisaged in the open topology as seen under a worm-eye view, that relations and processes that sustain incumbencies even of the most particular kinds, may nonetheless effectively pervade the entire landscape of socio-material phenomena [24]. Understood in this way, a worm-eye perspective holds further potentially profound implications for interpreting the generative dynamics of incumbency. Incumbency cannot in this view simply be assumed in a reductive fashion, to be something located in (pressuring 'outwards' from), some particularly-located and bounded socio-technical trajectory (eg: 'the regime'). As with physical phase changes like condensation or precipitation, incumbency is in this view a function of system-level properties: it is formed more from 'wholesin', than from 'parts-out' 434435472 [25].

As in other applications of field ontologies in social science, it is the need not to ignore the possible importance of these more open and pervasive social relations and processes, that substantiates the value of the concept of 'configuring fields'. Informed by many different kinds of social field theory [9], this is nonetheless quite distinct in its direct phenomenological style. To envisage "patterns of propensity across the totality of all possible sociomaterial configurations, that serve with respect to a particular focal socio-material pathway to foster this specific orientation for change more than others", requires no assumptions that there exist in reality, particular middle range social entities or structures. Each 'field' is, after all, as extensive (in varying intensities) as the milieu as a whole. All that is required for the above analysis to hold, is that it be conceded that incumbency is characterised by many kinds of power gradients.

Expressed as asymmetries in processes of structuring agency, then, the resulting patterns of intensity may be envisaged (without any privileging either of structure or agency), to have the effect of orienting directions for socio-material change [26]. So, what has been described amounts simply to the patterns of scalar and vector intensity introduced at the outset, without introducing presumptively concrete discontinuously-bounded and congruent categories like 'levels' or 'regimes'. Also avoided, are the kinds of assertions common in some other social field theories, where claims are often made to be able to identify supposedly individually discrete and operationally distinct categories or instances of the fields in question 415418112419420421422423424295425 . Whilst indicatively diverse forms of field are shown in Figures 3 and 5, the analysis here does not rest on any claim that these are precisely separable. Instead, the argument is pitched at the more general level of contrasting topologies, rather than implying the feasibility of more fine-grain characterisations. By focusing on topologies, no assumptions are introduced that are not already immanent in the fabric of the problematique itself.

It is these features of a configuring fields approach, then, that allow application to multiple variants of (for instance) the dynamics of 'lock in' - which may (after all) in any given setting also relate to an even greater multiplicity of different socio-material elements constituting a notionally single 'pathway'. What is enabled in a configuring fields approach is that these multiplicities of dynamics (like those relating to other incumbencysustaining processes shown in Figures 1, 3 and 5) can be represented in ways that avoid the restrictive assumptions of the eagle-eye view. In topological terms, these dynamics can be seen as pervasive, polycongruent, entangled and plural (as in Figure 5), as well the usual representation as confined, congruent, discrete and singular (as in Figure 3). It is this higher possible level of generalisation - without simply assuming crucial features of the phenomena under scrutiny - that arguably constitutes a key merit of this approach.

Equally capable of rendering either ideal type without bias, then, a configuring fields framework can be used for comparative purposes in ways that do not simply presume an outcome. If it is assumed that a given 'regime' is moncongruent, then this is what an analysis will find. Whilst not forcing a 'worm-eye' view, a configuring fields approach at least allows the possibility that an eagle-eye view be avoided. It allows it to be more easily understood, how even particular instances in a single family of processes can (like lock-in) be radically differently distributed throughout society. And if this point can be recognised to apply with respect even to such an ostensibly relatively straightforward, positive and material dynamic as 'lock-in', it evidently applies far more to diverse classes of supposedly regime-aligning dynamics taken together (such as: 'policy', 
'science', 'technology', 'markets', 'culture' in Figure 4). It is these more highly aggregated milieu-spanning aspects of society that are routinely disciplined under an eagle-eye approach into justifying bounded unitary notions of 'the regime', which might be especially usefully envisaged as constellations of configuring fields.

The implications of the alternative worm-eye picture of socio-material dynamics in Figure 5, are also entirely independent of whatever language might be used to describe it (like the terminology here, of 'configuring fields'). In whatever terms, the repercussions are potentially profound for general understanding of phenomena of incumbency. If the formative dynamics of any given instance of socio-material incumbency are distributed in incommensurable ways throughout what regime theory refers to as the socio-technical landscape', then it follows that political remedies cannot so easily be reduced and confined to relatively tractable policy interventions around a notionally singular and bounded entity called 'the regime'.

When allowed by a configuring fields approach to also be seen in a worm-eye view, however, the constitutive dynamics of incumbency may be recognised instead (at least in principle) inconveniently to implicate entire political economies, cross-national polities, institutional cultures, global discourses and social epistemologies. Where the task is seen to lie in countering these far deeper and more pervasive dynamics, interventions must be more about distributed, unruly, rhizomic collective action through social movement and democratic struggle than about centralized orderly strategies and policies targeted hierarchically by incumbent governance actors on some specific sector. In short, like social transformations more widely, ostensibly circumscribed socio-technical 'transitions' become visible as being more about 'politics' than 'policy' ${ }^{400}$.

And it is here that we can think back to the earlier discussion of the double hermeneutic in all social research and the implications of the dynamics of incumbency for how incumbency itself is studied. For it is also in these political terms, that it can be understood why worm-eye views like that elaborated here, tend to be far less well established in policy appraisal (or the 'impact'-hungry careers and disciplines that compete for privilege in this arena), than the eagle-eyed views of various forms of middle range theory like the multi-level perspective. Almost irrespective of their validity, it is the presumptive levels of confinement and congruence in the constituting dynamics of incumbency shown in Figure 3 - and the associated relative degrees of singularity and discreteness - that can arguably on their own explain the favoured status. For it is these properties that serve to support the crucial political commodity of justification 405406407408 in representations of incumbency .

No matter how mistaken it may be as a representation of the real-world phenomena under scrutiny, then, an eagle-eye view like that in Figure 3 may nonetheless remain convenient to incumbency - in providing a means to justify the 'fallacies of control' that work to maintain incumbent privilege. On the other hand, even if it offers a manifestly more valid picture, a worm-eye view like that in Figure 5 can be quite seriously inconvenient to incumbency, in that it makes discursively-expedient control stories far more difficult to propound. That this is so, is amply demonstrated by many energetic reactions to the present analysis!

So, it is this asymmetry of subjective expediency (rather than any mismatch in correspondence with underlying objective realities), that may help explain the preponderance of 'eagle-eye' views [27] in established approaches to socio-material incumbency. But if realities of incumbency are in fact more akin to the picture in Figure 5, then the prospects for the kinds of cockpit-style interventions that tend to be prompted by this view, are far less positive. Indeed, it might in this event reasonably be thought that this eagle-eye style of intervention is more likely serve to protect the complex hidden complexities of incumbency, rather than challenge them. This is because there would in this case be few more effective ways to sustain the open topologies of incumbency illuminated in the worm-eye view, than to establish a closed imagination of incumbency generated by the eagle-eye picture.

It is in this way, that the stakes are indeed very high in any setting, around the choice of which view is most appropriate. If incumbent pressures on mainstream analytical approaches to socio-material change discussed here, force them inadvertently to emphasise an eagle-eye response to the many pressing global challenges highlighted at the beginning of this paper, then it will be eagle-eye 'solutions' that can be expected to ensue. But if such preferences for simplified, controlling, power-reinforcing eagle-eye responses is actually a key part of the challenge in the first place, then even the most genuinely progressively-intended analysis for transformation, may become part of the problem rather than part of the solution. And it does not need to be 
argued that such a perverse dynamic will necessarily always - or even sometimes - be the case, for the logic to be compelling, that a more general framework that does not force this syndrome, should at least be considered.

\section{4: Challenging Socio-Material Incumbency: From Method to Action}

\section{1: Summary and Lessons for Methodology}

Drawing on a wide body of theory in social science - especially processual and relational understandings of structuration and power - this paper has developed an approach to socio-material incumbency built around a novel heuristic concept of 'configuring fields'. A broad axis of contrast has been proposed between two idealtypical patterns in such fields, with 'eagle-eye' and 'worm-eye' views, respectively, seeing incumbency in the form of relatively 'closed' and 'open' topologies. This reflects an empirical contrast in subjective ways of scrutinising incumbency, as well as in different forms of incumbency as objects of scrutiny. Crucially (and perhaps ironically given its debts to constructionism ${ }^{473}$ ), the resulting distinction is, in principle (and despite important general limits to these qualities ${ }^{474}{ }^{475}$ ), relatively testable ${ }^{476} 477$ - and even potentially falsifiable ${ }^{478}$ 479. This penultimate section will focus on practical methodological implications that may arise from this.

Based on the preceding discussion, Table 1 below summarises the main points of this analysis, highlighting the most salient theoretical and practical characteristics of the two contrasted prehensions of socio-material incumbency, as well as some concrete issues that arise for methodology and research design. The underlined bold phrases in the first part of the table indicate (with a few lines of summary explanation) the main distinguishable features in respect of each of these two ideal types, concerning in each case their respective: foci of scrutiny (what they are looking at); processes of scrutiny (how they do the looking); styles of prehension (how resulting pictures are portrayed) and the general forms of typically-highlighted policy and political interventions (what broad kinds of action are entailed). Key phrases from the earlier discussion in this article are italicised in bold in each respect.

The underlined bold phrases in the second part of Table 1 indicate a series of potentially empirically-testable properties of these ideal-types, of kinds that might be useful in informing onward academic research and strategic appraisal. This highlights quite readily-conceivable contrasts in the distribution and the patterning of whatever are held in any context, to constitute the relevant - and sufficiently-visible - 'configuring fields'. Table 1 also highlights associated features in the observed identities and relations of candidate instances of incumbency that can help diagnose them on the continuum from the perceived 'closed topology' of the (currently mainstream) eagle-eye view to the 'open topology' of the (proposed alternative) worm-eye view.

The efforts made at methodological clarity, specificity, transparency and testability in Table 1 (albeit only partially successful), reflect struggles towards elusive qualities that are sometimes lacking in many extant approaches to socio-material incumbency and change ${ }^{480}$. Although there can be no panaceas, the framework sketched there may help point towards a remedy for some currently key obscurities and ambiguities in other approaches discussed in this article ${ }^{481}$. By contrast with many presently well-established 'middle range' social theoretic approaches to incumbency (like those based around 'innovation systems', 'socio-technical' systems, 'transition management' or 'the multi-level perspective' for instance), this configuring fields approach does not take for granted so many conveniently reductive methodological constructs ${ }^{482}$. In itself, this may help avoid what even protagonists of mainstream approaches have criticised as the reification of what may mistakenly be held to be neatly-separable levels and instantiations of incumbency, like 'the' sector, industry, or regime. 


\begin{tabular}{|c|c|c|}
\hline & $\begin{array}{l}\text { MAINSTREAM } \\
\text { 'EAGLE-EYE VIEW' } \\
\text { (a stylised ideal-typical abstraction describing } \\
\text { diverse current practices in academia and } \\
\text { policy and illustrated schematically in Figure 3) }\end{array}$ & $\begin{array}{l}\text { ALTERNATIVE } \\
\text { 'WORM-EYE VIEW' } \\
\text { (a correspondingly stylised ideal-typical abstraction, } \\
\text { proposed in present paper as a complement to current } \\
\text { practices and illustrated schematically in Figure 5) }\end{array}$ \\
\hline \multicolumn{3}{|c|}{$\begin{array}{l}\text { RELEVANT PRACTICAL AND POLITICAL CHARACTERISTICS } \\
\text { of two contrasting circumstances equally in the (interlinked) apprehending and constituting of socio-technical incumbency }\end{array}$} \\
\hline $\begin{array}{l}\text { focus of scrutiny } \\
\text { of notional objective } \\
\text { phenomenon of incumbency }\end{array}$ & $\begin{array}{l}\text { shallow incumbency with closed topology } \\
\text { each instance of incumbency is understood in } \\
\text { terms of neatly-scaled 'levels' of analysis and } \\
\text { 'middle range' theoretical categories like } \\
\text { 'regimes', 'sectors', 'systems', 'industries' }\end{array}$ & $\begin{array}{l}\text { deep incumbency with open topology } \\
\text { each instance of incumbency is a specific reflection of } \\
\text { such diverse, pervasive power relations and processes, } \\
\text { that it is robustly understood only in irreducible terms of } \\
\text { entire societies, cultures, economies and materialities }\end{array}$ \\
\hline $\begin{array}{l}\text { process of scrutiny } \\
\text { salient self-identified } \\
\text { aspects of subjective view }\end{array}$ & $\begin{array}{l}\text { reification of coherence } \\
\text { inadvertently aligns with deep incumbency in } \\
\text { giving a "semi-coherent" picture which "tends } \\
\text { to reify" some key categories and relations }\end{array}$ & $\begin{array}{l}\text { engagement with multiplexity } \\
\text { resists aligning with deep incumbency by illuminating } \\
\text { complexity, aiming to balance incumbent pressures for } \\
\text { reifying of categories and exaggerating of coherence }\end{array}$ \\
\hline $\begin{array}{l}\text { style of apprehension } \\
\text { associated vision of key roles } \\
\text { for knowledge production in } \\
\text { social appraisal of } \\
\text { incumbency }\end{array}$ & $\begin{array}{l}\text { positive expert explanations } \\
\text { 'objective', 'evidence-based' academic } \\
\text { research and policy analysis are independent } \\
\text { of incumbency; producing "necessary } \\
\text { simplification" to enable practical control }\end{array}$ & $\begin{array}{l}\text { reflexive inter-subjective understandings } \\
\text { knowledge and action are co-constituting - and of } \\
\text { incumbency and its reactions. So stories of control are } \\
\text { expedient fallacies to justify incumbent privilege. And, } \\
\text { like others, this apprehension is itself an action }\end{array}$ \\
\hline $\begin{array}{l}\text { associated interventions } \\
\text { main societal actions for } \\
\text { rebalancing incumbency }\end{array}$ & $\begin{array}{l}\text { orderly policy instruments and mixes } \\
\text { engineered vertically down on 'regime' from } \\
\text { hierarchically separate governance 'cockpit' }\end{array}$ & $\begin{array}{l}\text { unruly, irreducibly political, democratic struggle } \\
\text { diverse mutualistic 'murmurations' in collective action; } \\
\text { rhizomically engage relevant susceptible configurations }\end{array}$ \\
\hline \multicolumn{3}{|c|}{$\begin{array}{l}\text { POTENTIALLY EMPIRICALLY TESTABLE PROPERTIES } \\
\text { of dynamics constituting socio-technical incumbency - viewed as configuring fields in a socio-material milieu of all possible configurations }\end{array}$} \\
\hline & CLOSED TOPOLOGY & OPEN TOPOLOGY \\
\hline $\begin{array}{l}\text { distribution } \\
\text { of each configuring field in } \\
\text { the socio-material milleu }\end{array}$ & $\begin{array}{l}\text { confined } \\
\text { relatively circumscribed and neatly-scaled, } \\
\text { helping to define a clearly 'mid-level' 'regime' }\end{array}$ & $\begin{array}{l}\text { pervasive } \\
\text { expansive and fractal (so neither scaled nor ubiquitous); } \\
\text { transcending levels of 'regime', 'niche' and 'landscape' }\end{array}$ \\
\hline $\begin{array}{l}\text { patterning } \\
\text { of relationships between } \\
\text { different configuring fields }\end{array}$ & $\begin{array}{l}\text { monocongruent } \\
\text { strongly overlapping, such as to delineate one } \\
\text { broadly contiguous set of configurations }\end{array}$ & $\begin{array}{l}\text { polycongruent } \\
\text { both complementary and overlapping in disparate ways, } \\
\text { so implicating a diversity of noncontiguous configurations }\end{array}$ \\
\hline $\begin{array}{l}\text { identity } \\
\text { constituting of notional } \\
\text { instances of incumbency }\end{array}$ & $\begin{array}{l}\text { singular } \\
\text { apparently "semi-coherent" and quite clearly } \\
\text { bounded, so as to justify idea of "the regime" }\end{array}$ & $\begin{array}{l}\text { plural } \\
\text { neither coherent nor clearly bounded, raising questions } \\
\text { over individualised ideas of 'the regime' in any setting }\end{array}$ \\
\hline $\begin{array}{l}\text { relations } \\
\text { between different } \\
\text { instances of incumbency }\end{array}$ & $\begin{array}{l}\text { discrete } \\
\text { sufficiently mutually separable to avoid } \\
\text { confusion over which 'regime' is which }\end{array}$ & $\begin{array}{l}\text { entangled } \\
\text { rhizomically interconnected and inseparable; querying } \\
\text { which 'regime' is which and how they interlink and nest }\end{array}$ \\
\hline
\end{tabular}

The main reason for this, is that it is not simply assumed that the many constituting relations and processes of incumbency (the different configuring fields), will all be conveniently monocongruent and confined in their differing effects. So, a configuring fields approach does not expediently presume in advance that the phenomena that constitute incumbency will necessarily resolve into the kinds of finely-partitioned prior ontologies of notionally discrete 'levels', 'phases', 'scales' that tend to be so prominent in current academic 
and policy analysis. It resists conflations between radically different concepts that happen to share the same name (like the two elided notions of 'regime' in Figure 4). It avoids implying that 'alignment' in one subset of socio-material parameters, must necessarily entail 'alignment' across all relevant dimensions (as also in Figure 4). Perhaps most importantly, by relationally addressing both subjective and objective circumstances, a configuring fields approach helps avert the performing of an illusory transcendent status for analysis, tacitly asserting as much separation from phenomena of incumbency themselves, as a soaring eagle (temporarily) achieves from 'the landscape' below.

By focusing more relationally and processually (rather than categorically) on contrasting topologies in what are acknowledged to remain intractably uncertain complexities in configuring fields, more scope may be provided for greater methodological appreciations for nuance ${ }^{358}$, variability ${ }^{483}$, plurality ${ }^{484}$, conditionality ${ }^{71}$, diversity 485486 uncertainty ${ }^{487}$, mess ${ }^{482}$, thick description ${ }^{488}$, reflexivity ${ }^{489}$, and phenomenological openness to surprise ${ }^{490}$. This does not mean that these aspects will necessarily be highlighted over more straightforward characteristics, where they are apparent. For a configuring fields approach to simply acknowledge the possibility of this kind of 'multiplexity' 129130134135 , is not to presume that this quality is relevant everywhere. In the face of strong incumbent pressures for reduction and simplification in academic and policy analysis ${ }^{71}$, it simply helps to ensure that there is at least some chance that aspects of multiplexity will be recognised under conditions where they are relevant. So, by opening up the possibility of recognising more deeply penetrating 'open topologies' in socio-material incumbency this approach in no way undermines or denies the possibility of identifying more closed topologies in the relatively shallow kinds of incumbency described by entities like 'the regime'. All that is happening, is that regimes are not simply assumed into being [28]. Otherwise, research frameworks whose only means to represent incumbency are in such relatively circumscribed and shallow ways, will not simply be wrong in many important cases. They will be part of the process of incumbency itself.

Equally when focused on different subjective ways of seeing incumbency, then, or on its ostensibly objective instantiations in different settings, a 'configuring fields' approach seems quite readily amenable to refutation, testing, validation or further exploration and development by a variety of different methods. Where a number of contrasting incumbency-sustaining dynamics can be considered with confidence to be resolvable in available disaggregated quantitative data, the framework might be held to offer a basis for well-established methods for analysing different kinds of 'big data' around alternative socio-technical pathways 491492493494 such as topic modelling 495496 corpus analysis 497498 or agent-based modelling 499500 as well as other nonaggregating quantitative approaches like (for instance) principal components 501502 , cluster analysis 503 or diversity analysis ${ }^{485} 504$. Especially when triangulated in conjunction with one another, the potential ability of such methods to discriminate between the traces left in disparate societal media can assist identification of contrasting geometries of incumbency and their relations with divergent socio-material pathways ${ }^{505}$.

This is especially so, if methods like these (capable of wide but 'thin' prehensions of whatever are held to be the relevant socio-material milieux) are carefully triangulated and complemented with the deeper but 'thicker' descriptions provided by interpretive enquiry 506507 . Indeed, the focus of this proposed configuring fields approach on an ontology of topology ('closed', 'open' or some more nuanced permutation thereof), may be especially fruitful for such mixed-method approaches 508509510511 . Both as a class of phenomena and in its associated disciplinary style, the concept of 'topology' is, after all (as alluded to earlier), itself something of a 'boundary object' 512513 between the Cartesian geometries of quantitative frameworks and the more flexible dimensionalities of interpretive sensibilities ${ }^{426}$. In this regard, hybrid analytic-interpretive methods (like, for instance, Q-method 514515 or multicriteria mapping 516517518 ) may offer particular value in specific contexts. In general, such approaches can also help bridge between the unduly estranged 'two cultures' of (roughly, but not perfectly, corresponding) quantitative-aggregating-instrumental and qualitative-differentiating-critical enquiry 519520 . Here again, the focus of a configuring fields approach on an ontology of topology, may make these and many other forms of methodological hybridisation especially relevant.

One mode of usage of these kinds of method to interrogate topologies of configuring fields is in comparative research. Here, operational divides between notional 'eagle' or 'worm' eye views - or, indeed, other views and corresponding topologies - becomes a matter for whatever may emerge as salient axes of contrast in the contexts in question. Another possible style of inquiry, however, might take the form of a single case study ${ }^{156}$. 
Of course, there would arise in this situation (just as with any other generalisation), questions over the degree to which single case study research is capable inductively ${ }^{521}$ or deductively ${ }^{522}$ of substantiating any wider relevance for any distinction between closed and open topology for incumbency in a particular setting ${ }^{523} 524$. But a single case study does still remain a useful way abductively 525526527 to illuminate a wider range of aspects for possible general explanation 528529530531532 [29]. So, if the phenomenon of socio-material incumbency can be seen even in only one relevant instance, to extend beyond the usually-assumed boundaries and modalities of a 'closed topology', then at least a similar potentiality would have been opened up for consideration in other instances. It is in this sense, that a single case study may also offer a fruitful way to apply a 'configuring fields' approach. This is the spirit in which the accompanying empirical article will report on an analysis of the circumstances of incumbency around civil nuclear power in the UK.

In respect of a single case study like that in the companion article to the present paper, then, the foregoing discussion above (as summarised in Table 1) also yields a series of quite practical possible questions - each suggestive of various associated hypotheses. In this way also, then, a 'configuring fields' approach might usefully help inform any investigation of possible incumbency around a specific socio-material pathway:

(1) First (and in terms substantiated earlier in this paper): are observed commitments of structuring agency around the focal pathway in the chosen case, judged to be sufficiently intense such as to clearly identify this as an instance of 'socio-material incumbency', rather than merely of 'contingent persistence'?

(2) Second: do diverse patterns of political commitment to the focal pathway, demonstrate with confidence that incumbency is aligned in this case in such a confined, monocongruent, discrete and singular way as to imply a single particular uniquely-definable 'regime'? If so, this would tend to confirm an 'eagle-eye view'.

(3) Third: are patterns of commitment to the focal pathway such that incumbency seems more distributed, polycongruent, entangled and plural, than is satisfactorily described as a single regime identifiable specifically with this pathway? If so, this diversity might be seen to open the possible relevance of a 'worm-eye view'.

(4) Fourth: can this 'configuring fields' approach to illuminating diverse possible modalities of socio-material incumbency, help yield practical insights for political action to address the observed form of incumbency in this focal case, of kinds that might arise less easily for attention under conventional 'regime theory'?

It is on this last point, that the present methodological discussion can rest. The argument has been sustained, that the topological focus of a configuring fields approach does present a basis equally for comparative enquiry according to a quite clear set of clear criteria concerning 'open' and 'closed' topologies in Table 1. And single in-depth case study research has also been shown to be potentially applicable, subject to the systematic series of questions $(1-4)$ identified above. Although raising many onward methodological queries, the levels of operational specificity offered here are at least as favourable as those typically yielded in mainstream incumbency research.

\section{2: Wider Political Implications}

It remains, in closing, to turn attention from issues of theory and methodology, back to questions of practice. The paper began with a series of momentous challenges for research on socio-material incumbency. What are the prospects that a 'configuring fields approach' might have anything substantive to offer as one further means among many for seeking to address these challenges? Here, it is obvious that the most important single quality lies neither in parochial rivalries between this and any other approach, still less in hubristic attempts to integrate some grand general framework (of the kind whose performed authority is so favoured by incumbency itself ${ }^{372}$ ). The proposal here of an alternative view, is made more in a spirit of methodological flexibility ${ }^{533} 534$ and disciplinary pluralism ${ }^{535} 536$ - of kinds whose forms can be as challenging to incumbencies in knowledge production as their contents may be to incumbencies in wider practice ${ }^{537}$. After all, what is at issue in this area, is far more than just the fortunes and misfortunes of contending academic disciplines, 
research frameworks or styles of policy appraisal. However they are viewed, if the deepest forms of incumbency are to be effectively interrogated and challenged, then it is likely that no single approach will be sufficient - and that a radical diversity of contrasting tools will be needed.

Of course, the validity of all this also remains to be established. As in the much-used phrase (attributed, among others, to Engels ${ }^{538}$ ) "the proof of the pudding, lies in the eating", the ultimate justification for any mode of understanding, will (whether acknowledged or not) typically lie in normative and operational judgements over the kinds of actions with which it is co-constituted - and which it can variously help enable or undermine ${ }^{539}$ ${ }^{540}$. In this sense too, then, the stakes are very high. Just as the urgency and severity of their worldwide impacts are coming to be recognised, so global incumbencies are evidently further entrenching on a planetary scale ${ }^{541}$ ${ }^{542}$. Across the range of different settings with which this paper began, mutually reinforcing historical contingencies and path-dependencies are seemingly further amplified by growing pressures of globalisation ${ }^{543}$, standardisation ${ }^{544}$, concentration ${ }^{542}$ and control ${ }^{545}$. In policy analysis as elsewhere, space for diversity and pluralism is under pressure ${ }^{308} 546$. This is the sense in which the 'gravitational effects' exercised by incumbency discussed here, can warp the very processes through which incumbency is interrogated and understood.

It is in this light that the contrast between 'eagle' and 'worm' eye views comes out of the plane of the diagram in Figures 3 and 5. Alongside the trends towards global intensification mentioned above, burgeoning processes of specialisation ${ }^{547}$, professionalization ${ }^{548}$ and technocratisation ${ }^{549}$ are widely seen to be further undermining the space for democracy itself 550303551552 [30]. And this is not just a parallel contingency in academic research or policy analysis on incumbency, but strikes to their core. For, it may be instructive to consider in relation to the kinds of political action described in Table 1, the implications of past experiences of transformative progress. Despite many crucial contrasts over time and in political-economic and institutional-cultural contexts, there seems a clear message from historic unfinished reorientations of incumbent interests achieved by serfs ${ }^{553}$, slaves ${ }^{554}$, colonized people ${ }^{555}$, workers ${ }^{556}$, oppressed ethnicities ${ }^{557}$, women ${ }^{558}$ and queer sexualities ${ }^{559}$. Orderly separations of action and knowledge and neatly 'integrated' vertical policy-based prescriptions of the eagle-eye view undoubtedly played key roles. But it is difficult to avoid concluding from these histories, that whatever kinds of success have been won in these struggles, is more often and more deeply due to unruly pluralistic 'murmurations' of dissenting understandings and values, direct collective action and horizontal culture change 40081560 [31]. This is why the re-orienting of the 'open topologies' of deep incumbency does not mainly rely on gaining access to policy 'cockpits'. Indeed, an over-emphasis on such aims repeatedly features in these histories, less as means of resistance to incumbency by its opponents, than of defensive reinforcement on the part of incumbency itself.

Despite the obscuring efforts of incumbency itself, then, what may unfold in even the most specific efforts to challenge even the most circumscribed of incumbencies, is the age-old general struggle between privilege and emancipation ${ }^{307}$. In the end, the best ways to disembed any given instance of entrenched power, may lie not so much (nor so wholly) in the narratives and routines of policy making and 'good governance', as in the rather different stories and practices of emancipatory democratic struggle. Without the resulting murmurating flows, waves, gyres, pivots, ratchets and levers - extending throughout political culture as a whole - even the most ostensibly minor forms of incumbency may be pressured into changing their masks, and yet remain more deeply immoveable in their underlying configurations ${ }^{238}$. If so, then - as a form of practice in their own right understandings of incumbency in research and policy analysis may lie as much at the heart of the struggle as many other kinds of political action. For if there can be no deeper foundation for incumbency, than when it has colonized its own critique, then there follows an important corollary. There may be no more rigorous or formative basis for redistributing and reorienting incumbency, than when this warping effect is corrected. 


\section{References}

1. Collin, P. H. Dictionary of Politics and Government. (Bloomsbury Publishing Plc, 2004).

2. OED.com. Oxford English Dictionary - online. (2013). at <http://www.oed.com/>

3. Nuffield Council on Bioethics. Emerging biotechnologies: technology, choice and the public good. (Nuffield Council on Bioethics, 2012).

4. OECD. System Innovation: Synthesis Report. (OECD, 2015).

5. Government Office for Science. Innovation: managing risk, not avoiding it - evidence and case studies (Annual Report of the Government Chief Scientific Adviser 2014). (UK Government Office for Science, 2014).

6. GEA. Davis, G. \& Goldemberg, J., eds. Global Energy Assessment: Toward a Sustainable Future. (Cambridge University Press, 2012).

7. Juma, C. Innovation and Its Enemies: why people resist new technologies. (Oxford Univ Press, 2016).

8. Shell. New Lens Scenarios: a shift in perspective for a world in transition. (Shell International BV, 2013).

9. GEA \& IIASA. Johansson, T. B., Nakicenovic, N., Patwardhan, A. \& Gomez-Echeverri, L., eds. Global Energy Assessment: toward a sustainable future, Key Findings, Summary for Policymakers, Technical Summary. (Cambridge University Press, 2012). doi:10.1017/СВ09780511793677

10. The Royal Society. Brain Waves Module 1: Neuroscience, Society and Policy. (The Royal Society, 2011).

11. UNESCO \& ISSC. World Social Science Report 2010 - knowledge divides. (United Nations Educational, Scientific and Cultural Organization (UNESCO) and International Social Science Council (ISSC), 2010).

12. Griggs, D. et al. Sustainable development goals for people and planet. Nature, 495, 305-7 (2013).

13. UNEP. 21 Issues for the 21 Century: Results of the UNEP Foresight Process on Emerging Environmental Issues. (United Nations Environment Programme (UNEP), 2012).

14. UN. The Millennium Development Goals Report 2013. (United Nations, 2013).

15. UNDP. Human Development Report 2013 - the Rise of the South: human progress in a diverse world. (United Nations Development Programme, 2013).

16. Reid, W. V et al. Earth System Science for Global Sustainability: Grand Challenges. Science (80-. )., 330, 916-917 (2010).

17. NAE. Grand Challenges for Engineering. (US National Academy of Engineering, 2008).

18. ICSU. Earth System Science for Global Sustainability: The Grand Challenges. (International Council for Science, 2010).

19. Piketty, T. Capital in the Twenty First Century. (The Belknap Press of Harvard University Press, 2014).

20. OECD. Divided We Stand: why inequality keeps rising. (OECD Publishing, 2011).

21. WEF. The Global Risks Report 2017. (World Economic Forum, 2017).

22. WPCCCRME. Universal Declaration of Rights of Mother Earth. (World People's Conference on Climate Change and the Rights of Mother Earth, 2010).

23. UN. Open Working Group Proposal for Sustainable Development Goals. (United Nations General Assembly, 2014).

24. USGCRP. Climate Science Special Report: Fourth National Climate Assessment, Volume I. (U.S. Global Change Research Program, 2017).

25. IPCC WGII. Climate Change 2014: Impacts, Adaptation, and Vulnerability. 1-44 (2014).

26. Chopra, K., Leemans, R., Kumar, P. \& Simons, H., eds. Ecosystems and Human Well-Being: policy responses: findings of the Responses Working Group of the Millennium Ecosystem Assessment. (Island Press, 2008).

27. UNEP. Assessing Global Land Use: Balancing Consumption with Sustainable Supply. A Report of the Working Group on Land and Soils of the International Resource Panel. (United Nations Environment Programme, 2014).

28. Harremoës, P. et al. The Precautionary Principle in the 20th Century: Late Lessons from Early Warnings. (Earthscan, 2002). at <http://books.google.co.uk/books?id=JSBjiEUPyJkC>

29. Gee, D. et al., eds. Late lessons from early warnings: science, precaution, innovation. (European Environment Agency, 2013).

30. NAIIC. The official report of The Fukushima Nuclear Accident Independent Investigation Commission. (The National Diet of Japan Fukushima Nuclear Accident Independent Investigation Commission, 2012).

31. UNSCEAR. Sources, Effects and Risks of lonizing Radiation: UNSCEAR 2016 Report: Report to the General Assembly. (United Nations Scientific Committee on the Effects of Atomic Radiation, 2016).

32. OTA. The Effects of Nuclear War. (United States Congress Office of Technology Assessment, 1979).

33. Mueller, J. Retreat from Doomsday: The Obsolescence of Major War. (Basic Books, 2001).

34. Scoones, I., Newell, P. \& Leach, M. Scoones, I., Leach, M. \& Newell, P., eds. The Politics of Green Transformations. (Earthscan Routledge, 2015).

35. Broers, A. The Triumph of Technology. (Cambridge University Press, 2005).

36. Hajer, M. The Politics of Environmental Discourse: ecological modernization and the policy process. (Clarendon Press, 1995). doi:10.1017/СBO9781107415324.004

37. Asafu-Adjaye, J. et al. An Ecomodernist Manifesto. (Breathrough Institute, 2015). at <http://www.ecomodernism.org/>

38. Wright, E. O. et al. in International Panel on Social Progress: Rethinking Society for the 21st Century, (Cambridge University Press, 2018).

39. Dosi, G. Technological Paradigms and Technological Trajectories: a suggested intepretation of the determinants and directions of technological change. Res. Policy, 11, 147-162 (1982).

40. Geels, F. \& Raven, R. Non-linearity and Expectations in Niche-Development Trajectories: Ups and Downs in Dutch Biogas Development (1973-2003). Technol. Anal. Strateg. Manag., 18, 375-392 (2006).

41. Bijker, W. \& Law, J., eds. Shaping Technology / Building Society: Studies in Sociotechnical Change. (MIT Press, 1992). doi:10.1007/BF02373670

42. Weber, M. \& Hemmelskamp, J., eds. Towards Environmental Innovation Systems. (Springer, 2005).

43. Stirling, A. in Annual Report of the Government Chief Scientific Adviser 2014, Innovation: Managing Risk, Not Avoiding It. 
Evidence and Case Studies, 49-62 (UK Government, 2014).

44. IAASTD. Agriculture at a Crossroads: international assessment of agricultural knowledge science and technology for development (IAASTD). (Island Press, 2009).

45. Brooks, S. et al. Environmental Change and Maize Innovation in Kenya: Exploring Pathways In and Out of Maize. (STEPS Centre, 2009).

46. Sumberg, J. \& Thompson, J., eds. Contested Agronomy: Agricultural Research in a Changing World. (Routledge, 2012).

47. Brooks, S. Rice biofortification: Lessons for global science and development. (Earthscan, 2010).

48. Artioli, F., Acuto, M. \& Mcarthur, J. The water-energy-food nexus : An integration agenda and implications for urban governance. Polit. Geogr., 61, 215-223 (2017).

49. Lankford, B., Bakker, K., Zeitoun, M. \& Conway, D., eds. Water Security: principles, perspectives and practices. (Earthscan Routledge, 2013).

50. Allouche, J., Middleton, C. \& Gyawali, D. Nexus Nirvana or Nexus Nullity? A dynamic approach to security and sustainability in the water-energy-food nexus. (STEPS Centre, 2014).

51. Leach, M., Scoones, I. \& Stirling, A. Governing epidemics in an age of complexity: Narratives, politics and pathways to sustainability. Glob. Environ. Chang., 20, 369-377 (2010).

52. Wang, T. \& Watson, J. China's energy transition: pathways for low carbon development. (Sussex Energy Group, SPRU and Tyndall Centre for Climate Change Research, 2009).

53. Byrne, R., Smith, A., Watson, J. \& Ockwell, D. Energy Pathways in Low Carbon Development: from technology transfer to sociotechnical transformation. (STEPS Centre Working Paper, 2011).

54. British Pugwash Working Group. Pathways to 2050 : Three possible UK energy strategies. (British Pugwash, 2013).

55. Rosenbloom, D. Pathways: An emerging concept for the theory and governance of low-carbon transitions. Glob. Environ. Chang., 43, 37-50 (2017).

56. HM Government. 2050 Pathways Analysis. (Department of Energy and Climate Change, 2010).

57. Foxon, T. J. Transition pathways for a UK low carbon electricity future. Energy Policy, 52, 10-24 (2013).

58. Thomas, C. Global Governance, Development and Human Security: The Challenge of Poverty and Inequality. (Pluto Press, 2000).

59. Kaldor, M. Human Security: Reflections on Globalization and Intervention. (Polity Press, 2007).

60. Tadjbakhsh, S. \& Chenoy, A. M. Human Security: Concepts and implications. (Routledge, 2007).

61. Marletto, G. Car and the city: Socio-technical transition pathways to 2030. Technol. Forecast. Soc. Change, 87, 164-178 (2014).

62. Ghosh, B. Sustainability Appraisal of Emerging Trajectories in Solar Photovoltaic and Urban Mobility Systems in India and Thailand: a multicriteria mapping analysis. (2014).

63. Beland, K., Sandström, C. \& Sténs, A. Alternative pathways to sustainability ? Comparing forest governance models. For. Policy Econ., 77, 69-78 (2017).

64. NRC. Increasing Capacity for Stewardship of Oceans and Coasts: a priority for the 21st century. (The National Academies Press, 2008).

65. Chapin, F. S. et al. Ecosystem stewardship: sustainability strategies for a rapidly changing planet. Trends Ecol. Evol., 25, 241-249 (2009).

66. Kalantzis-Cope, P. \& Gherab-Martin, K., eds. Emerging Digital Spaces in Contemporary Society: properties of technology. (Palgrave Macmillan, 2010).

67. Zuboff, S. Big other: surveillance capitalism and the prospects of an information civilization. J. Inf. Technol., 30, 75-89 (2015).

68. Committee on Grand Challenges for Sustainability in the Chemical Industry, Board on Chemical Sciences and Technology \& Division on Earth and Life Studies. Sustainability in the Chemical Industry: Grand Challenges and Research Needs - A Workshop Report. (The National Academies Press, 2006).

69. Smith, A. ; dem1tec;The Lucas Plan: What can it tell us about democratising technology today ? (2014). at <https://www.theguardian.com/science/political-science/2014/jan/22/remembering-the-lucas-plan-what-can-it-tell-us-aboutdemocratising-technology-today>

70. Anastas, P. T. \& Julie B. Zimmerman, eds. Innovations in Green Chemistry and Green Enginerring: selected entires from the encyclopedia of sustainability science and technology. (Springer, 2013).

71. Stirling, A. Keep it complex. Nature, 468, 1029-1031 (2010).

72. Beistegui, M. de, Bianco, G. \& Gracieuse, M., eds. The Care of Life: transdisciplinary perspectives in bioethics and biopolitics. (Rowman and Littlefield, 2015).

73. Chilvers, J. \& Longhurst, N. Participation in Transition(s): Reconceiving Public Engagements in Energy Transitions as Co-Produced, Emergent and Diverse. J. Environ. Policy Plan., 7200, 1-23 (2016).

74. Skjølsvold, T. M., Throndsen, W., Ryghaug, M., Fjellså, I. F. \& Koksvik, G. H. Orchestrating households as collectives of participation in the distributed energy transition: New empirical and conceptual insights. Energy Res. Soc. Sci., 46, 252-261 (2018).

75. Bellacasa, M. P. de la. Matters of Care: speculative ethics in more than human worlds. (Univ Minnesota Press, 2017).

76. Orlikowski, W. J. The sociomateriality of organisational life: considering technology in management research. Cambridge J. Econ., 34, 125-141 (2009).

77. Leach, M., Scoones, I. \& Stirling, A. Dynamic Sustainabilities: technology, environment, social justice. (Routledge, 2010).

78. Jasanoff, S. in Dreamscapes of Modernity: Sociotechnical Imaginaries and the Fabrication of Power, (Jasanoff, S. \& Kim, S.-H., eds.) 1-49 (Oxford University Press, 2015).

79. Appadurai, A. in Futures of Modernity: challenges of cosmopolitical thought and practice, (Heinlein, M., Kropp, C., Neumer, J., Poferl, A. Romhild, R., ed.) (Columbia University Press, 2012).

80. Felt, U. Under the Shadow of Time: Where Indicators and Academic Values Meet. 3, 53-63 (2017).

81. Stirling, A. Transforming power: Social science and the politics of energy choices. Energy Res. Soc. Sci., 1, 83-95 (2014).

82. Harremoës, P. \& European Environment, A. Late lessons from early warnings : the precautionary principle 1896-2000. (Office for Official Publications of the European Communities, 2001). at 
<http://reports.eea.eu.int/environmental_issue_report_2001_22/en/Issue_Report_No_22.pdf>

83. EEA. Late lessons from early warnings: science, precaution, innovation - summary. (European Environment Agency, 2013).

84. IPCC. Climate Change 2014 - Synthesis Report. (Intergovernmental Panel on Climate Change, 2015).

85. OECD. Environmental Outlook to 2050. (Organisation for Economic Co-operation and Development, 2012).

86. O'Neill, J. Tackling Drug-resistant Infections Globally: final report and recommendations, the review on antimicrobial resistance. (Review on Antimicrobial Resistance, 2016).

87. Augenstein, K. \& Palzkill, A. The Dilemma of Incumbents in Sustainability Transitions: A Narrative Approach. Adm. Sci., 6, 1 (2016).

88. Kungl, G. Stewards or sticklers for change? Incumbent energy providers and the politics of the German energy transition. Energy Res. Soc. Sci., 8, 13-23 (2015).

89. Fouquet, R. Historical energy transitions: Speed, prices and system transformation. Energy Res. Soc. Sci., 22, 7-12 (2016).

90. Arent, D., Arndt, C., Miller, M., Tarp, F. \& Zinaman, O., eds. The Political Economy of Clean Energy Transitions. (Oxford University Press, 2017)

91. Johnson, V. C. A., Sherry-Brennan, F. \& Pearson, P. J. G. Alternative liquid fuels in the UK in the inter-war period (1918-1938): Insights from a failed energy transition. Environ. Innov. Soc. Transitions, 20, 33-47 (2016).

92. Ehrnberg, E. \& Jacobsson, S. in Systems of Innovation: technologies, institutions and organizations, (Edqvist, C., ed.) 318-341 (Routledge, 1997).

93. Klitkou, A., Bolwig, S., Hansen, T. \& Wessberg, N. The role of lock-in mechanisms in transition processes: the case of energy for road transport. Environ. Innov. Soc. Transitions, 16, 22-37 (2015).

94. Perez, C. Technological Revolutions and Techno-economic Paradigms, Working Papers in Technology Governance and Economic Dynamics no. 20. (Tallin University of Technology, 2009).

95. Drechsler, W., Kattel, R. \& Reinert, E. S., eds. Techno-Economic Paradigms: essays in honour of Carlota Perez. (Anthem Press, 2009).

96. Callon, M. in A sociology of monsters: Essays on power, technology and domination, (Law, J., ed.) 132-161 (Routledge, 1991).

97. Callon, M. in Technological Change and Company Strategies: Economic and Sociological Perspectives, (Coombs, R., Saviotti, P. \& Walsh, V., eds.) 72-102 (Academic Press, 1992).

98. Callon, M., Laredo, P., Rabeharisoa, V., Gonard, T. \& Leray, T. The management and evaluation of technological programs and the dynamics of techno-economic networks: The case of AFME. Res. Policy, 21, 215-236 (1992).

99. Allen, M. T. \& Hecht, G., eds. Technologies of Power: essays in honor of Thomas Parke Hughes and Agatha Chipley Hughes. (MIT Press, 2001).

100. Hughes, T. Networks of Power: electrification in western society 1880-1930. (Johns Hopkins University Press, 1983).

101. Hughes, T. . in The Social Construction of Technological Systems, (Bijker, W. ., Hughes, T. . \& Pinch, T. ., eds.) 51 (MIT Press, 1989).

102. Porte, T. R. la, ed. Social Responses to Large Technical Systems: Control or Anticipation. (Springer, 1991).

103. Mayntz, R. \& Hughes, T. P. Mayntz, R. \& Hughes, T. P., eds. The Development of Large Technical Systems. (Campus Verlag, 1988). doi:10.2307/2072563

104. Trist, E. L. \& Bamforth, K. W. Some Social and Psychological Consequences of the Longwall Method of Coal-Getting - an examination of the psychological situation and defences of a work group in relation to the social structure and technological content of the work system. Hum. Relations, 4, 3-38 (1951).

105. Walker, G., Stanton, N., Salmon, P. \& Jenkins, D. A Review of Sociotechnical Systems Theory: A Classic Concept for New Command and Control Paradigms. (Human Factors Integration Defence Technology Centre, 2007).

106. Ellul, J. Ideas of Technology: The Technological Order. in 'Technology Cult. Proc. Encycl. Br. Confereence Technol. Order 3, No.4, Autumn 1962, 3, 394-421 (1962).

107. Winner, L. Autonomous Technology: Technics-out-of-Control as a Theme in Political Thought. (MIT Press, 1977).

108. Bijker, W., Hughes, T. P. \& Pinch, T. J. Bijker, W., Hughes, T. P. \& Pinch, T., eds. The Social Construction of Technological Systems: new directions in the sociology and history of technology. (MIT, 1987).

109. Felt, U. Keeping Technologies Out: sociotechnical imaginaries and the formation of Austria's technological identity. (2015).

110. Delina, L. L. Whose and what futures ? Navigating the contested coproduction of Thailand's energy sociotechnical imaginaries. Energy Res. Soc. Sci., 1-9 (2017). doi:10.1016/j.erss.2017.10.045

111. Hilgartner, S., Miller, C. A. \& Hagendijk, R., eds. Science and Democracy: making knowledge and making power in the biosciences and beyond. 33, (Routledge, 2015).

112. Fuenfschilling, L. \& Truffer, B. The structuration of socio-technical regimes-Conceptual foundations from institutional theory. Res. Policy, 43, 772-791 (2013).

113. Tyfield, D. Putting the Power in 'Socio-Technical Regimes ' - E-Mobility Transition in China as Political Process. Mobilities, 9, 585-603 (2014).

114. Lawhon, M. \& Murphy, J. T. Socio-technical regimes and sustainability transitions: Insights from political ecology. Prog. Hum. Geogr., 36, 354-378 (2011).

115. Smith, A. Translating Sustainabilities between Green Niches and Socio-Technical Regimes. Technol. Anal. Strateg. Manag., 19, 427-450 (2007).

116. Geels, F. W. \& Schot, J. Typology of sociotechnical transition pathways. Res. Policy, 36, 399-417 (2007).

117. Kemp, R., Schot, J. \& Hoogma, R. Regime shifts to sustainability through processes of niche formation: The approach of strategic niche management. Technol. Anal. Strateg. Manag., 10, 175-198 (1998).

118. Schot, J. \& Kanger, L. Deep transitions : Emergence, acceleration, stabilization and directionality. Res. Policy, 1-15 (2018). doi:10.1016/j.respol.2018.03.009

119. Schot, J. \& Steinmueller, E. A World in Deep Transition Urgently Needs Transformative Innovation Policy. at <http://www.johanschot.com/2016/10/20/transformative-innovation-in-post-brexit-and-trump-era/>

120. Scrase, I., Stirling, A., Geels, F., Smith, A. \& Zwanenberg, P. Van. Transformative Innovation: A report to the Department for Environment, Food and Rural Affairs. (SPRU - Science Policy Research Unit, University of Sussex, 2009). 

study of the British coal industry (1913-1967). Res. Policy, 42, 1749-1767 (2013).

122. Turnheim, B. \& Geels, F. W. Regime destabilisation as the flipside of energy transitions: Lessons from the history of the British coal industry (1913-1997). Energy Policy, 50, 35-49 (2012).

123. Roberts, J. C. D. Discursive destabilisation of socio-technical regimes : Negative storylines and the discursive vulnerability of historical American railroads. Energy Res. Soc. Sci., 31, 86-99 (2017).

124. Stegmaier, P., Visser, V. R. \& Kuhlmann, S. Governance of the Discontinuation of Socio-Technical Systems - An Exploratory Study of the incandescent light bulb phase-out. in Gov. Innov. Socio-Technical Syst. Eur. New Trends, New Challenges - Panel Gov. Innov. sociotechnical Syst. Des. Displac., (4S/EASST Conference, 2012).

125. Rogge, K. S. \& Johnstone, P. Exploring the role of phase-out policies for low-carbon energy transitions : The case of the German Energiewende. Energy Res. Soc. Sci., 33, 128-137 (2017).

126. Christensen, C. M. The Innovator's Dilemma: when new technologies cause great firms to fail. (Harvard Business School Press, 1997).

127. Kivimaa, P. \& Kern, F. Creative destruction or mere niche support? Innovation policy mixes for sustainability transitions. Res. Policy, 45, 205-217 (2016).

128. Stirling, A. in Future Directions for Scientific Advice in Europe, (Wilsdon, J. \& Doubleday, R., eds.) 133-151 (University of Cambridge, 2015).

129. Verbrugge, L. M. Multiplexity in Adult Friendships. (University of North Carolina Press, 1979).

130. Kim, J. Y. \& Goh, K.-I. Coevolution and correlated multiplexity in multiplex networks. Phys. Rev. Lett., 111, 1-5 (2013).

131. Westra, L., Bosselmann, K. \& Westra, R. Westra, L., Bosselmann, K. \& Westra, R., eds. Reconciling Human Existence with Ecological Integrity. (Earthscan, 2008).

132. Kroes, P. \& Verbeek, P.-P., eds. The Moral Status of Technical Artefacts. (Springer, 2014).

133. Styhre, A., Wikmalm, L., Ollila, S., Roth, J. \& Styhre, A. Sociomaterial practices in engineering work The backtalk of materials and the tinkering of resources. J. Eng. Des. Technol., 10, 151-167 (2012).

134. Haythornthwaite, C. Exploring Multiplexity: Social Network Structures in a Computer-Supported Distance Learning Class. Inf. Soc., 17, 211-226 (2006).

135. Cardillo, A. et al. Emergence of Network Features from Multiplexity. Nat. Sci. Reports, 3, 1-6 (2013).

136. Unruh, G. C. Understanding carbon lock-in. Energy Policy, 28, 817-830 (2000).

137. Kaldor, M. The Baroque Arsenal. (Abacus, 1981).

138. Arthur, W. B. Competing Technologies, Increasing Returns, and Lock-in by Historical Events. Econ. J., 99, 116-131 (1989).

139. Mollinga, P. P. The Material Conditions of a Polarized Discourse: Clamours and Silences in Critical Analysis of Agricultural Water Use in India. J. Agrar. Chang., 10, 414-436 (2010).

140. Vanloqueren, G. \& Baret, P. V. How agricultural research systems shape a technological regime that develops genetic engineering but locks out agroecological innovations. Res. Policy, 38, 971-983 (2009).

141. Oreskes, N. \& Conway-, E. M. Merchants of doubt: how a handful of scientists obscured the truth on issues from tobacco smoke to global warming. (Bloomsbury, 2010).

142. Scott, P. D. Drugs, Oil and War: the United States in Afghanistan, Colombia and Indochina. (Roman and Littlefield, 2003). doi:10.15713/ins.mmj.3

143. Martin, J. Drugs on the Dark Net: how cryptomarkets are transforming the global trade in illicit drugs. (Palgrave, 2014). doi:10.1057/9781137399052.0001

144. Sally C Davies. Infections and the rise of antimicrobial resistance-Annual Report of the Chief Medical Officer, Volume II. (Department of Health, 2011).

145. GFHR. The 10/90 Report on Health Research: 2003-2004. (Global Forum for Health Research, 2004).

146. Collingridge, D. Technology in the Policy Process: controlling nuclear power. (Frances Pinter, 1983).

147. Freeman, C. The economics of technical change. Cambridge J. Econ., 18, 463-514 (1994).

148. Markard, J. Sustainability Transitions : Exploring the emerging research field and its contribution to management studies. in Proc. 33rd EGOS Colloquium, Copenhagen, July 6-8, (ETH Zurich, 2017).

149. Rotmans, J., Kemp, R. R. \& Asselt, M. van. More Evolution than Revolution: transition management in public policy. Foresight, 03, 15-31 (2001).

150. Kemp, R., Loorbach, D. \& Rotmans, J. Transition management as a model for managing processes of co-evolution towards sustainable development. Int. J. Sustain. Dev. World Ecol., 14, 78-91 (2007).

151. Geels, F. W. Technological transitions as evolutionary reconfiguration processes: a multi-level perspective and a case-study. Res. Policy, 31, 1257-1274 (2002).

152. Flanagan, K., Uyarra, E. \& Laranja, M. Reconceptualising the 'policy mix' for innovation. Res. Policy, 40, 702-713 (2011).

153. Rogge, K. S. \& Reichardt, K. Policy mixes for sustainable transitions: an extended concept and framework for analysis. Res. Policy, (2016). doi:10.1016/j.respol.2016.04.004

154. Johnstone, P., Stirling, A. \& Sovacool, B. Policy mixes for incumbency: Exploring the destructive recreation of renewable energy, shale gas 'fracking,' and nuclear power in the United Kingdom. Energy Res. Soc. Sci., (2017). doi:10.1016/j.erss.2017.09.005

155. Edmondson, D. L., Kern, F. \& Rogge, K. S. The co-evolution of policy mixes and socio-technical systems : Towards a conceptual framework of policy mix feedback in sustainability transitions. Res. Policy, 1-14 (2018). doi:10.1016/j.respol.2018.03.010

156. Barzelay, M. The Single Case Study as Intellectually Ambitious Inquiry. J. Public Adm. Res. Theory, 3, 305-318 (1993).

157. Lockwood, M., Kuzemko, C., Mitchell, C. \& Hoggett, R. Historical institutionalism and the politics of sustainable energy transitions : A research agenda. Environ. Plan. C Gov. Policy, 35, 312-333 (2017).

158. Walker, W. Entrapment in large technology systems: institutional commitment and power relations. Res. Policy, 29, 833-846 (2000).

159. Mort, M. Building the Trident Network: a study of enrollment of people, knowledge and machines. (MIT Press, 2002).

160. Bakker, S., Lente, H. Van \& Meeus, M. T. H. Dominance in the prototyping phase - The case of hydrogen passenger cars. Res. 
Policy, 41, 871-883 (2012).

161. Garud, R. \& Karnoe, P. in Path Dependence And Creation, (Garud, R. \& Karnoe, P., eds.) 1-38 (Psychology Press, 2012).

162. Rip, A. \& Kemp, R. in Human Choice and climate change: an international assessment, (Rayner, S. \& Malone, E. L., eds.) 327-399 (Batelle Press, 1998).

163. Nelson, R. R. \& Winter, S. G. An Evolutionary Theory of Economic Change. (Belknap Press, Harvard, 1982).

164. Geels, F. W. Regime Resistance against Low Carbon Transitions: introducing politics and power into the multi-level perspective. Theory, Cult. Soc., 31, 21-40 (2014).

165. Gaede, J. \& Meadowcroft, J. A Question of Authenticity: Status Quo Bias and the International Energy Agency's World Energy Outlook. J. Environ. Policy Plan., 18, 608-627 (2016).

166. Law, J. \& Callon, M. in Shaping Technology/Building Society: Studies in Sociotechnical Change., (Bijker, W. E. \& Law, J., eds.) 2152 (MIT Press, 1992).

167. Feenberg, A. Questioning Technology. (Routledge, 1999).

168. Felt, U. et al. Felt, U. \& Wynne, B., eds. Taking European knowledge society seriously : report of the Expert Group on Science and Governance to the Science, Economy and Society Directorate, Directorate-General for Research, European Commission. (European Commission, 2008).

169. Dosi, G. \& Labinin, M. Technological Paradigms and Trajectories. (Edward Elgar, 2007).

170. Borup, M., Brown, N., Konrad, K. \& Lente, H. van. The Sociology of Expectations in Science and Technology. Technol. Anal. Strateg. Manag., 18, 285-298 (2006).

171. Arud, R., Nayyar, P. R. \& Shapira, Z. B., eds. Technological Innovation: oversights and foresights. (Cambridge University Press, 1997).

172. Grubler, A. \& Wilson, C., eds. Energy Technology Innovation: learning from historical successes and failures. (Cambridge University Press, 2014).

173. Verbeek, P.-P. in Philosophy and Design: from engineering to architecture, (Vermaas, P. E., Kroes, P., Light, A. \& Moore, S. A., eds.) 91-103 (Springer, 2007).

174. Latour, B. Facing Gaia: Six lectures on the political theology of nature. (Edinburgh University, 2013).

175. Giddens, A. The Constitution of Society: outline of the theory of structuration. (Polity Press, 1984).

176. Hitlin, S. \& Elder, G. H. Time, Self, and the Curiously Abstract Concept of Agency. Sociol. Theory, 25, 170-191 (2007).

177. Wright, J. C. \& Baines, J. T. Conservation as Supply. (1987).

178. Whitehead, A. N. Process and Reality.

179. Stirling, A. Is the new European ruling on GM techniques 'anti-science'? 1-18 (2018).

180. Gareau, B. J. We Have Never Been Human: Agential Nature, ANT, and Marxist Political Ecology. Capital. Nat. Social., 16, 127-140 (2005).

181. Urry, J. Global Complexity. (Polity Press, 2003).

182. Feldman, M. S. \& Orlikowski, W. J. Theorizing Practice and Practicing Theory. Organ. Sci., 22, 1240-1253 (2011).

183. Featherstone, M., Lash, S. \& Robertson, R., eds. Global Modernities. (Sage, 1997).

184. Osborne, T. Aspects of enlightenment: social theory and the ethics of truth. (UCL Press, 1998).

185. Schatzki, T. The Site of the Social: a philosophical account of the constitution of social life and change. (Pennsylvania Univ Press, 2002).

186. Giddens, A. Central Problems in Social Theory: action, structure and contradiction in social analysis. (Palgrave Macmillan, 1979).

187. Jackson, W. A. Dualism, duality and the complexity of economic institutions. 26, 545-558 (1999).

188. Sewell, W. H. . A Theory of Structure: Duality, Agency, and Transformation. 98, 1-29 (2008).

189. Archer, M. S. Morphogenesis versus structuration: on combining structure and action. Br. J. Sociol., 61 Suppl 1, 225-52 (2010).

190.

Scott-Ram, N. R. Transformed Cladistics, Taxonomy and Evolution. (1990). doi:10.1017/CBO9780511525759

191. Jessop, B. Interpretive Sociology and the Dialectic of Structure and Agency. Theory, Cult. Soc., 13, 119-128 (1996).

192. Jessop, B. Critical Realism and the Strategic Relational Approach. New Form., 56, 40-53 (2005).

193. Jessop, B. State Power: A Strategic-Relational Approach. (Polity, 2007).

194. Collingridge, D. The entrenchment of technology - the case of lead petrol additives. Sci. Public Policy, 6, 332-8 (1979).

195. Stirling, A. On the Economics and Analysis of Diversity. (Science Poilicy Research Unit, 1998).

196. Seyfang, G. \& Smith, A. Grassroots innovations for sustainable development: Towards a new research and policy agenda. Env. Polit., 16, 584-603 (2007).

197. Harding, T. G., Kaplan, D., Sahlins, M. D. \& Service, E. R. Sahlins, M. D. \& Service, E. R., eds. Evolution and Culture. (The University of Michigan Press, 1970).

198. Sahal, D. Technological Guideposts and Innovation Avenues. Res. Policy, 14, 61-82 (1985).

199. Latour, B. \& Callon, M. in Advances in Social Theory and Methodology: toward an integration of micro-and macro-sociologies, (Knorr-Cetina, K. \& Cicourel, A. V., eds.) 277-303 (Routledge and Kegan Paul, 1981).

200. Hughes, T. American Genesis: A Century of Invention and Technological Enthusiasm, 1870-1970. (Viking Penguin, 1989).

201. McKelvey, M. \& Holmen, M., eds. Flexibility and Stability in the Innovating Economy. (Oxford University Press, 2006).

202. Hommels, A. Studying Obduracy in the City: Toward a Productive Fusion between Technology Studies and Urban Studies. Sci. Technol. Human Values, 30, 323-351 (2005).

203. Collingridge, D., Genus, A. \& James, P. Inflexibility in the Development of North Sea Oil. Tewchnological Forecast. Soc. Chang., 45, 169-188 (1994).

204. Hodgson, G. \& Knudsen, T. Hodgson, G. M. \& Knudsen, T., eds. Darwin's Conjecture: The Search for General Principles of Social and Economic Evolution. (The University of Chicago Press, 2010).

205. Birch, K. Socio-Material Systems and Sustainability Transitions : Integrating Climate Change into Transport Infrastructure in Ontario, Canada. (Work in a Warming World Project (W3), 2015).

206. Mazzucato, M. A Computational Model of Economies of Scale and Market Share Instability. (Santa Fe Institute, 1997). 
Leydesdorff, L. \& Van den Besselaar, P. Competing technologies: Lock-ins and lock-outs. First Int. Conf. Comput. Anticip. Syst., 309-323 (2000). doi:10.1063/1.56335

Mowery, D. C. Defense-related R \& D as a model for “Grand Challenges" technology policies. Res. Policy, 41, 1703-1715 (2012). Popp, D. \& Newell, R. G. Where Does Energy R\&D Come From? Examining Crowding Out from Environmentally-friendly R\&D. (National Bureau for Economic Research, 2009).

Pierson, P. Increasing Returns, Path Dependence, and the Study of Politics. Am. Polit. Sci. Rev., 94, 251-267 (2000). Arrow, K. J. Increasing returns: historiographic issues and path dependence. Euro. J. Hist. Econ. Thought, 7, 171-180 (2000). Arthur, W. Increasing Returns and Path-dependency in the Economy. (University of Michigan Press, 1994).

Uzzi, B. The Sources and Consequences of Embeddedness for the Economic Performance of Organizations: the network effect. Am. Sociol. Rev., 61, 674-698 (1996).

David, P. A. Clio and the Economics of QWERTY. Econ. Hist., 75, 332-337 (1985).

van Merkerk, R. O. \& van Lente, H. Tracing emerging irreversibilities in emerging technologies: The case of nanotubes. Technol. Forecast. Soc. Change, 72, 1094-1111 (2005).

Deuten, J. J., Rip, A. \& Jelsma, J. Societal Embedding and Product Creation Management. Technol. Anal. Strateg. Manag., 9, 131148 (1997).

Djurfeldt, G., Holmén, H., Jirström, M. \& Larsson, R., eds. The African Food Crisis: lessons from the Asian green revolution. (CABI Publishing, 2005).

Berkhout, F., Smith, A. \& Stirling, A. in System Innovation and the Transition to Sustainability: Theory, Evidence, and Policy (Elzen, B., Geels, F. W. \& Green, K., eds.) 48-75 (Edward Elgar, 2004).

Ellul, J. The Technological Society. (Alfred A. Knopf, 1964).

Disco, C., Rip, A. \& van der Meulen, B. Technical innovation and the universities: divisions of labour in cosmopolitan technical regimes. Soc. Sci. Inf., 31, 465-507 (1992).

Deuten, J. J. Cosmopolitanising Technologies: A study of four emerging technological regimes. (2003).

Bradley, A. Originary Technicity: the theory of technology from Marx to Derrida. (Palgrave MacMillan, 2011).

Bourdieu, P. Acts of Resistance: Against the Tyranny of the Market. (1998).

Williams, R. \& Edge, D. The social shaping of technology. Res. Policy, 25, 865-899 (1996).

Johnson, D. G. \& Wetmore, J. M., eds. Technology and Society: building our sociotechnical future. (MIT Press, 2009).

Arthur, W. B. The Nature of Technology: What It Is and How It Evolves. (Penguin, 2009).

Leach, M., Scoones, I. \& Stirling, A. Dynamic Sustainabilities: Technology, Environment, Social Justice. (Earthscan, 2010).

Feenberg, A. Between Reason and Experience: Essays in Technology and Modernity. (MIT Press, 2010).

MacKenzie, D. \& Elzen, B. Knowing Machines: essays on technical change. (MIT Press, 1996).

Hommels, A., Mesman, J. \& Bijker, W., eds. Vulnerability in Technological Cultures: new directions in research and governance. (MIT Press).

Luhmann, N. Social Systems. (Stanford University Press, 1995).

Beck, U. Risk Society: Towards a New Modernity. (SAGE, 1992).

Hardin, G. The Ostrich Factor: our population myopia. (Oxford University Press, 1999).

Hess, D. J. Industrial fields and countervailing power : The transformation of distributed solar energy in the United States. Glob. Environ. Chang., 23, 847-855 (2013).

Ahlborg, H. Towards a conceptualization of power in energy transitions. Environ. Innov. Soc. Transitions, 25, 122-141 (2017). Rob Stones. Structuration Theory. (Macmillan, 2005).

Cohen, I. J. Structuration Theory: Anthony Giddens and the Constitution of Social Life. (Macmillan, 1989).

Stirling, A. in Knowing Governance: The Epistemic Construction of Political Order, (Voß, J.-P. \& Freeman, R., eds.) (Palgrave MacMillan, 2016).

Aron, R. in Power, (Lukes, S., ed.) 253-77 (Blackwell, 1986).

Kanter, R. M. Power failure in management circuits. Harv. Bus. Rev., July-Augus, 65-75 (1979).

Smeed, J., Kimber, M., Millwater, J. \& Ehrich, L. C. Power over, with and through: Another look at micropolitics. Lead. Manag., 15, 26-41 (2009).

Harrison, L., Little, A. \& Lock, E. Politics: the key concepts. (Routledge, 2015).

Agnew, J. Hegemony: the new shape of global power. (Temple University Press, 2005).

Lukes, S. Power: a radical view. (Palgrave MacMillan, 2005).

Toulstoukhov, A. \& Mielkov, I. Democracy For The Twenty-First Century: From Domination To Co-Creation. (2004).

The_Week. UK offshore wind power to double by 2030. 1-13 (2018).

Negri, A. Time for revolution. (Continuum, 2003).

VeneKlasen, L. \& Miller, V. A New Weave of Power, People and Politics: The Action Guide for Advocacy and Citizen Participation. (Practical Action Publishing, 2006).

Hoagland, S. L. Lesbian ethics: Toward new value. (Institute of Lesbian Studies, 1988).

Abensour, M. R. Democracy Against the State: Marx and the Machiavellian Moment. (Polity Press, 2011).

Gledhill, J. Power And Its Disguises: anthropological perspectives on politics - second edition. (Pluto Press, 1994).

Mansbridge, J. Feminism and Democracy,. Am. Prospect, 1, 134 (1990).

Spencer-Wood, S. in Household Chores and Household Choices: theorizing the domestic sphere in historical archaeology

(Brandon, K. S. B. and J. C., ed.) (The University of Alabama Press, 2004).

Butler, J. \& Scott, J. W., eds. Feminists Theorise the Political. (Routledge, 1992).

Sartre, J.-P. The Emotions: outline of a theory. (Citadel Press, 2001).

Nativ, A. Anthropocentricity and the Archaeological Record: Towards a Sociology of Things. Nor. Archaeol. Rev., 47, 180-195 (2014).

Chilvers, J., Pallett, H. \& Hargreaves, T. Ecologies of participation in socio-technical change : The case of energy system 
transitions. Energy Res. Soc. Sci., 42, 199-210 (2018).

Bateson, G. Steps to an Ecology of Mind: collected essays in anthropology, psychiatry, evolution and epistemology. (Aronson, 1972).

259. Bateson, G. Mind and Nature: a necessary unity. (E. P. Dutton, 1979).

260. Liebowitz, S. J. \& Margolis, S. E. The Fable of the Keys. J. Law Econ., 33, 1-25 (1990).

261. David, P. A. Path Dependency and the Quest for Historical Economics: one more chorus of the ballad of QWERTY. (Discussion Papers in Economic and Social History, University of Oxford, 1997).

262. Vergne, J. QWERTY is dead ; long live path dependence. Res. Policy, 42, 1191-1194 (2013).

263. Kay, N. M. Rerun the tape of history and QWERTY always wins: Response to Arthur, Margolis and Vergne. Res. Policy, 42, 11951196 (2013).

264. Bement, L. C. \& Turpin, S. A. Technological Continuity and Functional Change : The Case of the Dorso End Scraper. Plains Anthropol., 32, 191-196 (1987).

265. Potter, B. A. Radiocarbon Chronology of Central Alaska : Technological Continuity and Economic Change. Radiocarbon, 50, 181204 (2008).

266. Valerio, P. et al. Technological continuity in Early Iron Age bronze metallurgy at the South-Western Iberian Peninsula - a sight from Castro dos Ratinhos. J. Archaeol. Sci., 37, 1811-1819 (2010).

267. Dolata, U. Technological innovations and sectoral change : Transformative capacity, adaptability, patterns of change : An analytical framework. Res. Policy, 38, 1066-1076 (2009).

268. Avelino, F. \& Rotmans, J. Power in Transition: An Interdisciplinary Framework to Study Power in Relation to Structural Change. Eur. J. Soc. Theory, 12, 543-569 (2009).

269. Avelino, F. \& Wittmayer, J. M. Shifting Power Relations in Sustainability Transitions : A Multi-actor Perspective. J. Environ. Policy Plan., 18, 1-23 (2015).

270. Tyfield, D., Ely, A. \& Geall, S. Low Carbon Innovation in China: From Overlooked Opportunities and Challenges to Transitions in Power Relations and Practices. Sustain. Dev., 23, 206-216 (2015).

271. Callon, M. \& Latour, B. in Advances in Social Theory and Methodology: toward an integration of micro- and macro-sociologies, (Knorr-Cetina, K. \& A.V.Cicourel., eds.) (Routledge and Kegan Paul, 1981).

272. Pearce, J. Power and the Activist. Development, 55, 198-200 (2012).

273. A.Hall, J. \& Schroeder, R., eds. An Anatomy of Power: the social theory of Michael Mann. (Cambridge Univ Press, 2005).

274. Scott, J. Modes of power and the re-conceptualization of elites. Sociol. Rev., 56, 25-43 (2008).

275. Foucault, M. Discipline and Punish: the birth of the prison. (Vintage Books, 1977).

276. Gaventa, J. Finding the Spaces for Change: A Power Analysis. IDS Bull., 37, 23-33 (2006).

277. Chambers, R. Revolutions in Development Inquiry. (Earthscan, 2008).

278. Hardy, C. Understanding Power: bringing about strategic change. Br. Jounal Manag., 7, 3-16 (1996).

279. Mann, M. The Sources of Social Power - Volume 4: globalizations, 1945-2011. (Cambridge University Press, 2013).

280. Beck, U. Power in the Global Age: a new global political economy. (Polity Press, 2005).

281. Allen, J. Lost Geographies of Power. (Blackwell, 2003).

282. Wedel, J. R. Shadow Elite: How the World's New Power Brokers Undermine Democracy, Government, and the Free Market. (Nasic Books, 2009).

283. Haugaard, M. Concerted Power Over. Constellations, 22, (2015).

284. Clegg, S. R. Frameworks of Power. (SAGE, 1989).

285. Peet, R. Geography of Power: the making of global economic policy. (Zed, 2007).

286. Holloway, J. Change the World Without Taking Power. (Pluto Press, 2005).

287. Boonstra, W. J. Conceptualizing power to study social-ecological interactions. Ecol. Soc., 21, (2016).

288. Albiek, E. Between knowledge and power: Utilization of social science in public policy making. Policy Sci., 28, 79-100 (1995).

289. Lukes, S. Power and agency. Br. J. Sociol., 53, 491-496 (2002).

290. Clegg, S. R. \& Hardy, C., eds. Studying Organization: theory and method. (Sage Publications, 1999).

291.

292.

293.

294.

295.

Rambukkana, N., ed. Hashtag Publics: the power and politics of discursive networks. (Digital Formations, Peter Lang, 2015).

Depelteau, F. \& Powell, C., eds. Applying Relational Sociology: relations, networks and society. (Palgrave MacMillan, 2013).

Lukes, S. Essays in Social Theory. (Macmillan, 1977).

Barnett, M. \& Duvall, R. Power in International Politics. Int. Organ., 59, 39-75 (2005).

Fligstein, N. \& McAdam, D. A Theory of Fields. (Oxford Univ Press, 2012).

Hargreaves, T., Haxeltine, A., Longhurst, N. \& Seyfang, G. Sustainability Transitions from the bottom-up: civil society, the multilevel perspective and practice theory. (Centre for Social and Economic Research on the Global Environment, 2011).

297.

Edwards, T., ed. Cultural Theory: classical and contemporary positions. (Sage Publications, 2007).

Berenskoetter, F. \& Williams, M. J., eds. Power in World Politics. (Routledge, 2007).

Foucault, M. Faubion, J., ed. Power. (Penguin, 2002).

Bolton, R. \& Foxon, T. J. Infrastructure transformation as a socio-technical process - Implications for the governance of energy distribution networks in the UK. Technol. Forecast. Soc. Chang., 90, 538-550 (2014).

301. Dahl, R. A. The Concept of Power. Behav. Sci., 2, 201-215 (1957).

302. Cerbaro, R. H. Competition-trapping the Concept of Power. Eur. J. Soc. Sci., 21, 148-153 (2011).

303. Benhabib, S., ed. Democracy and Difference: contesting the boundaries of the political. (Princeton University Press, 1996).

304. Clegg, S. R. \& Haugaard, M., eds. The Sage Handbook of Power. (SAGE, 2009).

305. Gibson-Graham, J. K. A Postcapitalist Politics. (University of Minnesota Press, 2006). doi:10.1080/03085140801933348

306. Stirling, A. Deliberate futures: precaution and progress in social choice of sustainable technology. Sustain. Dev., 15, 286-295 (2007).

307. Stirling, A. in The Innovation for Development Report, (Lopez-Claros, A., ed.) 199-210 (Palgrave Macmillan, 2010). 
Stirling, A. Direction, Distribution, Diversity! Pluralising Progress in Innovation, Sustainability and Development. (STEPS Centre, University of Sussex, 2010).

309. Abramsky, K., ed. Sparking a WorldWide energy revolution: social struggles in the transition to a post-petrol world. (AK Press, 2010).

310. McLean, G. D., Garrett, R. G. \& Ruesink, W. G. in Plant virus epidemics: monitoring, modelling and predicting outbreaks, (McLean, G. D., Garrett, R. G. \& Ruesink, W. G., eds.) (MIT Press, 1986).

311. Dickson, D. Technological Culture as Social Control. (Open University Technology Policy Group, 1987).

312. Loon, J. van. Risk and Technological Culture: towards a sociology of virulence. (Routledge, 2002).

313. Warde, A. After taste : Culture, consumption and theories of practice. J. Consum. Cult., 14, 279-303 (2014).

314. R.L. Rutsky. High Techne: art and technology from the machine aesthetic to the posthuman. (University of Minnesota Press, 1999).

315. Lamers, M. \& Verbeek, F. J., eds. Human-Robot Personal Relationships: Third International Conference, HRPR 2010 Leiden, The Netherlands, June 23-24, 2010 Revised Selected Papers. (Springer).

316. Schyfter, P. The bootstrapped artefact: a collectivist account of technological ontology, functions and normativity. Stud. Hist. Philos. Sci. Part A, 40, 102-111 (2009).

317. Winner, L. Autonomous Technology: technics out of control as a theme in political thought. (MIT Press, 1977).

318. Marres, N. Material Participation: technology, the environment and everyday publics. (Palgrave Macmillan, 2012).

319. Ansari, S. (Shaz) \& Krop, P. Incumbent performance in the face of a radical innovation: Towards a framework for incumbent challenger dynamics. Res. Policy, 41, 1357-1374 (2012).

320. Robertson, S. A longitudinal quantitative-qualitative systems approach to the study of transitions toward a low carbon society. J. Clean. Prod., 128, 221-233 (2015).

321. Geels, F. W. Reconceptualising the co-evolution of firms-in-industries and their environments: Developing an inter-disciplinary Triple Embeddedness Framework. Res. Policy, 43, 261-277 (2014).

322. Geels, F. W., Berkhout, F. \& van Vuuren, D. P. Bridging analytical approaches for low-carbon transitions. Nat. Clim. Chang., 6, 576-583 (2016).

323. Papachristos, G. Transition inertia due to competition in supply chains with remanufacturing and recycling: A systems dynamics model. Environ. Innov. Soc. Transitions, 12, 47-65 (2014).

324. Barry, J., Hume, T., Ellis, G. \& Curry, R. in Energy \& Environmental Transformations in a Globalizing World, (Kalantzakos, S. \& Farantouris, N. E., eds.) (Nomiki, 2015).

325. Johnstone, P. \& Newell, P. Sustainability transitions and the state. Environ. Innov. Soc. Transitions, In Press, (2017)

326. Muntigl, P. \& Ventola, E. in New Adventures in Language and Interaction, (Streeck, J., ed.) (John Benjamin, 2010).

327. Davidson, D. Subjective, Intersubjective, Objective. (Clarendon Press, 2001). doi:10.1017/CBO9781107415324.004

328. Edelkamp, S. \& Schrodl, S. Heuristic Search: theory and applications. (Elsevier, 2012).

329. Ippoliti, E. Ippoliti, E., ed. Heuristic Reasoning. (Springer, 2015).

330. Abbott, A. Methods of Discovery: heuristics for the social sciences. (W. W. Norton, 2004).

331. Fukuyama, F., ed. Blindside: how to anticipate forcing events and wild cards in global politics. (Brookings Institution Press, 2007). 332. Kingdon, J. W. Agendas, Alternatives, and Public Policies. (Pearson Education Ltd, 2014).

333. Crist, E. \& Rinker, H. B., eds. Gaia in Turmoil: climate change, biodepletion and earth ethics in an age of crisis. (MIT Press, 2010).

334. Levy, J. The Doomsday Book: scenarios for the end of the world. (Vision, 2005).

335. Ward, P. The Medea Hypothesis: is life on Earth ultimately self-destructive. (Princeton Univ Press, 2009).

336. Rees, M. Our Final Hour: a scientist's warning - how terror, error and environmental disaster threaten humankinds future in this century - on earth and beyond. (Basic Books, 2003).

337. Tainter, J. A. \& Joseph Tainter. The Collapse of Complex Societies. (Cambridge Univ Press, 1988).

338. Battilana, J. \& D’Aunno, T. in Institutional Work: Actors and Agency in Institutional Studies of Organizations, 31-58 (Cambridge University Press, 2009). doi:10.1017/CBO9780511596605.002

339. Collier, R. B. \& Collier, D. Shaping the political arena: Critical junctures, the labor movement, and regime dynamics in Latin America. (Princeton University Press, 1991).

340. Thelen, K. How Instituions Evolve: the political economy of skills in Germany, Britain, the United States and Japan. (Cambridge University Press, 2004).

341. Perez, C. \& Soete, L. in Technical change and economic theory, (Dosi, G., Freeman, C., Nelson, R., Silverberg, G. \& Soete, L., eds.) (Pinter Publishers, 1988).

342. Archibugi, D. \& Pietrobelli, C. The globalisation of technology and its implications for developing countries: Windows of opportunity or further burden? Technol. Forecast. Soc. Change, 70, 861-883 (2003).

343. IRENA. REthinking Energy 2017: Accelerating the global energy transformation. (International Renewable Energy Agency, 2017).

344. Bucchi, M. Beyond Technocracy: Science, Politics and Citizens. (Springer, 2009).

345. Garud, R. \& Karnøe, P., eds. Path Dependence and Creation. (Psychology Press, 2001).

346. Rosen, M. On Voluntary Servitude: false consciouness and the theory of ideology. (Polity Press, 1996).

347. Jackson, P. T. in Interpretation and Method: Empirical Research Methods and the Interpretive Turn, (Yanow, D. \& Schwartz-Shea, P., eds.) 264-280 (Routledge, 2006).

348. Sismondo, S. An Introduction to Science and Technology Studies. (Blackwell, 2010).

349. Gadamer, H.-G. Truth and Method. (Continuum, 1989).

350. Mirowski, P. More Heat than Light: economics as social physics: physics as nature's economics. (Cambridge University Press, 1989).

351. Law, J. \& Bijker, W. in Shaping technology/Building society: studies in sociotechnical change, $290-308$ (MIT Press, 1992).

352. Bolton, R. \& Foxon, T. J. A socio-technical perspective on low carbon investment challenges - Insights for UK energy policy. Environ. Innov. Soc. Transitions, 14, 165-181 (2015). 

Innovation Systems (TIS). Environ. Innov. Soc. Transitions, 16, 73-75 (2015).

354. Voß, J. Performative policy studies : realizing "transition management". Innov. Eur. J. Soc. Sci. Res., 27, 317-343 (2014).

355. Steward, F. Breaking the boundaries: transformative innovation for the global good. (National Endowment for Science, Technology and the Arts, 2008). at <http://www.ncbi.nlm.nih.gov/pubmed/22285576>

356. Genus, A. \& Stirling, A. Collingridge and the dilemma of control: Towards responsible and accountable innovation. Res. Policy, 47, 61-69 (2017).

357. Raven, R., Kern, F., Smith, A., Jacobsson, S. \& Verhees, B. The politics of innovation spaces for low-carbon energy: Introduction to the special issue. Environ. Innov. Soc. Transitions, 18, 101-110 (2016).

358. Jasanoff, S., ed. States of Knowledge: the co-production of science and social order. (Routledge, 2004). doi:10.4324/9780203413845

359. Irwin, A., Rothstein, H., Yearley, S. \& McCarthy, E. Regulatory Science - towards a sociological framework. Futures, 29, 17-31 (1997).

360. Voß, J.-P. \& Freeman, R., eds. Knowing Governance: The Epistemic Construction of Political Order. (Palgrave MacMillan, 2016).

361. Abraham, J. The pharmaceutical industry as a political player. Lancet, 360, 1498-1502 (2002).

362. Sabatier, P. Social Movements and Regulatory Agencies : Toward a More Adequate - and Less Pessimistic - Theory of 'Clientele Capture'. Policy Sci., 6, 301-342 (1975).

363. Laffont, J.-J. \& Tirole, J. The Politics of Government Decision-Making: A theory of regulatory capture. Q. J. Econ., 106, 1089-1127 (1991).

364. Bó, E. D. Regulatory Capture: A Review. Oxford Rev. Econ. Policy, 22, 203-225 (2006).

365. Wynne, B. The Rhetoric of Consensus Politics: a critical review of technology assessment. Res. Policy, 4, 108-158 (1975).

366. Stirling, A. "Opening Up" and “Closing Down": Power, Participation, and Pluralism in the Social Appraisal of Technology. Sci. Technol. Hum. Values, 23, 262-294 (2008).

367. Shove, E. \& Walker, G. CAUTION! Transitions ahead: politics, practice, and sustainable transition management. Environ. Plan. A, 39, 763-770 (2007).

368. Shove, E. \& Walker, G. Transition Management ${ }^{\mathrm{TM}}$ and the Politics of Shape Shifting. Environ. Plan. A Econ. Sp., 40, 1012-1014 (2007).

369. Hendriks, C. M. Policy design without democracy? Making democratic sense of transition management. Policy Sci., 42, 341-368 (2009).

370. Meadowcroft, J. What about the politics? Sustainable development, transition management, and long term energy transitions. Policy Sci., 42, 323-340 (2009).

371. Smith, A. \& Stirling, A. The Politics of Social-ecological Resilience and Sustainable Socio-technical Transitions. Ecol. Soc., 15, (2010).

372. Stirling, A. Pluralising progress: From integrative transitions to transformative diversity. Environ. Innov. Soc. Transitions, 1, 82-88 (2011).

373. Smith, A., Voß, J.-P. \& Grin, J. Innovation studies and sustainability transitions: The allure of the multi-level perspective and its challenges. Res. Policy, 39, 435-448 (2010).

374. Gillard, R., Gouldson, A., Paavola, J. \& Van Alstine, J. Transformational responses to climate change: beyond a systems perspective of social change in mitigation and adaptation. WIREs Clim. Chang. Rev., 7, 251-265 (2016).

375. Kern, F. Engaging with the politics, agency and structures in the technological innovation systems approach. Environ. Innov. Soc. Transitions, 16, 67-69 (2015).

376. Scoones, I., Newell, P. \& Leach, M. in The Politics of Green Transformations, (Scoones, I., Leach, M. \& Newell, P., eds.) 1-42 (Routledge, 2015).

377. Merton, R. K. On Theoretical Sociology: five essays, old and new. (Free Press, 1987).

378. Geels, F. W. Feelings of Discontent and the Promise of Middle Range Theory for STS: Examples from Technology Dynamics. Sci. Technol. Human Values, 32, 627-651 (2007).

379. Bergek, A., Jacobsson, S., Carlsson, B., Lindmark, S. \& Rickne, A. Analyzing the functional dynamics of technological innovation systems: A scheme of analysis. Res. Policy, 37, 407-429 (2008).

380. Bergek, A. et al. Technological innovation systems in contexts: Conceptualizing contextual structures and interaction. Environ. Innov. Soc. Transitions, 16, 51-64 (2015).

381. Markard, J., Hekkert, M. \& Jacobsson, S. The technological innovation systems framework: Response to six criticisms. Environ. Innov. Soc. Transitions, 16, 76-86 (2015).

382. Hilton, I. \& Gyawali, D. Taking the toad's eye view. China Dialogue, 1-4 (2009).

383. Reisch, L. \& Sunstein, C. R. Redesigning Cockpits: Introduction to Special Issue of Journal of Consumer Policy on Behavioural Economics, Environmental Policy and the Consumer. J. Consum. Policy, 37, (2014).

384. Sunstein, C. R. Simpler: the future of government. (Simon and Schuster, 2013).

385. Scott, J. C. Seeing Like a State: How Certain Schemes to Improve the Human Condition Have Failed. (Yale University Press, 1998).

386. Hajer, M. et al. Beyond Cockpit-ism: Four Insights to Enhance the Transformative Potential of the Sustainable Development Goals. Sustainability, 7, 1651-1660 (2015).

387. Ward, C. Housing: an anarchist approach. (Freedom Press, 1976).

388. Cecla, F. La. Against Architecture. (PM Press, 2012).

389. Viola, L. Peasant Rebels Under Stalin: Collectivization and the Culture of Peasant Resistance. (Oxford University Press, 1996).

390. Zavialov, P. Physical Oceanography of the Dying Aral Sea. (Springer Verlag, 2005).

391. McCully, P. Silenced Rivers: the Ecology and Politics of Large Dams. (Zed Books, 2001).

392. Wilson, I. Thinking Beyond War: civil-military relations and why America fails to win the peace. (Palgrave Macmillan, 2007).

393. Kaysen, C., Miller, S. E., Malin, M. B., Nordhaus, W. D. \& Steinbruner, J. D. War with Iraq: costs, consequences, and alternatives. (American Academy of Arts and Sciences, 2002). 
394. Goodson, L. P. Afghanistan's Endless War: state failure, regionl politics and the rise of the Taliban. (University of Washington Press, 2001).

395. Belasco, A. The Cost of Iraq, Afghanistan, and Other Global War on Terror Operations Since 9/11. (Congressional Research Service, 2011).

396. Seymour, J. Body Count: casualty figures after 10 years of the 'war on terror', Iraq, Afghanistan, Pakistan. (Physicians for Social Responsibility, 2015). doi:10.1353/psg.2007.0185

397. Braithwaite, R. Afgantsy: the Russians in Afghanistan 1978-89. (Profile Books, 2012).

398. Kaldor, M., Karl, T. L. \& Said, Y., eds. Oil Wars. (Pluto Press, 2007).

399. Friedman, J., ed. Globalization, the State, and Violence. (Altamira Press, 2003).

400. Stirling, A. Emancipating Transformations: from the controlling 'the transition' to culturing plural radical progress. (STEPS Centre, University of Sussex, 2014).

401. Weyer, J., Adelt, F. \& Hoffmann, S. Governance of complex systems: a multi-level model. (Technische Universität Dortmund, 2014).

402. Leigh, J. R. Control Theory. (Institute of Electrical Engineers, 2004).

403. Rose, N. Powers of Freedom: reframing political thought. (Cambridge University Press, 2004).

404. Martin, B. What is Happening to our Universities? (SPRU - Science Policy Research Unit, University of Sussex, 2016).

405. Habermas, J. Justification and Application: remarks on discourse ethics. (MIT Press, 2001).

406. Habermas, J. Truth and Justification. (MIT Press, 2003).

407. Boltanski, L. \& Thevenot, L. On Justification: Economies of Worth. (Princeton University Press, 1991).

408. Collingridge, D. The Social Control of Technology. (Open University Press, 1980).

409. Langer, E. The Illusion of control. J. Pers. Soc. Psychol., 32, 311-328 (1975).

410. Willis, D. The Fallacy of Control. (Sapient Government Services, 2009).

411. Parry, R., Hood, C. \& James, O. Reinventing the Treasury: Economic Rationalism or an Econocrat's Fallacy of Control? Public Adm., 75, 395-415 (1997).

412. Penna, C. C. R. \& Geels, F. W. Multi-dimensional struggles in the greening of industry: A dialectic issue lifecycle model and case study. Technol. Forecast. Soc. Change, 79, 999-1020 (2012).

413. Rip, A. The Context of Innovation Journeys. Creat. Innov. Manag., 21, 158-170 (2012).

414. Molnar, G. \& Mumford, S. Powers : A Study in Metaphysics. (Oxford University Press, 2003).

415. Bourdieu, P. \& Wacquant, L. An Invitation to Reflexive Sociology. (Polity Press, 1992).

416. Rabinow, P. The Accompaniment: assembling the contemporary. (University of Chicago Press, 2011).

417. Leakey, R. \& Lewin, R. The Sixth Extinction: Patterns of Life and the Future of Humankind. (Anchor Books, 1996).

418. Dolata, U. Radical Change as Gradual Transformation: characteristics and variants of socio-technical transitions. (Institute for Social Sciences, Organizational Sociology and Innovation Studies, University of Stuttgart, 2011).

419. Dimaggio, P. J. \& Powell, W. W. The Iron Cage Revisited: Institutional Isomorphism and Collective Rationality in Organizational Fields. Am. Sociol. Rev., 48, 147-160 (1983).

420. Scott, R. W. Institutions and Organizations: foundations for organizational science. (Sage, 1995).

421. Mohr, J. W. Towards a Genealogy of Contemporary Institutional Theory: the role of spatial metaphors in constructions of the organizational environment. in Am. Sociol. Assoc. Meet. Denver, CO, August, (2012).

422. White, D. R., Owen-Smith, J., Moody, J. \& Powell, W. W. Networks, Fields and Organizations : Micro-Dynamics, Scale and Cohesive Embeddings. Comput. Math. Organ. Theory, 10, 95-117 (2004).

423. Barley, S. R. Building an Instituional Field to Corral a Government: A Case to Set an Agenda for Organization Studies. Organ. Stud., 31, 777-805 (2010).

424. Fligstein, N. \& McAdam, D. Toward a General Theory of Strategic Action Fields. (Institute for Research on Labor and Employment, UC Berkeley, 2010).

425. Stone, M. M. \& Sandfort, J. R. Building a policy fields framework to inform research on nonprofit organizations. Nonprofit Volunt. Sect. Q., 38, 1054-1075 (2009).

426. Naimzada, A. K., Stefani, S. \& Torreiro, A., eds. Networks, Topology and Dynamics: theory and applications to economics and social systems. (Springer Verlag, 2009).

427. Coenen, L., Benneworth, P. \& Truffer, B. Toward a spatial perspective on sustainability transitions. Res. Policy, 41, 968-979 (2012).

428. Fitzpatrick, G. The Locales Framework: understanding and designing for wicked problems. (Springer Science+Business Media, 2003).

429. Schatzki, T. R. The Timespace of Human Activity: on performance, society, and history as indeterminate teleological events. (Lexington Books, 2010).

430. May, J. \& Thrift, N., eds. Timespace: geographies of temporality. (Routledge, 2003).

431. Geels, F. Technological Transitions and System Innovations: a co-evolutionary and socio-technical analysis. (Edward Elgar, 2005).

432. Zeppini-Rossi, P. \& van den Bergh, J. C. J. M. Optimal Diversity in Investments with Recombinant Innovation. J. Econ. Behav. Organ., 68, 565-580 (2008).

433. Murmann, J. P. \& Frenken, C. Toward a Systematic Framework for Research on Dominant Designs, Technological Innovations, and Industrial Change. Res. Policy, 35, 925-952 (2006).

434. Stiegler, B. For a New Critique of Political Economy. (Polity Press, 2010).

435. Schuler, D. \& Day, P., eds. Shaping the Network Society: the new role of civil society in cyberspace. (MIT Press, 2004).

436. Geels, F. W. The multi-level perspective on sustainability transitions: Responses to seven criticisms. Environ. Innov. Soc. Transitions, 1, 24-40 (2011).

437. Markard, J. \& Truffer, B. Technological innovation systems and the multi-level perspective: Towards an integrated framework. Res. Policy, 37, 596-615 (2008). 
438.

439.

440.

441.

442.

443.

444.

445

446

447

448

449

450

451

452

454

455

456

457.

458.

459

460

461.

462.

463.

464

465

466

467.

468.

469.

470.

471.

472.

473.

474.

475 .

476.

477.

478

479.

Nelson, R. R. \& Winter, S. G. In Search of a Useful Theory of Innovation. Res. Policy, 6, 36-76 (1977).

Smith, A. \& Raven, R. What is protective space? Reconsidering niches in transitions to sustainability. Res. Policy, 41, 1025-1036 (2012).

Meadowcroft, J. Environmental political economy, technological transitions and the state. New Polit. Econ., 10, 479-498 (2005). Hekkert, M. P., Suurs, R. a. a., Negro, S. O., Kuhlmann, S. \& Smits, R. E. H. M. Functions of innovation systems: A new approach for analysing technological change. Technol. Forecast. Soc. Change, 74, 413-432 (2007).

Nelson, R. \& Winter, G. An Evolutionary Theory of Technological Change. (Harvard University Press, 1982).

Geels, F. W. From sectoral systems of innovation to socio-technical systems. Res. Policy, 33, 897-920 (2004)

Geels, F. W. Processes and patterns in transitions and system innovations: Refining the co-evolutionary multi-level perspective. Technol. Forecast. Soc. Change, 72, 681-696 (2005).

Geels, F. W. \& Kemp, R. Dynamics in socio-technical systems: Typology of change processes and contrasting case studies. Technol. Soc., 29, 441-455 (2007).

Tolkamp, J. User-Centred Business Model Innovation for Energy Efficiency: A Literature Review. (Eindhoven University of Technology, 2015).

Geels, F. W. Analysing the breakthrough of rock ' $n$ ' roll (1930-1970) Multi-regime interaction and reconfiguration in the multilevel perspective. Technol. Forecast. Soc. Change, 74, 1411-1431 (2007).

Geels, F. W. Ontologies, socio-technical transitions (to sustainability), and the multi-level perspective. Res. Policy, 39, 495-510 (2010).

Geels, F. W., Mcmeekin, A., Mylan, J. \& Southerton, D. A critical appraisal of Sustainable Consumption and Production research : The reformist, revolutionary and reconfiguration positions. Glob. Environ. Chang., 34, 1-12 (2015).

Konrad, K., Truffer, B. \& Voß, J.-P. Multi-regime dynamics in the analysis of sectoral transformation potentials: evidence from German utility sectors. J. Clean. Prod., 16, 1190-1202 (2008).

Abernathy, W. J., Clark, K. B., White, G., Kantrow, A. \& Hayes, R. Innovation: Mapping the winds of creative destruction. Res. Policy, 14, 3-22 (1985).

Verbong, G. P. J. \& Geels, F. W. Exploring sustainability transitions in the electricity sector with socio-technical pathways. Technol. Forecast. Soc. Change, 77, 1214-1221 (2010).

Raven, R. P. J. M. \& Geels, F. W. Socio-cognitive evolution in niche development: Comparative analysis of biogas development in Denmark and the Netherlands (1973-2004). Technovation, 30, 87-99 (2010).

Schot, J. \& Geels, F. W. Strategic niche management and sustainable innovation journeys: theory, findings, research agenda, and policy. Technol. Anal. Strateg. Manag., 20, 537-554 (2008).

Verbong, G. \& Geels, F. The ongoing energy transition: Lessons from a socio-technical, multi-level analysis of the Dutch electricity system (1960-2004). Energy Policy, 35, 1025-1037 (2007).

Sovacool, B. K. \& Geels, F. W. Further reflections on the temporality of energy transitions: A response to critics. ERSS, 22, 232237 (2016).

Cherp, A., Vinichenko, V., Jewell, J., Suzuki, M. \& Antal, M. Comparing electricity transitions : A historical analysis of nuclear , wind and solar power in Germany and Japan. Energy Policy, 101, 1-17 (2016).

Geels, F. Two steps forward, one step back: The arduous transition to a low-carbon society. in Challenges Eur. a New Age (Aalborg, 14-15 March, 2013), (2013). doi:10.1016/j.arthro.2011.08.291

Geels, F. Two steps forward, one step back: the arduous transition to a low-carbon society. in Challenges Eur. a New Age (Aalborg, 14-15 March, 2013), (2013). doi:10.1016/j.arthro.2011.08.291

Genus, A. \& Coles, A.-M. Rethinking the multi-level perspective of technological transitions. Res. Policy, 37, 1436-1445 (2008).

Smith, A., Stirling, A. \& Berkhout, F. The governance of sustainable socio-technical transitions. Res. Policy, 34, 1491-1510 (2005).

Geels, F. W. \& Schot, J. in Transitions to sustainable development: new directions in the study of long term transformative change., (Grin, J., Rotmans, J. \& Schot, J., eds.) (Routledge, 2010).

Geels, F. W. \& Verhees, B. Cultural legitimacy and framing struggles in innovation journeys: A cultural-performative perspective and a case study of Dutch nuclear energy (1945-1986). Technol. Forecast. Soc. Change, 78, 910-930 (2011).

Grin, J., Rotmans, J., Schot, J., Geels, F. \& Loorbach, D. Transitions to Sustainable Development: new directions in the study of long term transformative change. (Routledge, 2010).

Elzen, B., Geels, F. W., Leeuwis, C. \& van Mierlo, B. Normative contestation in transitions 'in the making': Animal welfare concerns and system innovation in pig husbandry. Res. Policy, 40, 263-275 (2011).

Raven, R. Co-evolution of waste and electricity regimes: Multi-regime dynamics in the Netherlands. Energy Policy, 35, 2187-2208 (2016).

Sawyer, R. K. Social Emergence: societies as complex systems. (Cambridge University Press, 2005).

Byrne, D. Complexity Theory and the Social Sciences: an introduction. (Routledge, 1998).

Deleuze, G. \& Guattari, F. A Thousand Plateaus: capitalism and schizophrenia. (University of Minnesota Press, 1987).

Whitehead, A. N. Science and the Modern World. (The New American Library, 1948).

Stirling, A. in Oxford Handbook on the Law and Regulation of Technology, (Brownsword, R., Scotford, E. \& Yeung, K., eds.) (Oxford University Press, 2017).

Bucher, T. A Technicity of Attention:"how software 'makes sense'. Cult. Mach., 13, 1-23 (2012).

Guba, E. \& Lincoln, Y. S. in Handbook of qualitative research, (Denzin, N. K. \& Lincoln, Y. S., eds.) 105-117 (Sage, 1994).

Kuhn, T. S. The Structure of Scientific Revolutions. (Chicago UP, 1970).

Law, J. \& Lodge, P. Science for Social Scientists. (MacMillan, 1984).

Popper, K. The Logic of Scientific Discovery. (Routledge, 1959).

Boylan, T. \& O'Gorman, P. F. Beyond Rhetoric and Realism in Economics: Towards a reformulation of economic methodology.

(Routledge).

Popper, K. The Poverty of Historicism. (Beacon Press, 1957). doi:10.2307/2549642

Rosenberg, A. Philosophy of Social Science. (Westview Press, 2008). 

Testability Issue, and Methodological Implications. J. Manag. Stud., 47, (2010).

481. Sorrell, S. Explaining sociotechnical transitions: A critical realist perspective. (SPRU - Science Policy Research Unit, University of Sussex, 2017).

482. Law, J. After Method: Mess in Social Science Research. (Routledge, 2004).

483. Saltelli, A., Tarantola, S., Campolongo, F. \& Ratto, M. Sensitivity Analysis in Practice: a guide to assessing scientific models. (John Wiley \& Sons Ltd, 2004).

484. Rescher, N. Pluralism: against the demand for consensus. (Oxford University Press, 1993).

485. Stirling, A. A General Framework for Analysing Diversity in Science, Technology and Society. J. R. Soc. Interface, 4, 707-19 (2007).

486. Page, S. E. The Difference: how the power of diversity creates better groups, firms, schools and societies. (Princeton University Press, 2007).

487. Faber, M., Manstetten, R. \& Proops, J. L. R. Humankind and the Environment: An Anatomy of Surprise and Ignorance. Environ. Values, 1, 217-241 (1992).

488. Geertz, C. The Interpretation of Cultures: selected essays by Clifford Geertz. (Basic Books, 1973).

489. Lynch, M. Against Reflexivity as an Academic Virtue and Source of Privileged Knowledge. Theory, Cult. Soc., 17, 26-54 (2000).

490. Nenon, T. \& Blosser, P., eds. Advancing Phenomenology: essays in honour of Lester Embree. (Springer, 2010).

491. Rotolo, D., Hicks, D. \& Martin, B. What Is an Emerging Technology ? (SPRU, University of Sussex, 2015).

492. Kushnir, D. Foresight and Feedback: monitoring and assessing the environmental implications of trajectories in emerging technologies.

493. Rotolo, D., Rafols, I. \& Hopkins, M. How scientometrics can contribute to the understanding of tentative governance: a multiperspective approach. (SPRU - Science Policy Research Unit, University of Sussex, 2013).

494. Rotolo, D., Rafols, I., Hopkins, M. \& Leydesdorff, L. Scientometric Mapping as a Strategic Intelligence Tool for the Governance of Emerging Technologies. (SPRU - Science Policy Research Unit, University of Sussex, 2015).

495. Carenini, G., Murray, G. \& Ng, R. Methods for Mining and Summarizing Text Conversations. (Morgan \& Claypool, 2011).

496. Wang, Q. I. Studies in the Dynamics of Science: exploring emergence, classification and interdisciplinarity. (2016).

497. Connor, U. \& Upton, T. A., eds. Discourse in the Professions: perspectives from corpus linguistics. (John Benjamin, 2004).

498. Willis, R. Taming the Climate? Corpus analysis of politicians' speech on climate change speech on climate change. Env. Polit., 26, 212-231 (2017).

499. Youngman, P. \& Hadzikadic, M., eds. Complexity and the Human Experience: modeling complexity in the humanities and social sciences. (Taylor \& Francis, 2014).

500. Gilbert, N. \& Troitzsch, K. G. Simulation for the Social Scientist. (Open University Press, 2005).

501. Dunteman, G. H. \& H. Dunteman, G. Principal Components Analysis. (Sage, 1989).

502. Kaplan, D., ed. The Sage handbook of Quantitative Methodology for the Social Sciences. (Sage, 2004).

503. Aledenderfer, M. S. \& Blashfield, R. Cluster Analysis. (Sage, 1984).

504. Stirling, A. Multicriteria diversity analysis: A novel heuristic framework for appraising energy portfolios. Energy Policy, 38, 16221634 (2010).

505. Stirling, A. Developing 'Nexus Capabilities': towards transdisciplinary methodologies. (SPRU, University of Sussex, 2015).

506. Marcus, G. E. Ethnography through Thick and Thin. (Princeton University Press, 1998).

507. Rauschmayer, F., Bauler, T., Schapke, N. \& Schäpke, N. Towards a thick understanding of sustainability transitions - Linking transition management, capabilities and social practices. Ecol. Econ., 109, 211-221 (2015).

508. Law, J. After ANT: complexity, naming and topology. Sociol. Rev., 47, (1999).

509. Marres, N. On Some Uses and Abuses of Topology in the Social Analysis of Technology (Or the Problem with Smart Meters). Theory, Cult. Soc., 29, (2012).

510. Bourgine, P. \& Lesne, A., eds. Morphogenesis: origins of patterns and shapes. (Springer, 2011).

511. Lury, C., Parisi, L., Terranova, T. \& Lury, C. Introduction: The Becoming Topological of Culture Introduction. Theory Cult. Soc., 29, 3-35 (2014).

512. Star, S. L. in Readings in distributed artificial intelligence, (Huhns, M. \& Gasser, L., eds.) (Morgan Kaufman, 1988).

513. Star, S. L. \& Griesemer, J. R. Institutional Ecology, 'Translations' and Boundary Objects: Amateurs and Professionals in Berkeley's Museum of Vertebrate Zoology, 1907-39. Soc. Stud. Sci., 19, 387-420 (1989).

514. McKeown, B. \& Dan Thomas. Q Methodology. (Sage, 1988).

515. Cairns, R. \& Stirling, A. 'Maintaining Planetary Systems' or 'Concentrating Global Power?' High Stakes in Contending Framings of Climate Geoengineering. Glob. Environ. Chang., 28, 25-38 (2014).

516. Stirling, A. in Valuing nature? Economics ethics and the environment, (Foster, J., ed.) 186-210 (Routledge, 1997).

517. Coburn, J. \& Stirling, A. Multicriteria Mapping Manual - Version 2.0. (SPRU - Science Policy Research Unit, University of Sussex, 2016).

518. Stirling, A. \& Mayer, S. A novel approach to the appraisal of technological risk: a multicriteria mapping study of a genetically modified crop. Environ. Plan. C-Government Policy, 19, 529-555 (2001).

519. Snow, C. P. The Two Cultures. (Cambridge University Press, 2000).

520. Goertz, G. \& Mahoney, J. A Tale of Two Cultures: qualitative and quantitative research in the social sciences. (Princeton University Press, 1996). doi:10.1016/S1369-7021(03)00024-5

521. Eisenhardt, M. Building Theories from Case Study Research. Acad. Manag. J., 14, 532-550 (1989).

522. Mills, A., Eurepos, G. \& Wiebe, E., eds. Encyclopedia of Case Study Research. (Sage, 2010).

523. Flyvbjerg, B. Five Misunderstandings About Case-Study Research. Qual. Inq., 12, 219-245 (2006).

524. Erickson, F. Comments on Causality in Qualitative Inquiry. Qual. Inq., 18, 686-688 (2012).

525. Flick, U., ed. The Sage Handbook of Qualitative Data Analysis. (Sage, 2014).

526. Hermwille, L. The role of narratives in socio-technical transitions-Fukushima and the energy regimes of Japan, Germany, and 
the United Kingdom. Energy Res. Soc. Sci., 11, 237-246 (2016).

Aliseda, A. Abductive Reasoning: logical investigations into discovery and explanations. (Springer, 2006).

Ragin, C. C. \& Becker, H. S., eds. What is a Case: exploring the foundations of social inquiry. (Cambridge University Press, 1992). Flyvbjerg, B. in The Sage Handbook of Qualitative Research, (Denzin, N. K. \& Lincoln, Y. S., eds.) 301-316 (Sage, 2011).

Yin, R. K. Case Study Research: design and methods. (Sage, 2003).

Byrne, D. \& Ragin, C. C., eds. The SAGE Handbook of Case-Based Methods. (Sage Publications, 2009).

Welch, C., Piekkari, R., Plakoyiannaki, E. \& Paavilainen-Mäntymäki, E. Theorising from case studies: Towards a pluralist future for international business research. J. Int. Bus. Stud., 42, 740-762 (2011).

Bajc, V. Abductive Ethnography of Practice in Highly Uncertain Conditions. Ann. Am. Acad. Pol. Soc. Sci., 642, 72-85 (2012).

Balsiger, P. W. Supradisciplinary research practices: history, objectives and rationale. Futures, 36, 407-421 (2004).

Feyerabend, P. Against Method. (Verso, 1975).

Kellert, S. H., Longino, H. E. \& Waters, C. J., eds. Scientific Pluralism. (University of Minnesota Press, 2006).

Soskice, D. et al. Crossing paths: interdisciplinary institutions, careers, education and applications. (The British Academy, 2016). Wright, E. O. Class Counts. (Cambridge University Press, 2004).

Parsons, T. The Social System. (Routledge, 1953). doi:10.2307/2087860

Pereira, A. G. \& Funtowicz, S., eds. Science, Philosophy and Sustainability: the end of the Cartesian dream. (Earthscan, 2015). Stirling, A. Emancipating Transformations : from controlling' the transition ' to culturing plural radical progress. (STEPS Centre, University of Sussex, 2014).

Mooney, P. R. The ETC century: erosion, technological transformation and corporate concentration in the 21 st century. Dev. Dialogue, 1-2, 1-128 (1999).

Hirst, P. Q., Simon, B. \& Thompson, G. Globalization in Question. (Polity Press, 2009).

Kiely, R. Empire in the age of globalisation: US hegemony and neoliberal disorder. (Pluto Press, 2005). at

<http://books.google.co.uk/books?id=mi25AAAAIAAJ\&q=intitle:Empire+in+the+Age+of+Globalisation\&dq=intitle:Empire+in+the +Age+of+Globalisation \&hl=\&cd=1\&source=gbs_api>

Sassen-Koob, S. in Urbanization in the World Economy, (Timberlake, M., ed.) (Academic Press, 1985).

Misa, T. J., Brey, P. \& Feenberg, A., eds. Modernity and Technology. (MIT Press, 2003).

Amin, A., ed. Post-Fordism: a reader. (Blackwell Publishers, 1994).

Gieryn, T. F., Bevins, G. M. \& Zehr, S. C. Professionalization of American Scientists : Public Science in the Creation / Evolution Trials. Am. Sociol. Rev., 50, 392-409 (1985).

Roszak, T. The Making of a Counter Culture: reflections on the technocratic society and its youthful opposition. (Doubleday, 1969).

Bohmann, J. \& Rehg, W., eds. Deliberative Democracy: essays on reason and politics. (MIT Press, 1997).

Dryzek, J. S. Deliberative Democracy and Beyond: liberals, critics, contestations. (Oxford University Press, 2000).

Bouwel, J. van, ed. The Social Sciences and Democracy. (Palgrave MacMillan, 2009).

Carol S. Leonard. Agrarian Reform in Russia: the road from serfdom. (Cambridge University Press, 2011).

Davis, D. B. The Problem of Slavery in the Age of Emancipation. (Knopf, 2014).

Fanon, F. Toward the African Revolution: Political Essays. (Grove Press, 1967).

E. P. Thompson. The Making of the English Working Class. (Knopf, 1966).

Sudbury, J. Other Kinds of Dreams: black women's organisations and the politics of transformation. (Routledge, 1998).

Paletschek, S. \& Pietrow-Ennker, B., eds. Women's Emancipation Movements in the Nineteenth Century: a European Perspective. (Stanford University Press, 2004)

Giffney, N. \& O’Rourke, M., eds. The Ashgate Research Companion to Queer Theory. (Ashgate, 2009).

Stirling, A. in Knowing Governance: The Epistemic Construction of Political Order, (Voß, J.-P. \& Freeman, R., eds.) (Palgrave Macmillan, 2016).

Yearley, S. Making Sense of Science: understanding the social study of science. (Sage, 2005).

Jasanoff, S. EPA's Regulation of Daminozide: Unscrambling the Messages of Risk Author. Sci. Technol. Hum. Values, 12, 116-124 (1987).

Zhou, X. The Dynamics of Organizational Rules. Am. J. Sociol., 98, 1134-1166 (1993).

Rafols, I. et al. How journal rankings can suppress interdisciplinary research: A comparison between Innovation Studies and Business \& Management. Res. Policy, 41, 1262-1282 (2012).

Karin, D., Roger, K. \& Richard, W., eds. The social process of scientific investigation. (Reidel, 1981).

Blind, K. The Impact of Standardization and Standards on Innovation: Compendium of Evidence on the Effectiveness of Innovation Policy Intervention. (Manchester Institute of Innovation Research, University of Manchester, 2013).

Chou, C. \& Shy, O. The crowding-out effects of long duration of patents. RAND J. Econ., 24, 304-312 (1993).

Chic. Kent. Law Rev., 81, 197-224 (2009).

Kaplinsky, R. Globalisation and Unequalisation: What Can Be Learned from Value Chain Analysis? J. Dev. Stud., 37, 117-146 (2000).

Michael, M. Comprehension, Apprehension, Prehension: Heterogeneity and the Public Understanding of Science. Sci. Technol. Hum. Values, 27, 357-378 (2002).

Mesle, C. R. Process-Relational Philosophy: an introduction to Alfred North Whitehead. (Templeton Foundation press, 2008).

Pickering, A. The Mangle of Practice: time, agency and science.

Sternberg, R. J. \& Preeiss, D. D., eds. Intelligence and Technology: the impact of tools on the nature and development of human abilities. (Lawrence Erlbaum, 2005).

Knappett, C. \& Malafouris, L., eds. Material Agency: towards a non-anthropocentric approach. (Springer, 2008).

James, W. A pluralistic universe. (Longmans Green and Company, 1920). 
Lowe, V. William James and Whitehead's Doctrine of Prehensions. J. Philos., 38, 113-126 (2018)

Ashmore, M. The Life Inside / The Left-Hand Side. Soc. Stud. Sci., 35, 827-830 (2005).

Werner Rammert. Where the action is: distributed agency between humans, machines, and programs. (The Technical University Technology Studies, 2008).

Campbell, J. K., O'Rourke, M. \& Silverstein, H. S., eds. Action, ethics, and responsibility. (MIT Press, 2010).

Larsen, N. Modernism and hegemony: a materialist critique of aesthetic agencies. (University of Minnesota Press, 1990). Sugarman, J. \& Martin, J. Theorizing Relational Agency. J. Constr. Psychol., 24, 283-289 (2011).

Arora, S. et al. Relational Agency: Pathways into and out of Poverty, during Green Revolutions in South India and Kenya. in Int. Work. Madras Inst. Dev. Stud. (MIDS), Chennai, India, 16-17 Febr., (2017).

Werner Rammert. Distributed Agency and Advanced Technology or How to Analyse Constellations of Collective Inter-Agency. (Technical University Technology Studies, 2011).

Sageng, J. R., Fossheim, H. \& Larsen, T. M., eds. The Philosophy of Computer Games. (Springer, 2012).

Mathews, F. Reinhabiting Reality: towards a recovery of culture. (State University of New York Press, 2005).

Castree, N., Coe, N. M., Ward, K. \& Samers, M. Spaces of Work: global capitalism and the geographies of labour. (Sage Publications, 2004).

Cooren, F. Textual Agency: How Texts Do Things in Organizational Settings. Organization, 11, 373-393 (2004).

Law, J. Decentering the Object in Technoscience-Duke University Press (2002).pdf. (Duke University Press, 2002).

Callon, M. Some elements of a sociology of translation: domestication of the scallops and the fisherman of Saint Brieuc Bay. Sociol. Rev., 32, 196-233 (1984).

Moore, H. L. \& Sanders, T. Moore, H. \& Sanders, T., eds. Anthropologgy in Theory: Issues in Epistemology.

Franks, D. D. \& Turner, J. H., eds. Handbook of Neurosociology.

Gagliano, M. In a green frame of mind: perspectives on the behavioural ecology and cognitive nature of plants. 1-8 (2018). doi:10.1093/aobpla/plu075

Boyle, E. Neuroscience and Animal Sentience. 1-12 (2009).

Plumwood, V. Environmental Culture: The Ecological Crisis of Reason. (Routledge, 2002).

Uhlír, V., Stella, M. \& Dennett, D. WHO NEEDS MEMETICS? POSSIBLE DEVELOPMENTS OF THE MEME CONCEPT AND BEYOND. 127-142 (2012).

Latour, B. Agency at the Time of the Anthropocene. 1-18 (2014).

Bennett, J. Vries, H. de \& Sullivan, L. E., eds. Vibrant Matter: a political ecology of things. (Duke University Press, 2010).

Whatmore, S. Hybrid Geographies: natures, cultures, spaces. (Sage, 2002).

Grusin, R., ed. The Nonhuman Turn. (University of Minnesota Press, 2015).

Varela, C. R. Science for Humanism: the recovery of human agency. (Routledge, 2009).

Turner, B. S. Social Fluids: Metaphors and Meanings of Society. Body Soc., 9, 1-10 (2003).

Lefebvre, H. Rhythmanalysis: Space, Time and Everyday Life. (Continuum, 2004).

Lash, S. M. \& Urry, J. Economies of Signs and Space. (Sage, 1994).

Canzler, W., Kaufman, V. \& Kesselring, S., eds. Tracing Mobilities: towards a cosmopolitan perspective. (Ashgate, 2008). Hall, S. \& Gieben, B., eds. Formations of Modernity. (Blackwell, 1992).

Brighenti, A. M. The Ambiguous Multiplicities: materials, episteme and politics of cluttered social formations. (Palgrave Pivot, 2014). doi:10.1057/9781137384997.0001

Luke, T. W. Scanning Fast Capitalism: Quasipolitan Order and New Social Flowmations. 1-11 (2005). at <https://www.uta.edu/huma/agger/fastcapitalism/1_1/luke.html>

Herod, A., Tuathail, G. o \& M.Roberts, S., eds. An Unruly World: Globalization, governance and geography. (Routledge, 1998). Stengers, I. Cosmopolitics I. (University of Minnesota Press, 2003).

Stengers, I. Introductory Notes on an Ecology of Practices. 183-196 (2003).

Arora, S. Defying Control: Aspects of caring engagement between divergent knowledge practices. (STEPS Centre, 2017).

Walker, G. The dynamics of energy demand: Change, rhythm and synchronicity. Energy Res. Soc. Sci., 1, 49-55 (2014).

Toffler, A. The Third Wave: teh classic study of tomorrow. (Bantam, 1980).

Bessinger, M. R. How Nationalisms Spread: Eastern Europe Adrift the Tides and Cycles of Nationalist / Contention. Soc. Res. (New. York)., 63, 97-146 (2018).

Hannerz, U. Flows, boundaries and hybrids: keywords in transnational Anthropology. Mana, 3, 7-39 (1997).

Sewell, W. H. Logics of History: Social Theory and Social Transformation. (University of Chicago Press, 2005).

Therborn, G. Globalizations: dimensions, historical waves, regional effects, normative governance. Int. Sociol., 15, 151-179 (2000).

Aunger, R. Major transitions in 'big' history. Technol. Forecast. Soc. Chang., 74, 1137-1163 (2007).

Perez, C. Technological Revolutions and Financial Capital: The Dynamics of Bubbles and Golden Ages. (Edward Elgar, 2003).

Olkhov, V. Econophysics of Macroeconomics: 'Action-at-a-Distance' and Waves. SIAM J. Financ. Math., 6, 467-486 (2015).

Punzo, L. F. Punzo, L. F., ed. Cycles, Growth and Structural Change. (Routledge, 2001).

Bloom, A. Bloom, A. \& Breines, W., eds. 'Takin"' it to the streets": a sixties reader'. 37, (Oxford Univ Press, 2003).

Andrew Hsiao, Audrea Lim, T. A., ed. The Verso Book of Dissent: From Spartacus to the Shoe-Thrower of Baghdad. (Verso, 2010).

Croteau, D., Hoynes, W. \& Ryan, C., eds. Rhyming hope and history: activists, academics and social movement scholarship. (University of Minnesota Press, 2005).

John Guidry, Michael D. Kennedy, M. Z., ed. Globalizations and Social Movements: Culture, Power, and the Transnational Public Sphere. (Universiy of Michigan Press, 2000).

Kindleberger, C. P. \& Aliber, R. Z. Manias, Panics and Crashes: a history of financial crises. (Palgrave MacMillan, 2005).

Shiller, R. J. Stock Prices and Social Dynamics. Brookings Pap. Ecnomic Act., 2, 457-510 (1984).

Seabright, P. The company of strangers: a natural history of economic life. (Princeton Univ Press, 2004). at 
<http://www.ncbi.nlm.nih.gov/pubmed/8007547>

629. Bruun, C., ed. Advances in Artifical Economics: the economy as a complex adaptive system. (S[ringer, 2006).

630. Macmillan, M. The Rhyme of History: Lessons of the Great War. (Brookings Institution Press, 2013).

631. Levy, J. S. \& Thompson, W. R. Causes of War. (Wiley Blackwell, 2010).

632. Goertz, G. \& Levy, J. S. Goertz, G. \& Levy, J., eds. Explaining War and Peace: case studies and necessary condition counterfactuals. 20074332, (Routledge, 2007).

633. Halperin, S. War and Social Change in Modern Europe: the great transformation revisited. (Cambridge Univ Press, 2004).

634. Mann, M. States, War and Capitalism: studies in political sociology. (Blackwell, 1988).

635. Aron, R. Progress and Disillusion; the dialectics of modern society.

636. Johnston, A. Badiou, Zizek, and Political Tranformations: the cadence of change. (Northwestern University Press, 2009).

637. Cooper, D., Brown, J., Greenwood, R. \& Hinings, C. R. Sedimentation and transformation in organizational change: The case of Canadian law firms. Organ. Stud., 17, 623-647 (1996).

638. Ven, A. H. Van de \& Hargrave, T. J. in Handbook of Organizational Change and Innovation, (Poole, M. S., Poole, M. S. \& Ven, A. H. van de, eds.) (Oxford Univ. Press, 2004).

639. Aldrich, H. E. \& Ruef, M. Organizations Evolving. (Sage, 2006).

640. Davis, G. F., McAdam, D., Richard, W., Mayer, S. \& Zald, N., eds. Social Movements and Organization Theory. (Cambridge Univ. Press, 2005).

641. Hogselius, P., Hommels, A., Kaijser, A. \& Vleuten, E. van der, eds. The Making of Europe's Critical Infrastructure: common connections and shared vulnerabilities. (Palgrave MacMillan, 2013).

642. Kaiser, W. \& Schot, J. Writing the Rules for Europe: experts, cartels, and international organizations. (Palgrave MacMillan, 2014).

643. Bourdieu, P. The Logic of Practice. (Stanford Univ Press, 1990).

644. Shove, E., Pantzar, M. \& Watson, M. The Dynamics of Social Practice: Everyday Life and How it Changes. (Sage Publications, 2012).

645. Schot, J., Kanger, L. \& Foxon, T. Deep Transitions: Emergence, Acceleration, Stabilization and Directionality. Res. Policy, 47, 10451059 (2016).

646. Charvet, J. A Critique of Freedom and Equality. (Cambridge Univ. Press, 1981).

647. Capoccia, G. in Advances in Comparative-Historical Analysis, (Mahoney, J. \& Thelen, K., eds.) (Cambridge University Press, 2015).

648. Bailey, J. \& Projects, H. R. The Medicine Bow Wind Energy Project. (2014).

649. Strauss, S., Rupp, S. \& Love, T., eds. Cultures of Energy: power, practices, technologies. (Left Coast Press, 2013).

650. O'Donovan, C. The emergence of innovation systems in new locations: theoretical explorations and an in-depth case study of wind energy in Ireland, 1990-2014. (2016).

651. Szarka, J., Cowl, R., Ellis, G., Strachan, P. A. \& Warren, C., eds. Learning from Wind Power: governance, societal and policy perspectives on sustainable energy. (Palgrave, 2012).

652. Ornetzeder, M. \& Rohracher, H. Of solar collectors, wind power, and car sharing : Comparing and understanding successful cases of grassroots innovations. Glob. Environ. Chang., 23, 856-867 (2013).

653. Dickson, D. Alternative Energy: and the politics of technical change. (Fontana, 1974).

654. Cooper, M. Power Shift: the deployment of a 21st Centrury elecrticity sector and the nuclear war to stop it. (2015).

655. Willoughby, K. W. Technology Choice: a critique of the appropriate technology movement. (Westview, 1990).

656. Smith, A. The Alternative Technology Movement: An Analysis of its raming and Negotiation of Technology Development. 12, 106-119 (2005).

657. Smith, A. et al. Grassroots Innovation Movements. (Routledge Earthscan, 2017).

658. IRENA. 30 Years of Policies for Wind Energy. (International Renewable Energy Agency, 2012).

659. Ratinen, M. \& Lund, P. Policy inclusiveness and niche development : Examples from wind energy and photovoltaics in Denmark, Germany , Finland, and Spain. Energy Res. Soc. Sci., 6, 136-145 (2015).

660. Mortensen, H. B. The Valuation History of Danish Wind Power: the ongoing struggle of a challenger technology to prove its worth to society. (2018).

661. Garud, R. \& Karnøe, P. Bricolage versus breakthrough: distributed and embedded agency in technology entrepreneurship. Res. Policy, 32, 277-300 (2003).

662. Haraway, D. Situated Knowledges: the science question in feminism and the privilege of partial perspective. Fem. Stud., 14, 575599 (1988).

663. Nagel, T. The View From Nowhere. (Oxford Univ Press, 1986).

664. Jasanoff, S. Virtual, visible, and actionable: Data assemblages and the sightlines of justice. 1-15 (2017). doi:10.1177/2053951717724477

665. Sevareid, E. Worm's Eye View. Curr. Hist. Forum, 93, (1940).

666. Chia, R. C. H. \& Holt, R. Strategy Without Design: the silent efficacy of indirect action. (Cambridge Univ. Press, 2009).

667. Bok, M. J. \& Nilsson, D. E. Fan worm eyes. Curr. Biol., 26, R907-R908 (2016).

668. Gross, B. Friendly Fascism: the new face of power in America. (South End Press, 1980).

669. Knowles, E. M. What they didn't say: a book of misquotations. (Oxford University Press, 2006).

670. Law, J. Law, J., ed. A Sociology of Monsters: Essays on Power, Technology and Domination. (Routledge, 1991).

671. Rosenberger, R. \& Verbeek, P.-P., eds. Postphenomenological Investigations - essays on human-technology relations. (Lexington Books, 2015).

672. Mumford, S. \& Tugby, M., eds. Metaphysics and Science. (Oxford University Press, 2013).

673. Jessop, B. Institutional re(turns) and the strategic-relational approach. Environ. Plan. A, 33, 1213-1235 (2001).

674. Paschek, F. Rethinking structure and agency in the multi-level perspective. in 5th Int. Conf. Int. Conf. Sustain. Transitions (IST 2014), 1-25 (2014).

675. Kistler, M. \& Gnassounou, B., eds. Dispositions and Causal Powers. (Ashgate Publishing, 2007). 
677. Groark, K. P. Language \& Communication Toward a cultural phenomenology of intersubjectivity : The extended relational field of the Tzotzil Maya of highland Chiapas, Mexico. Lang. Commun., 33, 278-291 (2013).

678. Boothby, R. Freud as Philosopher: metapsychology after Lacan. (Routledge, 2001).

679. Brightman, R. Forget Culture: Replacement, Transcendence, Relexification. Cult. Anthropol., 10, 509-546 (1995).

680. Griller, R. The Return of the Subject ? The Methodology of Pierre Bourdieu. Crit. Sociol., 22, 3-28 (1996).

681. Grafarend, E. \& Heidenreich, A. The generalized Mollweide projection of the biaxial ellipsoid. Bull. Geod., 69, 164-172 (1995). 682. Hildebrandt, M. Smart Technologies and the End(s) of Law: novel entanglements of law and technology. (Edward Elgar, 2015).

683. Funtowicz, S. \& Ravetz, J. R. Emergent complex systems. Futures, 26, 568-582 (1994).

684. La Torre, D. \& Marsiglio, S. Endogenous technological progress in a multi- sector growth model. Econ. Model., 27, 1017-1028 (2010).

685. Smith, A., Stirling, A. \& Berkhout, F. The governance of sustainable socio-technical transitions. Res. Policy, 34, 1491-1510 (2005)

686. McDowall, W. \& Eames, M. Forecasts, scenarios, visions, backcasts and roadmaps to the hydrogen economy: A review of the hydrogen futures literature. Energy Policy, 34, 1236-1250 (2006).

687. Baillieul, J. et al. Baillieul, J. et al., eds. Robotics. (American Mathematical Society).

688. Tzafestas, S., ed. Advances in Intelligent Autonomous Systems. (Springer, 1999).

689. Venkatesh, V. \& Bala, H. Technology Acceptance Model 3 and a Research Agenda on Interventions. Decis. Sci., 39, 273-315 (2008).

690. Venkatesh, V., Davis, F. D., Venkatesh, V. \& Davis, F. D. Theoretical Extension of the Technology Acceptance Model: Four Longitudinal Field Studies. Manage. Sci., 46, 186-204 (2000).

691. Schot, J. W. Constructive Technology Assessment and Technology Dynamics: The Case of Clean Technologies. Sci. Technol. Human Values, 17, 36-56 (1992).

692. Rip, A. A Quasi-Evolutionary Model of Technological Development and a Cognitive Approach to Technology Policy. Riv. di Stud. Epistemol. e Soc. sulla Sci. e la Tecnol., 2, 69-102 (1992).

693. Kemp, R. Technology and the Transition to Environmental Sustainability the problem of technological regime shifts. Futures, 10, 1023-1046 (1994).

694. Sovacool, B. K., Noel, L. \& Orsato, R. J. Stretching, embeddedness, and scripts in a sociotechnical transition: Explaining the failure of electric mobility at Better Place (2007 - 2013). Technol. Forecast. Soc. Chang., 123, 24-34 (2017).

695. Geels, F. W. \& Penna, C. C. R. Societal problems and industry reorientation : Elaborating the Dialectic Issue LifeCycle (DILC) model and a case study of car safety in the USA (1900-1995). Res. Policy, 44, 67-82 (2015).

696. Freeman, C. The 'National System of Innovation' in historical perspective. Cambridge J. Econ., 19, 5-24 (1995).

697. Archibugi, D., Howells, J. \& Michie, J., eds. Innovation Policy in a Global Economy. (Cambridge University Press, 1999).

698. Howells, J. in Innovation Policy in a Global Economy, (Archibugi, D., Howells, J. \& Michies, J., eds.) (Cambridge University Press, 1999).

699. Freeman, C. Continental, national and sub-national innovation systems: complementarity and economic growth. Res. Policy, 31, 191-211 (2002).

700. Malerba, F. Sectoral systems of innovation and production. Res. Policy, 31, 247-264 (2002).

701. Sovacool, B. K. Experts, theories, and electric mobility transitions: Toward an integrated conceptual framework for the adoption of electric vehicles. Energy Res. Soc. Sci., 27, 78-95 (2017).

702. Cherp, A., Vinichenko, V., Jewell, J., Brutschin, E. \& Sovacool, B. Integrating techno-economic, socio-technical and political perspectives on national energy transitions: A meta-theoretical framework. Energy Res. Soc. Sci., 37, 175-190 (2018).

703. Venkatesh, V., Thong, J. Y. L. \& Xu, X. Consumer acceptance and Use of Information Technology: extending the unified theory of acceptance and use of technology. MIS Q., 36, 157-178 (2012).

704. Latour, B. Reassembling the Social: An Introduction to Actor-Network-Theory. (Oxford University Press, 2005).

705. Marston, S. A., Paul, J., lii, J. \& Woodward, K. Human Geography without Scale. Trans. Inst. Br. Geogr., 30, 416-432 (2005).

706. Schatzki, T. R., Cetina, K. K. \& Savigny, E. von, eds. The Practice Turn in Contemporary Theory. (Routledge, 2001).

707. Arora, S. \& Glover, D. Power and Practice: insights from technography and actor-network theory for agricultural sustainability. (STEPS Centre, 2017).

708. MacKenzie, D. \& Wajcman, J. The Social Shaping of Technology. (Open University Press, 1985).

709. Latour, B. \& Woolgar, S. Laboratory Life: the construction of scientific facts. (Princeton University Press, 1986).

710. Knorr-Cetina, K. \& A.V.Cicourel. Advances in Social Theory and Methodology: toward an integration of micro-and macrosociologies. (Routledge and Kegan Paul, 1981).

711. Latour, B. Science in Action: how to follow scientists and engineers through society. 6, (Harvard University Press, 1987).

712. Omaniyi, T. \& Fishman, J. A., eds. Explorations in the Sociology of Language and Religion. (John Benjamins, 2006).

713. Law, J., ed. Power, Action, and Belief: A New Sociology of Knowledge. (Routledge, 1986).

714. Callon, M., Law, J. \& Rip, A., eds. Mapping the Dynamics of Science and Technology: sociology of science in the real world. (MacMillan, 1986).

715. Woodhouse, E., Hess, D., Breyman, S. \& Martin, B. Science Studies and Activism: Possibilities and Problems for Reconstructivist Agendas. Soc. Stud. Sci., 32, 297-319 (2002).

716. Needham, R. Polythetic Classification: convergence and consequences. Man, 10, 349-369 (1975).

717. Appadurai, A. Disjuncture and Difference in the Global Cultural Economy. Public Cult., 2, (1990).

718. Wittgenstein, L. Philosophical Investigations. (Blackwell, 1958).

719. Appadurai, A. Modernity at Large: Cultural Dimensions of Globalisation. (University of Minnesota Press, 1996).

720. Biggiero, L. Sources of Complexity in Human Systems. 5, 3-19 (2001).

721. Schutz, A. Embree, L., ed. Collected Papers V. Phenomenology and the Social Sciences. (Springer, 2011). 
Pearce, S. M., ed. Interpreting Objects and Collections. (Routledge, 1994).

Slobodkin, L. B. The good, the bad and the reified. Evol. Ecol. Res., 3, 1-13 (2001).

Robinson, K., ed. Deleuze, Whitehead, Bergson Rhizomatic Connections. (Palgrave MacMillan).

Cohen, H. \& Lefebvre, C., eds. Handbook of Categorization in Cognitive Science. (Elsevier, 2005).

Borges, J. L. Other Inquisitions, . (Simon \& Schuste).

Ritzer, G., ed. Encyclopedia of Social Theory - Volume I \& II. (Sage Publications, 2000).

Voss, J., Bauknecht, D. \& Kemp, R., eds. Reflexive Governance for Sustainable Development. (Edward Elgar, 2006).

Konefal, J. Governing Sustainability Transitions: Multi-Stakeholder Initiatives and Regime Change in United States Agriculture. Sustainability, 7, 612-633 (2015)

Wittmayer, J. M., Steenbergen, F. Van, Rok, A. \& Roorda, C. Governing sustainability : a dialogue between Local Agenda 21 and transition management. Local Environ., 21, 37-41 (2016).

Bulkeley, H., Jordan, A., Perkins, R. \& Selin, H. Governing sustainability: Rio+20 and the road beyond. Environ. Plan. C Gov. Policy, 31, 958-970 (2013).

Adger, W. N. \& Jordan, A., eds. Governing sustainability. (Cambridge University Press, 2009).

Johnstone, P., Stirling, A. \& Sovacool, B. Policy mixes for incumbency: Exploring the destructive recreation of renewable energy, shale gas 'fracking,' and nuclear power in the United Kingdom. Energy Res. Soc. Sci., 0-1 (2017). doi:10.1016/j.erss.2017.09.005

Geels, F. W. The impact of the financial-economic crisis on sustainability transitions : Financial investment, governance and public discourse. Environ. Innov. Soc. Transitions, 6, 67-95 (2014).

Kinn, M. C. An Analysis Of The Sociotechnical Transition Process From The Existing Centralised Alternating Current Voltage Electrical System In The UK To One Where Distributed Direct Current Voltage Is Used To Meet The Energy Needs Of The Built Environment. (2016).

Schot, J. \& Ghosh, B. Mapping socio-technical change in mobility regimes: the case of Kolkata. (2018).

Thagard, P. Conceptual Revolutions. (Princeton Univ Press, 1992).

Wagner-Pacifici, R. Theorizing the STandoff: contingency in action. (Cambridge Univ Press, 2004).

Stirling, A. in The Politics of Green Transformations, (Scoones, I., Leach, M. \& Newell, P., eds.) 54-67 (STEPS Centre, University of Sussex, 2015).

Lian, B. H., Liu, C.-H. \& Yau, S.-T. A Reconstruction of Euler Data. arXiv:math, (2000). at <https://arxiv.org/abs/math/0003071> Garg, H. K. On the Factorization of Polynomials and Direct Sum Properties in Integer Polynomial Rings. Circuits Syst. Signal Process., 15, 415-435 (1996).

Plaisted, D. A. Theoretical Divisibility Problems for Slowly Utilized Oracles. Theor. Comput. Sci., 35, $245-260$ (1985).

Quirke, L. Rogue Resistance: Sidestepping Isomorphic Pressures in a Patchy Institutional Field. Organ. Stud., 34, 1675-1699

(2013).

Deleuze, G. Dualism, Monism and Multiplicities (Desire-Pleasure-Jouissance). Contretemps, 2, 92-108 (2001).

Jensen, C. B. \& Rodje, K., eds. Deleuzian Intersections: Science, Technology, Anthropology. (Berghan, 2010).

Nicolini, D. Practice theory, work, and organization. (Oxford Univ Press, 2013).

Barrett, E. \& Bolt, B., eds. Practice as Research: approaches to creative arts enquiry. (Tauris, 2007).

Stirling, A. in Science, Citizenship and Globalisation, (Berkhout, F., Leach, M. \& Scoones, I., eds.) (Zed, 2005).

Jessop, B. Political Capitalism , Economic and Political Crises, and Authoritarian Statism. Spectr. J. Glob. Stud., 7, 1-18 (2014).

Baker, L. et al. The Political Economy of Energy Transitions: The Case of South Africa. New Polit. Econ., 19, 791-818 (2014).

Crouch, C. Post Democracy. (Polity, 2004).

Streeck, W. Buying Time: The Delayed Crisis of Democratic Capitalism. (Verso, 2013).

Agamben, G. Means Without End: notes on politics. (Univ Minnesota Press, 2000).

Swyngedouw, E. Interrogating post-democratization : Reclaiming egalitarian political spaces. Polit. Geogr., 30, 370-380 (2011). Streeck, W. How Will Capitalism End: Essays on a Failing System. (Verso, 2011).

Rosanvallon, P. Counter-Democracy: politics in an age of distrust. (Cambridge Univ. Press, 2008).

Hicks, D., Wouters, P., Waltman, L., de Rijcke, S. \& Rafols, I. The Leiden Manifest for Research Metrics. Nature, 520, 429-431 (2015).

Ruggie, J. G. International regimes, transactions, and change: embedded liberalism in the postwar economic order. Int. Organ., 36, 379-415 (1982).

Philips, N. The Case of the Naked Quark. TWA Ambassad. Mag., Oct, (1980).

Roper, B. S. The History of Democracy: a Marxist interpretation. (Pluto Press, 2013).

Stirling, A. Transforming power: Social science and the politics of energy choices. Energy Res. Soc. Sci., 1, (2014).

Stirling, A. in What Next for Sustainable Development?: Our Common Future at Thirty., (Oxford Univ Press).

Rose, N. \& Abi-Rached, J. M. Neuro: the new brain sciences and the management of the mind. (Princeton Paperbacks, 2013).

Davies, P. in From Complexity to Life: On the Emergence of Life and Meaning, (Gregersen, N. H., ed.) 20, 1-9 (Oxford Univ Press, 2003).

Lima, M. Visual Complexity. 1-8 (2009). at <http://www.visualcomplexity.com/vc/blog/?m=200901>

Clayton, P. \& Davies, P., eds. The Re-Emergence of Emergence: the emergentist hypothesis from science to religion. (Oxford Univ Press, 2006).

Elder-Vass, D. Reconciling Archer and Bourdieu in an Emergentist Theory of Action. Sociol. Theoryol Theory, 25, 325-346 (2007). Elder-Vass, D. Integrating institutional, relational and embodied structure: an emergentist perspective. Br. J. Sociol., 59, 281-299 (2008).

Puttarajappa, C., Shapiro, R. \& Tan, H. P. Antibody-Mediated Rejection in Kidney Transplantation: A Review. J. Transplant., 2012, 1-9 (2012).

Lipsey, R. G., Carlow, K. I. \& Bekar, C. T. Economic Transformations: general purpose technologies and long term economic growth. (Oxford Univ Press, 2005). 


\section{Endnotes}

1 The author owes a great debt to the unusual culture around SPRU and the STEPS Centre, for providing an environment in which such a tangled knot of eccentric research interests can (for better or worse!) quite happily coalesce and be so tolerantly nurtured over several years. An even larger debt is owed to the countless individual colleagues with whom conversations have helped illuminate various parts of the argument. Especially useful, are the many forceful critiques! A regretfully incomplete list of people providing much-appreciated feedback includes: Marina Apgar, Saurabh Arora, Frederique Bone, Marie-Claire Brisbois, Josie Coburn, James Fairhead, Tim Foxon, John Gaventa, Dominic Glover, Amber Huff, Phil Johnstone, Laur Kanger, Ben Martin, Gordon McGranahan, Erik Millstone, Cian O'Donovan, Ismael Rafols, Christoph Rogge, Johan Schot, lan Scoones, Jan Selby, Benjamin Sovacool, Adrian Smith, Ed Steinmueller, Jonas Torrens and Barbara van Dyck - as well as Topsy Jewell in Lewes, Gyorgy Scrinis and John Wiseman at Melbourne University and Arie Rip in Utrecht, who gave an especially generous and helpful set of comments. In addition, a referee for the SPRU Working Paper Series who remained anonymous, also made some extremely useful suggestions. To others who ailing memory has caused to be missed from this list, I can only apologise - and affirm that (like the murmurations celebrated at the end of this analysis) it is the anonymous collective contributions that are always most momentous.

2 As well as academic drivers like disciplinary interests ${ }^{561}{ }^{562}$, organisational agendas ${ }^{563}$, personal career incentives ${ }^{564}$ and professional rivalries ${ }^{565}$, wider shaping forces and interests include various kinds of profit motive and economic pressures to: standardise infrastructures ${ }^{566}$, establish organisational momentum ${ }^{100}$, appropriate intellectual property ${ }^{567} 568$, build monopolies ${ }^{102}$, realise rent on value chains ${ }^{569}$, condition user preferences through marketing ${ }^{317}$, capture regulators ${ }^{362}$ or entrap competing political interests ${ }^{158}$.

3 Owing a debt especially to Mike Michael's very helpful discussion (after Whitehead ${ }^{178}$ ) of contrasting meanings in this context ${ }^{570}$, between 'comprehension', 'apprehension' and 'prehension', what is intended in the pivotal usage here of the term 'prehension' is an emphasis on the process-relational nature of structuring agency ${ }^{571}$ as well as on the tacit and material dimensions 572573574 . In these terms, prehensions of or by structuring agency (like power - or the topologies of incumbency discussed later) are reciprocally selfconstituting processes [3]. What is in focus, are not the notional categories of subject or object, but the interlinking dynamics relating - and partly constituting each of - the two. And it is also in the interests of emphasising the embodied materiality of such processes, that it is arguable that the appropriate term for this relation is (after James 575 and Whitehead ${ }^{178}$ ) the word 'prehension' ${ }^{576}$. Further worthy of note about this distinction concerning apprehension and prehension, is that it is itself a relational result of prehension, rather than exclusively either an 'objective' property of what is prehended, or a 'subjective' feature of what is prehending.

4 Here, a diversity of specific forms of 'agency' are implicated in literatures bearing on socio-material change. Although many ideas in this field are (even for social science) especially hotly contested, it is important to note that some notions of 'nonhuman' 577 , 'distributed' 578, 'collective' 360 579, 'cultural' 580, 'relational' 581 582, 'inter-' 583, 'prosthetic' 584, 'synergistic' 585 586, 'textual' 587 , 'technological' 588 and 'material' 574 agency can (at least in some analyses and despite objections) be effectively independent of any direct or explicit process of human cognition, intentionality, deliberation or decision ${ }^{589}$. Although experienced very vividly as singular and personal, after all, even individual human intentionality is shown in recent research to be far more neurologically, metabolically and socially implicit, plural, distributed and emergent ${ }^{590}{ }^{591}$. And in Nature, likewise, myriad plants ${ }^{592}$, animals ${ }^{593}$, ecologies ${ }^{594}$ arguably evolution ${ }^{595}$ and the Earth itself ${ }^{596}$ - are all revealed in different scientific disciplines to be routinely exerting their own forms of 'agency' 597598.

The willingness of a 'nonhuman turn' 599 to contemplate such possible broadly-inclusive (biological and potentially material) prehensions of agency, can be challenging to dogmatically exclusive anthropocentric accounts ${ }^{600}$. However, it is not necessary for present purposes to take a firm position among the deep scientific-religious theologies motivating these ontological wrangles, to appreciate that at least some of the several kinds of 'agency' shaping directions for socio-material change, need not take individualised human forms. In these terms, the potential scope of the present analysis of socio-material incumbency is in principle quite radically wider than the particular socio-technical processes focused on in this paper ${ }^{258}$. And in keeping with the general picture here of what counts in any given context as salient 'configuring fields' (cf: Figure 2), this same aspect will be developed more generally with respect to later discussion in this paper of the 'double hermeneutic' 175 - that subjective orientations, modalities and frameworks for comprehension, apprehension and prehension [2] are as much a part of the formative context for characterising salient configuring fields, as any notionally objective conditions.

It is in this sense, that 'agency' can be defined for present purposes (as in Figure 2), in very general terms as 'orienting among many prehensible pathways for change' [2]. As illuminated in the structuration theories discussed in the text, this jointly objectively-and subjectively-defined concept of agency is co-constituted along with myriad structures - as 'conditions constituting potentialities across contrasting prehensible orientations for change'. Thus seen in terms of general generativity of change, these entangled aspects of structure and agency may alternatively be prehended in narrowly human, or wider material terms. So this way of thinking about 'structuring agency' is effectively independent of subjective lines drawn under any given perspective between (or around) sociality and materiality. With 'sociality' thought of simply as a relational mode of association, 'social materiality' extends in principle beyond the human domain, to also encompass a "sociology of things" 256 . The term 'socio-material' can thus acquire a much broader meaning. Whatever the conditions of prehension, however, the basic conceptual framework outlined in Figure 2 arguably still holds [6][23].

5 A distinct term like 'epi-dynamics' seems necessary here, because even the large array of incumbency-constituting phenomena organized in Figure 1 only addresses (roughly-distinguishable) individual processes. In excluding crucial aggregate issues of relational interactions, emergent patterns and cumulative effects over time, this picture misses many of the most salient aspects in the shaping of socio-material continuity and change. For, as in familiar experience of other interacting metaphorical fluids and solids ${ }^{601}$, it is these collective epi-dynamics in contending modalities and orientations among these different processes and their responses that are often most important ${ }^{602}$. Insights here can be found in recent studies of diverse kinds of mobilities ${ }^{603} 604$. For instance, moving in cumulative as well as oscillating and erosive ways, these aggregate patterns may be seen not as fixed formations ${ }^{605} 606$, but as alternatively 'slow' or 'fast' 607 political flowmations ${ }^{608}$, continuously reproduced by restless ecologies of practice 609610611612 . 
To illustrate this, phenomena to be found on an everyday beach might be pondered as heuristic analogies for the complex - typically nonlinear - temporalities of social affairs. Here, what might variously be imagined as historical tides ${ }^{613} 614$, cultural currents ${ }^{615} 616$, civilizational waves ${ }^{617} 618$, industrial surges ${ }^{619} 95$, macroeconomic swells ${ }^{620} 621$, revolutionary floods ${ }^{622} 623$, subaltern eddy-flows ${ }^{624} 625$, financial gyres ${ }^{626} 627$ and market swash ${ }^{628} 629$ - all punctuated by irregular variously-scaled 'tsunamis' to 'splashes' of disruptive violence 630631632633634 - each bring their own specific forms of dialectical backwash ${ }^{635} 636$. As if left by waves of agency on beaches of structure, then, layered institutional sediments may persist ${ }_{237}^{638}$ adorned with shifting organisational shingles ${ }^{639} 640$, strewn (and channelled) by - often highly generative and onwardly instrumental - infrastructural strand-wrack ${ }^{99} 641642$. And if the relatively simple materialities and temporalities of a beach can be so richly ordered, how much more so might this be prehended in the dynamics of structuring agency? In each, what is 'fluid' and what is 'solid' will typically be so inseparably entwined in the formative dynamics, that what exactly counts as each is not only relative but effectively irrelevant to the jointly emerging orders. Either way, the imaginable broadly analogous patterns in structuring agency are much too extensive to be addressed by the specific atomistic details in Figure 1 . But they are also far too fine-grain for unqualified broad-brush terminologies (especially in the singular) like 'structuration' 175 236, 'practice' 643644 'transition' 645148149 ... or undifferentiated 'mobilities' 603604 . If lame analogies around seas and beaches are to be escaped, then greater academic attention is needed to particular kinds of ecologies and epi-dynamics of incumbency 609610611.

$6 \quad$ The author is very grateful on this point to Ed Steinmueller for his challenge to further clarify the contrasting implications of what is here termed 'incumbency' and 'persistence', within what might also be distinguished as the more general phenomena of social and material continuity. Relating to the vexed question of quite how distributed the notion of 'agency' should be (cf: [3] and [5]), this raises what is likely to be a highly prevalent concern among more positivistically-minded readers. To define socio-material persistence by relevance to 'salience' is one way in which to avoid this becoming an unnecessary obstacle or distraction. If agency is prehended in very inclusive supra- ${ }^{646}$ or transhuman ${ }^{646}$ terms, then salience will be defined accordingly broadly. If not, then the domain of what is prehended (without reference to agency) merely as socio-material 'persistence' will correspondingly grow (cf: [23]). Either way (resting as it does on notions of prehensions that span subjective and objective conditions, the basic framing of the present analysis (see Figure 2) will remain intact. In other words, all the key points made here with respect to dynamics of power in socio-material incumbency, may be argued to stand insofar as the focal phenomena are prehended to relate to agency.

7 This refers to a form of field in which the quality of intensity at each point has a property not only of 'scalar' magnitude, but also of 'vector' orientation with respect to the focal pathway by reference to which, the field in question is defined. Here, a link can be made with discussions of 'vector intensity' in epidaemiology, defined for that context as "a product of propensity and activity" 310 . So, sociomaterial 'vector intensity' might be defined here as "a function both of the scalar intensity in power concentrations implicated in an array of socio-material configurations and of the associated propensity to orient a specific onward pathway for interlinked social and material change". Such configurations are referred to here as 'socio-material' (rather than more narrowly 'socio-technical'), because they implicate not only the momenta, affordances and constraints embedded in artefacts, but also those embodied in wider 'natural' material phenomena. The dynamics in question are referred to as 'pathways', rather than 'trajectories' to help avoid the implication of relatively simple and deterministic dynamics and to emphasise the complex formative role played by the encompassing milieu, as a 'landscape' that helps shape these pathways (that it both constitutes individually and is collectively constituted by).

8 On a wider canvas than just the history of technology, institutional theory in particular arguably identifies many further illustrative examples. Cappocia holds such cases to include, for instance: the long-run effects of the 1832 British Reform Act; the emergence of 'confessional parties' in nineteenth century western Europe; policy reactions to the US Great Depression; the contrasting fates of democracy in Guatemala and Cost Rica; or micro-dynamics around figures like Mahatma Ghandi or Nelson Mandela ${ }^{647}$.

9 Subject to the perils of counterfactuals 480262 , this example is readily elaborated. Early high profile experiments with prematurely large wind turbines by major utilities in many countries were widely asserted in mainstream energy policy in the 1970s and 80 s, to show that wind power was simply not feasible at what were held to be the necessary scales ${ }^{648}{ }^{649}$. Yet meanwhile, collective action by social movements in favour of alternative energy experimented and learned from a diverse array of much smaller designs ${ }^{650} 651652$. But these experiences were systematically marginalised by incumbent interests in energy systems 653654655656657 . Only under the relatively idiosyncratic conditions of the small explicitly anti-nuclear nation of Denmark, was it possible to build up an early critical mass of linkages between grassroots enthusiasm, engineering expertise and requisite levels of public support and financing 658659660 . But for this contingency, the early necessary stages for the gaining of later global momentum might never have been achieved towards machines that are now far larger and massively more efficient than the early utility-sponsored failures ${ }^{651}$. If it had not been for the crucially divergent early experience in Denmark, then, wind power might now still be judged to have been proven non-viable. The currently highly globally competitive mainstream applications of this technology might conceivably have been entirely foregone ${ }^{345} 661$.

10 Gyawali's vividly-expressed concept resonates with Haraway's influential identification of "the God trick" in science and technology and feminist studies 662 - and Jasanoff's associated distinctions (riffing on Nagel ${ }^{663}$ ) between "views from somewhere", "views from everywhere" and "views from nowhere" 664 . In Gyawali's own metaphor, the contrast to an 'eagle-eye view' is a 'toad-eye view' 50 . But the worm has been chosen here as an alternative counterpoint for a number of reasons. First, (although usually not compared with that of an eagle) a "worm's eye view" is already a colloquial phrase ${ }^{665}{ }^{666}$. Second, it arguably better addresses the crucial point of immersion in the phenomena under view. A toad's view is (after all) still elevated above a notional 'ground', but simply less so than that of an eagle. Worms are embedded in an entirely different medium. And in relation to this medium of the soil, a third reason is that the idea of a 'worm-eye view' also accords better with relational 'rhizomic' (or root-like) understandings elaborated later in this paper. Fourth, association with a toad might (unfairly) seem pejorative, with the elite/subaltern connotations seemingly suggesting a predator-prey relation. Worms, by contrast, are inaccessible to being eaten by eagles. Indeed, it is kinds of worms that consume most eagles in the end! And if it jars to think of worms having 'views', then it can be recalled that some 'worms' do, in fact, have eyes ${ }^{667}$.

11 There are many straightforward extant concepts of different modalities of agency. That the analogy is so often made with such manifestly inapplicable simplistic tightly-circumscribed mechanistic models, is itself an indication of the power of pressures for justification. The function of these stories of control is not plausibly about securing stated substantive goals (without collateral effects) in the manner actually evoked by strict notions of control. Their political prominence is instead far more credibly explained as a means 
to maintain prevailing patterns of privilege, whilst seeking to 'stay on top' (as Gross quotes Domhoff ${ }^{668}$ ), in the 'surfing' ${ }^{81}$ of inherently uncontrollable contingencies reputedly lamented by one British Prime Minister as "events, dear boy, events" 669.

12 The concept of a 'configuring field' is developed here in relatively directly phenomenological 670671 terms by reference to the focus of central interest in interrogating the dispositions ${ }^{414} 672$ of socio-material incumbency. Whatever their nature, it is these dispositions across the totality of all possible socio-material configurations, that condition a propensity towards one particular pathway for change rather than others. In conceiving of these propensities within a 'milieu' of all possible configurations, there naturally arises a sense of the relevance of many other well-established kinds of social field theory. With so many extant variants of such theorising, however (including social fields ${ }^{417}$, organizational fields ${ }^{112} 419420421$, institutional fields ${ }^{422} 423$, strategic action fields ${ }^{424} 295$ and policy fields ${ }^{425}$.) doubts may arise over the necessity and rationale for any new approach. So a further footnote might be useful here, in explaining why a 'configuring field' approach as described here might be thought more applicable than these other alternatives.

For Dolata, for instance, 'socio-technical fields' correspond quite closely to the middle range category of the industrial 'sector'. So this falls foul of the concerns raised here regarding misplaced concreteness in the assertion of such categories. And the association is anyhow also directly critiqued later in Dolata's own analysis as a basis for understanding incumbency ${ }^{418}$. Perhaps more relevant then, in building on Giddensian structuration theory (as also used defining power for the present analysis), is Fuenfschilling and Truffer's analysis that provides a useful and sophisticated review of other field theories of socio-technical change ${ }^{112}$. But their approach is also undertaken disproportionately by reference to what is also critiqued later here as an 'eagle-eye' view of the 'socio-technical regime' as what they call "the paradigmatic core of a sector" ${ }^{112}$. In these terms, 'configuring fields' are better understood as fields in processes and relations of structuration itself, rather than as distinct and discrete phenomena which relate in independent ways to the notionally categorical 'levels of structuration' or 'degrees of institutionalisation' referred to by Fuenfschilling and Truffer.

Perhaps more relevant on this point, then, is Jessop's 'strategic relational' view of fields 673193 - for instance in ways well explored in sociotechnical regime theory by Paschek ${ }^{674}$. This involves criticism of Giddens' structuration theory in a manner that relates to exactly the point made above. But this framework in its own turn displays a series of divergences with the present approach and depends on a series of clashing assumptions. For instance, it adopts a critical realist position, rather than being open to the more constructionist insights highlighted here concerning the importance of Giddens' double hermeneutic in the understanding of incumbency. And, by contrast with the present generalized scope, Jessop's framework highlights particular spatial and temporal specificities. As a result, it also seems to neglect to generalise the importance addressed here, of both structure and agency being intrinsically normativelyoriented in ways that vary in all kinds of particular objective settings and subjective perspectives (not just across space and time).

So, what seems to most distinguish the present idea of a 'configuring field', is that it does not depend for its applicability, on detailed commitment to the above kinds of more particular and circumscribed explanatory frameworks and categories. Instead, it simply requires a shared interest in the focal phenomenon of socio-material incumbency as defined here. Applied in various guises in many areas (like philosophy ${ }^{675}$, linguistics ${ }^{676} 677$, psychology ${ }^{678}$ and social anthropology ${ }^{679}$ ), perhaps the closest approximation in extant field ontologies, is the rather general idea of 'dispositional fields' ${ }^{414}$. Widely understood in social science by reference to Bourdieu's formative concept of habitus ${ }^{415} 416$, this does share the process-relational structure-agency understanding of power adopted here and relates to well-established notions of 'social practice' ${ }^{680}$. So, practice theory may offer an especially helpful basis for testing or development of these ideas. But even here, intense paradigmatic divides in social science make it sadly necessary to point out, that the heuristic value of this concept of configuring fields does not require wholesale adherence to detailed features of practice theory.

13 Technically, the picture in Figure 3 is a 'Mollweide projection' ${ }^{681}$. This shows the manifold containing the relevant socio-material configurations as an enveloping hypersphere, which is then projected onto the two-dimensional plane of the white ellipse. Usefully for analysis of 'worm-eye' / 'eagle-eye' contrasts, this sphere can be viewed (respectively) alternatively as from within or without.

14 Rather than simply a 'space', however, this white ellipse might better be understood (heuristically and metaphorically), as a 'timespace' of affordances and constraints around the material feasibility and societal viability of different socio-material pathways ${ }^{612}$ 682. The orderings of such pathways are, after all, functions equally of different kinds of social and material latitude ('space') and unfoldings of various possible histories ('time'). In these terms, by definition, any particular kind of incumbency-sustaining dynamic will have the effect of reinforcing only a subset of all possible pathways encompassed in the timespace. As with all projections, any given assemblage of configurations will look different under contrasting perspectives. Furthermore, it follows from this metaphor not only that representation of contained phenomena will vary depending on the angle of projection, but that the relative visibility of different dimensions will also depend on this orientation. Any of the (potentially many) dimensions that are orthogonal to the perspective of the projection will remain effectively invisible. So the metaphor includes account of the double hermeneutic discussed here, in that the subjective angle of view is as formative of the resulting picture as the features of the viewed objects themselves.

15 Like "phase space" 162683684 , "possibility space" 685686 , or (perhaps most appropriately for this analysis) "configurational space" 687688.

16 Somewhat confusingly, but (as will be seen below) significantly, it is not just 'the landscape' that is held in regime theory to constitute socio-technical 'deep structure', but also the ostensibly-distinguished 'regime' ${ }^{436} 481$. That 'deep structure' thus conflates in this approach supposedly defining attributes equally of 'the regime' and of 'the landscape', supports the present analysis that incumbency is more rhizomic, distributed and multiplex than the apparently neat segregation of these 'misplacedly concrete' categories suggests.

17 There are many examples of aspiring policy-informing academic approaches in which focal Mertonian 'middle range' 377378 social categories tend to display this feature. Even without including some of the more overtly instrumental theories of 'technology acceptance' 689690 , these might include: the 'multi-level perspective' 151, 'sustainability transitions' 148; 'transition management' 149 150; 'strategic niche management' 691692693 ; 'dialectical issue life-cycle model' 694 695; 'triple-embeddedness framework' 321; 'technological innovation systems' 379 380; 'socio-technical systems' 225 41; 'large technical systems' 99100101102103 and 'techno-economic paradigms' 94 95 and 'deep transitions' 118119 . Also sharing these tendencies are 'innovation ecosystems' and 'systems of innovation' ${ }^{147}$ frameworks including: 'national' 696 , 'sub-national' ${ }^{697}$, 'regional' ${ }^{698}$, 'continental' ${ }^{699}$, 'sectoral' 700 (and many other) notionally discrete kinds of 'system'). Especially prone to instrumentalisation, are grand ambitions to articulate many such approaches in order to achieve 'complete' explanations ${ }^{448}$ through single 'integrated frameworks' 437149701702701 , 'integrated models' ${ }^{322}$, or 'unified theory' 703.

It should be noted, however, that (for reasons addressed later in this paper), important exceptions to this pattern of instrumentalising 'misplaced concreteness' 470372 can be found in the relatively open and flexible 'flat ontologies' 704705 of 'social practice' 644706609707 , 
'social construction' 708 224, 'techno-economic networks' 969798 and 'actor network' 709710704711712713714 approaches. But these in their turn have been criticised for failing to give due levels of consideration to power ${ }^{715}$. The present approach seeks to reconcile this.

18 To anticipate a later part of this analysis at this point, the term 'semi-coherence' (when evidently understood in this restrictive way), seriously misses the possibility addressed in the worm-eye view in Figure 5, that incumbency can be distributed, complex and polycongruent in far more radical ways than are captured by ostensibly categorical interactions with other notionally discrete regimes. The 'worm-eye view' goes beyond this kind of circumscribed eagle-eye picture of "possible" "internal conflict" ${ }^{436}$ between what are still seen as ostensibly neatly-nested 'sub-regimes' of what effectively remains 'reified' as a (notionally discrete and singular) 'regime'. Under a worm-eye view, it is the orderly vision of neatly-bounded regimes and sub-regimes itself that breaks down.

To appreciate further why this is, it is necessary to consider an important general feature of socio-material dynamics, relating to the ubiquitous predicament in social science of Giddens' 'double hermeneutic' discussed above ${ }^{372}$. This concerns the difference between seeing focal phenomena as 'monothetic' or 'polythetic' ${ }^{716}$. The contrast here is between, first: a monothetic view of a phenomenon as if adequately definable according to a specific stated characteristic (like membership of the category 'regime'); and second: a polythetic view in which the focal phenomenon is acknowledged instead to require characterisation encompassing a more complex diversity of cross-cutting dimensions, defying Euclidean category structures ${ }^{717}$. As illuminated in Wittgenstein's metaphor of 'family resemblances' 718 , the resulting disparate attributes may not relate to each other in the kinds of conveniently orderly ways that allow categories to be confidently partitioned and instances neatly segregated ${ }^{679}$. With resulting relations often then taking a 'fractal' form 719 (transcending clearly distinguishable 'levels' or 'scales' 720468 ), correspondences may be radically more mismatched than is expedient for assertion of analytical frameworks with the requisite "necessary simplification" ${ }^{373}$. To ignore this more directly phenomenological view ${ }^{721}$ and reduce such polythety to monothety ${ }^{722}$ is to fall foul of Whitehead's 'fallacy of misplaced concreteness' 470 and so risk the error of 'reification' 723

To some, such errors may seem like somewhat esoteric concerns, but it is difficult to overstate the practical importance - especially for research purporting to address high stakes environment and political challenges like those around socio-material incumbency. To treat a set of neatly-bounded, segregated and ordered frameworks of words and categories as settled upon within a particular discipline, as if these necessarily correspond in directly consistent ways with the implicated phenomena in the outside world, is not only to perpetrate an error, but to become dangerously vulnerable to inevitable to mismatches ${ }^{724}$. Where a focal phenomenon "cannot be described simply by a conjunction of properties" 725 , it is (as Borges has it) "hazardous to think that a coordination of words... can have much resemblance to the universe" ${ }^{726}$. Another result is a blindness to particularity - as Bourdieu points out: "in reducing the polythetic to the monothetic, objectivism destroys the specificity" ${ }^{643}$. To recognise a phenomenon as polythetic, by contrast, is to acknowledge that "the occurrence of a single feature in every member of a category is not sufficient to justify any claim that this is the essence of the category" 725 . The resulting complexities are inconvenient to the kinds of 'simplifications' held to be 'necessary' ${ }^{373}$ for purposes of disciplinary policing and policy justification. But they are crucial if the understanding of socio-material incumbency is to move away from the superficiality of what Ritzer calls a 'monothetic glance' and be open instead to prehending what he calls the 'polythetic flux' in associated power dynamics ${ }^{727}$.

Perhaps the most crucial implication of reduced monothetic representations of incumbency, however, are turned to at the end of this paper. For it is this same 'reified' 436372 characteristic of apparent simplicity that supports the impression that incumbency might satisfactorily be addressed by equally reductive societal responses. Attention can in this way more easily be deceived into preoccupations with more depoliticised notions of 'governance' 728360729730731732 , under which attention fixates on circumscribed strategies, instruments and interventions as if viewed from the same imaginarily detached vision of a 'cockpit' 386 that inspired the seeming 'eagle-eyed' view of incumbency itself ${ }^{238}$. With incumbency is viewed instead in a polythetic way, attention more easily moves beyond just instrumental 'policy mixes' ${ }^{733}$, towards an appreciation for the broader and deeper kinds of political 'mess' 482 . And it is only then, that the importance of comes clearly into view of the political processes of democracy itself, rather than the merely administrative procedures of 'policy making' 400560 .

It is in this way that apparently abstract features in representations of incumbency can become crucial to prospects for success in addressing imperatives of environment and social justice - and the fate of associated essential democratic struggles. Indeed, it is in these terms that a key distinction between the 'shallow' and 'deep' manifestations of socio-material incumbency distinguished in this analysis, can be seen to lie in the holistically-pervasive nature of deep incumbency. The 'metastasizing' of incumbency to encompass contexts not only of the relevant range of prehensible objects of incumbency, but also the diversity of salient prehending subjects might be seen as a crucial reference point of concern in democratically-motivated thought and action.

19 In addition to the present point, the names, definitions and partitionings of both the putative categories in this diagram and their instantiations also vary radically between analyses 151436734121 . Indeed, even when restricting attention to discussions specifically of the electricity generating system alone, a systematic review by Kinn of contrasting usages by Geels of the same term 'regime', enumerates twelve substantively different meanings attached to this core concept by this single canonical author ${ }^{735}$.

Likewise, it can become highly ambiguous exactly what might be meant in the standard definition of socio-technical regimes, by the crucially-constituting concept of 'rules' ${ }^{736}$. In one recent detailed and insightful analysis, Schot and Ghosh acknowledge that the core concept of the regime is "hardly systematic" 736 . Yet in seeking to remedy this situation the resulting analysis (albeit unusually clear in this field) risks compounding the very confusions it sets out to address. Further more finely-partitioned variants of the same ontology yield concatenations of tacitly-asserted permutations in kinds and degrees of notionally distinct concepts and instances. Included alongside 'routines' and 'heuristics', for example, as constituting parameters of the focal regime, are notionally distinct categories of 'rules', elaborately classed as: 'meta' (and by implication 'regular'); 'formal/regulative'; 'cultural-cognitive'; 'normative' and 'ground' rules. It is unclear how reliably all these categories can be differentiated from setting to setting, let alone in distinguishing the particular instances under each. If they are interrogated systematically (rather than just taken on trust), such heroic taxonomic impulses yield their bewildering complexity in determining what exactly might actually count in any given setting as a 'regime'.

Such problems grow with each defining category of rule being further divided between five apparently firmly-distinct kinds of 'regime dimension', each apparently displaying their own further distinguishable 'trajectories' and 'super-trajectories' ${ }^{736}$. And whether these 'trajectories' refer to particular socio-material configurations, or to the 'dimensions' these are defined under, is also surprisingly unclear. Yet amidst all these degrees of conceptual freedom, research is expected to be able confidently to grade different degrees of change in each, such as to allow meaningful comparative distinctions across radically different national and sectoral settings. As

$$
\text { page } 46 \text { of } 49
$$


ambiguities recursively compound, this proliferating menagerie of categories, instances and intensities quickly grows prohibitively baroque. Mismatches between performative precision and 'hardly systematic' 'reification' are exacerbated rather than relieved by the ostensibly finer grain resolution. Like unfalsifiable Ptolemaic epicycles ${ }^{737}$, the main weight is placed on scholastic assertiveness.

So, it is against this background, that the relatively simple general heuristic distinctions made in the present paper (for instance) between 'open' and 'closed' topologies, might be recognised (despite their own degrees of abstraction and the complexity of the language necessary in order to sustain and specify this) to actually be in many ways both more parsimonious and more operational.

20 In a spider's web, for instance, the processes and relations that keep the spider aloft in the centre are actually able to do this, precisely because they do not align with each other ${ }^{81560}$. So, the balancing of orthogonal and counterposing forces seems just as potentially important as their alignment? This suggests a necessary feature of rigour and prudence in the understanding of dynamics in any multidimensional manifold (like a socio-material 'phase space', 'possibility space', 'landscape', 'timespace' or 'milieu') ${ }^{683}$. In short, it would be irrational and unreasonable simply to assume from the outset, that the subset of dimensions in which a given pathway is oriented within this manifold will be the same as the dimensionalities of the aligning dynamics ${ }^{684}$. To do this in ways that are obscured by other key conceptual elisions, would be even more precarious.

Indeed, there is a possibility that the importance of this kind of orthogonality is not just contingent in socio-material change, but can be an essential property. If the necessary leverage is to be achieved in order to re-orient the massive momentum of incumbency in some particular setting, then the marshalling of requisite vector intensities in the configuring fields needed to perform this, will require a societal 'pivot' capable of bearing such a load. When seen relationally, interventions like this acting in one direction of a societal dimension, can be expected to engender a reaction acting in the other direction. So if an intervention is not simply to reproduce the intensity of the dimension along which it is oriented, the pivot must be orthogonal ${ }^{238}$. For example, if incumbent violent control is countered with efforts at subaltern violent control, then what may be most reinforced is an overall axis of violent control ${ }^{738}$. If cultures, institutions and practices of violent control are instead countered by reinforcing (effectively orthogonal) dimensions around mutualistic solidarity and care, then this orthogonal pivot can offer greater hopes of success in displacing violence than counter-violence ${ }^{739}$.

21 The concept of 'poly-congruence' is used in mathematics ${ }^{740}$, signal processing ${ }^{741}$ and computer science ${ }^{742}$ to refer to properties of polynomial functions that relate in broad terms to the present sense of: "a pattern between fields, implicating multiple rather than single loci of congruence". A different term also sometimes used for similar ideas of mapping in relation to the kinds of social field concepts used here is "non-isomorphic" ${ }^{743}$. However, in focusing rather more straightforwardly simply on the shape, rather than also the varying intensity and polycentricity of the configurations referred to, ideas around '(iso)morphism' might be taken to imply a greater degree of simplicity and clarity than is invoked in the notion of poly-congruence.

22 Either way, the practical implications of multiplexity in Figure 5 are accentuated, by considering that each of the coloured fields refers not to all possible manifestations of a given kind of incumbency-sustaining dynamic, but (as capitalised indices suggest) to a specific instance. For example, the form of the field representing a general dynamic of 'lock-in', depends on exactly what is envisaged as being 'locked in'. So there might be multiple contrasting forms even for a single field like that associated with 'lock-in'. If all such instances were shown for each field, then qualities of multiplexity would be even more pronounced than is already the case. So, the point stands even more strongly, that a worm-eye view recognises more than an eagle-eye view, that effects of different incumbencysustaining dynamics may not necessarily map onto each other.

23 This point about the reification of 'levels' of analysis, is sometimes well acknowledged in parts of the innovation literature, but remins frequently neglected in mainstream discussion on 'socio-technical transitions' ${ }^{413}$. It is a particular feature that the present analysis seeks to address. Under a worm-eye view, phenomena under scrutiny are not best represented in categorical ways - as if discrete and unitary and confined to some specific ontological 'level' or 'scale'. When seen as relational processes, the picture is more consistent with emerging studies of complex nonlinear social and physical systems. Here, dissipative gradients (like those envisaged for power as flows of 'asymmetrically structuring agency' [4]) routinely give rise to 'fractal' patterns 719 that are essentially self-similar at different geographical, institutional or socio-technical 'levels' or 'scales' 720468 . For reasons also addressed above [17], one further especially fruitful body of thinking around this kind of ontology, may be found in rhizomatics 469724744745 , as widely explored in areas of practice theory ${ }^{746} 747$.

24 Crucially, recognising such pervasiveness under a worm-eye relates only to the extent of the distribution across the milieu, not to its completeness. It does not, therefore, necessarily entail full saturation of the entire milieu - with every detailed socio-material configurations thereby held to be equally implicated in the specific incumbency referred to. As can be seen from Figure 5, although more extensive than when seen under an eagle-eye view, the form of each field recognised in a worm-eye view nonetheless leaves many 'gaps' in the timespace. Many configurations are thereby recognised not to be substantively enrolled in maintaining the focal incumbency. But what does hold under a worm-eye view, is that the collectivity of all incumbency-generating dynamics with respect to any given focal pathway, does nonetheless implicates such a wide expanse of disparate configurations, that this collectivity does preclude confinement in any definable continuously monocongruent domain of the milieu that might be called 'the regime'.

25 This more complex kind of holism is sometimes unfashionable in much contemporary problem-oriented research. This is especially so, where there are strong aims to secure the attention of policy processes for which the most important resource is justification discussed above 74871356 . Given this, it is interesting that this kind of holistic approach does nonetheless resonate with some of the most reductive mechanisms in positivistic policy analysis of socio-technical change. For instance, narrow economistic ideas of 'lock in' under 'increasing returns to adoption' can be characterised in terms of some very particular feature of some single device (like the portability of a mobile phone) ${ }^{138}{ }^{261}$. Yet the dynamics that constitute associated positive feedbacks may be as complex and comprehensive in their dispersion through disparate parts of society, as the fields shown in Figure 5 . And different features of the same device may actually implicate contrasting patterns in these reinforcing dynamics, distributed in different ways through the milieu of socio-material configurations.

Rather than propagating outwards from a specific centre, then, the flows and gradients of power associated with particular sociomaterial pathways might be seen as if 'condensing' inwards from generally extant societal patterns in asymmetrically structuring agency $^{749}$. This contrasts with a reductive search for confined generative loci of incumbency like the 'the regime'. It offers instead a

$$
\text { page } 47 \text { of } 49
$$


'holistic' way of seeing the underlying constituting dynamics. As when particular kinds of dust particle are seen to serve more readily than others as condensation points for vapour, so salient features may be recognised that are specific to the focal socio-material pathways themselves. But these will in this worm-eye view be of secondary importance to the general properties of the encompassing 'socio-material milieu' taken as a whole 434435472

26 This idea of 'configuring fields' holds in common with other field concepts in the social sciences, a potentially greater fidelity of fit with topologies of power that are more like the worm-eye view in Figure 5, than the eagle-eye view in Figure 3. It is empirically grounded, in that it takes its meaning from the manifest socio-material configurations which are its visible results. Like other field concepts (but unlike the notion of 'the regime'), an ontology of configuring fields can accommodate a variety of messy formative processes, beyond conveniently-presumed congruence. But unlike other extant forms of field theory, the idea of configuring fields relates to diverse and pervasive processes of structuration, rather than to notionally specific 'mid-range' social phenomena like 'organizations', 'policies', 'institutions', 'social movements' 'community preferences', actor 'dispositions', 'intersubjectivities' or 'strategic action'.

27 Without such instrumental simplification in prevailing understandings of incumbency, for instance, it would be less credible that various forms of 'socio-technical transition' might so often be seen to be achievable merely by means of relatively circumscribed managerial or policy interventions 37337175034367369370 undertaken from a notional governance 'cockpit' ${ }^{386}$. If socio-material incumbency were acknowledged to be more complex, diverse, deeply-penetrating or pervasive through society than suggested in Figure 3, then the task of countering it might be recognised to be more onerous. Deeper forms of political conflict and social transformation might then be understood to implicated, relating more strongly to collective action, democratic struggle or political revolution affecting an entire socio-material milieu, than to more routine kinds of 'policy' interventions conceived to be confined within a discrete region of the milieu 400560 .

These more expansive visions of transformation are less favoured by incumbency itself, when this takes the 'deep' form described by the open topology represented in Figure 5. Indeed the prompting by a 'worm-eye' view of a deeper, more unruly form of democratic politics can be more overtly threatening than 'eagle-eye' characterisations that invite only circumscribed policy interventions of kinds that this type of 'deep' incumbency is itself a picture in a strong position to condition - especially when it is concealed by an eagle-eye misrepresentation as a 'shallow incumbency'. More explicitly and expansively political 'worm-eye' views of incumbency are less readily subverted, diverted or appropriated by incumbency itself 751752753754755756 . For instance, more complicated 'worm-eye' understandings make it more difficult to establish stories that demonstrate efficacy and appropriate credit for particular 'policy interventions' ${ }^{404}$. Likewise, it becomes in this view, more difficult to operationalise patronage through preferential attribution of 'academic relevance' and 'policy impacts' 757 . Whatever its veracity, then, it can be predicted that the simple singular ('eagle-eye') picture of incumbency would be much more convenient than the 'worm-eye' view, in justifying the policy communities and processes from which these analytic literatures seek to gain attention.

28 In discussing the distinct but related phenomenon of the 'international regime', for instance, Ruggie ${ }^{758}$ offers an apt quote from Philips in musing that "[a] philosopher is someone who goes into a dark room at night, to look for a black cat that isn't there. A theologian does the same thing, but comes out claiming he found the cat" ${ }^{759}$. When they are interrogated by 'theological' approaches that simply assume their existence - and are incapable or disinclined to find otherwise - then socio-technical regimes (like the international regimes considered by Ruggie) may be cats that aren't there. This presents a contrast with the operational 'unit of analysis' in the present approach, in that configuring fields are defined more phenomenologically (as 'patterns of propensity with respect to a particular focal socio-material pathway, across the totality of all possible socio-material configurations, that serve to foster one specific orientation for change more than others'). To the extent that it is manifestly the case that there exist such patterns in these far more comprehensively encompassing kinds of phenomena, then a configuring fields approach is less theological in this respect. That the focus is on broadly distinguishable topologies in assemblages of processes and relations, rather than notionally precise configurations in any one categorical entity, may further reduce tendencies to this same kind of epistemic vulnerability.

Likewise, the fact that the present focus is on general topologies of configuring fields, rather than on the notional geometries of particular constituent fields, also strengthens this point. The granularity of the broad distinction made in this paper between 'open' and 'closed' topologies can be investigated with significantly greater humility, than if there were pressures to identify more specific patterns. It may be that accumulated empirical research in this vein might enable finer-grain developments - for instance, perhaps, by distinguishing other slightly more nuanced forms of 'concave' or 'convex' topology of socio-technical incumbency with respect to a focal socio-material pathway, that are intermediate between these 'open' and 'closed' ideal types. But this is presently speculative.

29 A large literature on the role of case study research in social science, can be cited in justification of a variety of different positions in this regard 528529530 . But the argument at this point is quite modest in its claims and more general than much of this discussion of the analytical value of case studies - remaining broadly consistent with the majority of perspectives on this issue ${ }^{531}$. Indeed, under some strongly argued analyses in this field, the weight of 'contextualised explanation' 532 that can be borne by a carefully designed and implemented single qualitative case study like this, can actually be significantly greater than is being claimed here.

30 In ways that chime with understandings of power and incumbency in the present analysis, it has been proposed that general social conditions of democracy (especially in process-relational terms, as murmurations of collective action in ongoing struggles for the culturing of more emancipatory societies ${ }^{760}$ ) can be characterised in a way that generalises across many otherwise contrasting styles of emphasis. This is consistent with the definitions employed throughout this analysis, in which power is conceived as 'asymmetrically structuring agency' 81238 and associated diverse forms of 'democracy' are understandable as multiple kinds of struggle for 'access by the least powerful, to the capacities for challenging power' 81238 .

31 It lies beyond the scope of the present paper, to elaborate the many ways in which distributed, nonscaled, emergent, relational and rhizomic political processes referred to here as 'murmurations' may relate to the present understanding of power and incumbency in terms of 'configuring fields' 400238761 . The serendipitous dual sense of the English word 'murmuration' at the same time of 'horizontally-coordinated movement' and 'subversive criticism', may itself be seen as a reflection of murmurating dynamics in language ${ }^{2}$. Either way, what is clear is that deep and pervasive redistributions and reorientations of power are not effectively 
achievable by the kinds of vertical mechanisms highlighted in the fallacies of control so favoured by incumbency as a means to secure justification and sustain privilege ${ }^{762}$.

As in other dissipative relational processes (from small-scale neural to large-scale cosmic activities ${ }^{763} 764765$ ) the configurations of socio-material incumbency may often be better understood in these 'emergentist' 766767768 (rather than reductive) terms - in terms of features of the wholes in which they are immersed more than in terms of their own notionally discrete properties. Such a view sees socio-material incumbency as condensing out of palimpsests of configuring fields of structuring agency distributed throughout an entire socio-material milieu taken as a whole, not as a discretely-located and bounded category of power. As with other emergent patterns, such incumbency can be expected to be fractal 467468181719720 (rather than neatly-scaled) and rhizomic 312469724744745 (deeply multiple, pervasive and interconnected) in nature.

As an additional final hint towards implications for action, however, it follows from all this that if socio-material incumbency is prehended in the monothetic ${ }^{716} 724$ terms of many conventional approaches [18], then fallacies of misplaced-concreteness ${ }^{470}{ }^{372}$ will likely arise. The present emergentist approach instead upholds a more polythetic understanding ${ }^{716} 727$. Likewise, routine actions undertaken against incumbency under this conventional approach are monovalent in style ${ }^{769}$, as if the only salient implications of intervention are those initially intended by notionally controlling policy actors ${ }^{762}$. Here again, the present emergentist view urges instead that actions be undertaken in the more polyvalent style of mutualistic murmurations ${ }^{238}$. And with regard to the processes by which countering action might be hoped to transform incumbency, a conventional approach tends to highlight one-directional 'logistic curve' trends, unfolding according to orderly monotonic 'phases' 770 . Again by contrast, the present emergentist approach expects incumbency to be more likely to erode in non-monotonic ways - in waves of oscillating effect to and fro, sometimes appearing to be counterproductive. If the possibility of this kind of much more messy process is not at least better understood (if not anticipated), then the likelihood that all kinds of incumbency will be effectively challenged is seriously diminished. 


\section{Recent papers in the SPRU Working Paper Series:}

\section{November}

Scientific Output of US and European Universities Scales Super-Linearly with Resources. Benedetto Lepori, Aldo Geuna and Antonietta Mira

Do Firms Publish? A Multi-Sectoral Analysis. Roberto Camerani, Daniele Rotolo and Nicola Grassano

\section{October}

A Co-Evolutionary, Long-Term, Macro-Economic Forecast for the UK Using Demographic Projections. Nick Jagger

How Can Intermediaries Promote Business Model Innovation: The Case of 'Energiesprong' Whole-House Retrofits in the United Kingdom (UK) and the Netherlands. Donal Brown, Paula Kivimaa and Steven Sorrell

Climate Resilience Pathways of Rural Households. Evidence from Ethiopia. Solomon Asfaw, Giuseppe Maggio and Alessandro Palma

Public Procurement and Reputation: An Agent-Based Model. Nadia Fiorino, Emma Galli, Ilde Rizzo and Marco Valente

\section{September}

Mapping Socio-Technical Change in Mobility Regimes: The Case of Kolkata. Bipashyee Ghosh and Johan Schot

The Limitations of the Conceptual Framework of the Heterogeneous Engineer for Leadership in Megascience Projects. David Eggleton

\section{August}

Prices of Value Added and Competitiveness in Global Value Chains. Maciej J. Grodzicki

Interdependencies Between Civil and Military Nuclear Infrastructures. Andy Stirling and Phil Johnstone

\section{Suggested citation:}

Andy Stirling (2018). How Deep Is Incumbency? Introducing a 'Configuring Fields' Approach to the Distribution and Orientation of Power in Socio-Material Change. SPRU Working Paper Series (SWPS), 2018-23: 1-49. ISSN 2057-6668. Available at: www.sussex.ac.uk/spru/swps2018-23

\section{SPRU - Science Policy Research Unit}

University of Sussex

Falmer, Brighton, BN1 9SL,United Kingdom

SWPS Website: www.sussex.ac.uk/spru/research/swps

SPRU Website: www.sussex.ac.uk/spru

SPRU Twitter: @SPRU 